\title{
EL ARTE RUPESTRE DE YAMOR, CUENCA ALTA DEL RÍO FORTALEZA, BOLOGNESI - ANCASH
}

\author{
Pieter D. VAN Dalen Luna \\ UnIVERSIDAD NACIONAL MAYOR DE SAN MARCoS \\ pvandalen2@hotmail.com \\ Hamilton Obregón Pillaca \\ UNIVERSIDAD NACIONAL SAN CRISTÓBAL DE HUAMANGA \\ hamilpillaca@hotmail.com \\ DANIEL ALLENDE JoAQuín \\ UNIVERSIDAD NACIONAL SAN CRISTÓBAL DE HUAMANGA \\ dan51997@hotmail.com
}

\section{RESUMEN}

El presente artículo muestra las características de los sitios con pictografías o quillqas asociadas a estructuras funerarias tipo chullpas que existen en la jurisdicción del pueblo y Comunidad Campesina de Yamor, en el distrito de Antonio Raymondi. Estas quillqas fueron elaboradas en las paredes de grandes farallones rocosos, a distintas alturas con respecto a la superficie, pintadas con óxido de hierro existente en grandes cantidades en los alrededores de Yamor.

PAlABRA ClAVEs: Arqueología, arte rupestre, Ancash, Bolognesi, Yamor, río Fortaleza.

\section{Abstract}

This article presents the characteristics of the sites associated with pictographs or quillqas funeral chullpas type structures that exist in the jurisdiction of the people and Rural Community Yamor in the district of Antonio Raymondi. These quillqas were drawn on the walls of large rocky cliffs, at different heights relative to the surface, painted with oxide of iron in large amounts around Yamor.

KEYWORDS: Archeology, rock art, Ancash, Bolognesi, Yamor, Fortaleza river. 


\section{1.- INTRODUCCIÓN}

La cuenca alta del río Fortaleza es un vasto territorio, políticamente compartido por las provincias de Bolognesi y Recuay, en el departamento de Ancash; pero sin embargo muy poco conocido por las disciplinas científico sociales. Cabe resaltar los valiosos aportes del Dr. Román Robles Mendoza, sobre las características de las comunidades campesinas como Raquia, Marca, Huayapampa, Yamor, Cajacay, entre otras (Robles 2007, 2009); así como de sus manifestaciones culturales (Robles 2000, 2005). Con respecto a las investigaciones arqueológicas realizadas en la zona, salvo los trabajos de Pieter van Dalen $(2007,2013)$ en los sitios de Palpín en Cajacay y San Ignacio en Yamor, así como un balance sobre la arqueología de la vecina provincia de Ocros (van Dalen 2014) o los estudios de Arturo Ruiz en el distrito de Chiquián (Ruiz 2003, 2008, 2009), no existen otros trabajos. Se conoce que en la Colonia, Yamor y sus alrededores fue el escenario de feroces campañas de extirpación de idolatrías que conllevaron a destruir numerosos centros ceremoniales (Duviols 1986, Huertas 1981, Pereyra 1989, Sánchez 1991).

Durante los meses de mayo y junio de 2015, bajo el auspicio de la Municipalidad Distrital de Antonio Raymondi y la Universidad Nacional Mayor de San Marcos, los autores del presente artículo desarrollamos trabajos de investigación en el ámbito del distrito de Antonio Raymondi, territorio de las comunidades campesinas de San Bernardo de Yamor y Raquia, con el objetivo de elaborar un catastro arqueológico que nos permita conocer las características de la totalidad de sitios arqueológicos existentes en este ámbito territorial, conocer a que periodos culturales prehispánicos corresponden, las relaciones existentes entre los sitios coetáneos y las características de las sociedades que se desarrollaron en este territorio en periodos prehispánicos.

El Catastro arqueológico es un proceso de la arqueología que busca realizar el censo o inventario oficial de los bienes culturales (sean arqueológicos o históricos) de una cuenca o región determinada, la cual se realiza mediante el trabajo prospectivo. El logro final de un catastro arqueológico es el ordenamiento sistemático de la totalidad de elementos patrimoniales previamente inventariados (Milla 1977-78:41). El catastro arqueológico desarrollado en el distrito de Antonio Raymondi ha seguido cuatro etapas metodológicas bien definidas:

1.- Revisión de antecedentes de estudio en el distrito de Antonio Raymondi, en particular y en las provincias de Bolognesi y Recuay en general. En esta etapa se trató de identificar los antecedentes de estudios arqueológicos, históricos, antropológicos, lingüísticos, geomorfológicos, ecológicos y geológicos del área de estudio, distrito de Antonio Raymondi en particular, y al no encontrar dato alguno, se hizo extensiva al ámbito de toda las provincias de Bolognesi y Recuay.

2.- Estudios cartográficos y fotogramétricos. En esta etapa se trató de identificar mediante el análisis de la carta nacional escala 1:100 000 № 2242 (29-P) - Cajacay del IGN, y las fotos aéreas de Antonio Raymondi del SAN en escala aprox. 1:10 000, en la cual se hace imposible la visibilidad de sitio arqueológico alguno, pero sí las características geomorfológicas de los sectores naturales conformantes dentro del ámbito del distrito.

3.- Prospección arqueológica Superficial sin excavaciones. En esta etapa se procedió a realizar la prospección arqueológica por todo el ámbito del distrito de Antonio Raymondi, comunidades campesinas de Yamor y Raquia. El objetivo de la prospección fue la identificación y registro de la totalidad de restos arqueológicos prehispánicos y coloniales existentes en estas localidades. El registro arqueológico consistió en la descripción de las características de cada sitio arqueológico mediante el llenado 
de fichas de registro, en las cuales se contemplan ítems como ubicación del sitio, emplazamiento, tipología de sitio, descripción del sitio por sectores, descripción de las técnicas y materiales constructivos, descripción de los materiales observados en superficie, filiación cronológica y cultural, y estado de conservación identificando los principales agentes de deterioro y problemas estructurales y superficiales de los muros. Se utilizó la Ficha General de Inventario del Ministerio de Cultura. El trabajo de prospección arqueológica se desarrolló mediante el reconocimiento y exploración sistemática de cada componente geomorfológico del territorio, como valles, cerros, quebradas aledañas al valle, altipampas, entre otros. Sin embargo, cabe señalarse que en el desarrollo de estos trabajos se consideró aspectos relevantes que permitieron identificar muchos sitios.

4.- Trabajo de Gabinete y Procesamiento de datos. En esta etapa se procesó toda la información recogida en campo, vaciando la información de las fichas de registro de campo y elaborando el mapa arqueológico del distrito.

5.- Elaboración del informe final y los expedientes técnicos para su declaratoria como Patrimonio Cultural de la Nación. En esta etapa se elaboró el informe final a ser presentado a la Municipalidad Distrital de Antonio Raymondi.

Como resultado de estas investigaciones se logró identificar y registrar un total de 25 sitios arqueológicos de diferentes tipos: pueblos, áreas funerarias, andenes, canales, pinturas rupestres, etc; correspondientes a todos los periodos culturales prehispánicos, coloniales e incluso republicanos. En esta oportunidad presentamos solo la información referida a los sitios con pinturas rupestres identificados en el ámbito de la comunidad campesina de Yamor, casi todos asociados a áreas funerarias con estructuras funerarias tipo chullpas.

\section{2.- UBICACIÓN Y MEDIO AMBIENTE}

La comunidad Campesina de Yamor se encuentra ubicada en el distrito de Antonio Raymondi (el nombre mal escrito figura de la creación política del distrito), provincia de Bolognesi, departamento de Ancash. Geográficamente se ubica en ambas márgenes del río Yamor y del río Raquia, afluentes del río Fortaleza por la margen izquierda. El territorio de esta comunidad campesina se eleva desde el mismo río Fortaleza hasta los contrafuertes más elevados en la región puna.

Esta comunidad se ubica dentro de las regiones naturales Quechua, Suni y Puna, con cerros de regular pendiente y cubiertos de vegetación arbustiva espinosa y que se elevan accidentadamente desde el fondo del valle, surcados por pequeñas y profundas quebradas que son escorrentías naturales que drenan hacia las quebradas más amplias que forman los valles de Yamor y Raquia. Entre la fauna que habita estas zonas figuran desde aves e insectos hasta vizcachas y venados, así como pumas.

La cuenca del río Fortaleza, perteneciente al sistema hidrográfico del Pacífico, cuenta con un área total de drenaje de 2348 Kilómetros cuadrados y una longitud de 111 kilómetros. Presenta un curso sinuoso, en especial en la cuenca alta donde se caracteriza por presentar un paisaje encajonado, de fondo profundo y quebrado, de un relieve escarpado y abrupto de gran pendiente y estrechas gargantas. El río Fortaleza o Paramonga nace en las alturas de las lagunas de Huamblac y Macato, discurriendo sus aguas por las quebradas de Upapampa y Moyocancha, las cuales en su confluencia dan origen al río Fortaleza. Este río es de régimen muy irregular y torrentoso, presentando marcadas diferencias entre sus descargas extremas (ONERN 1972). 


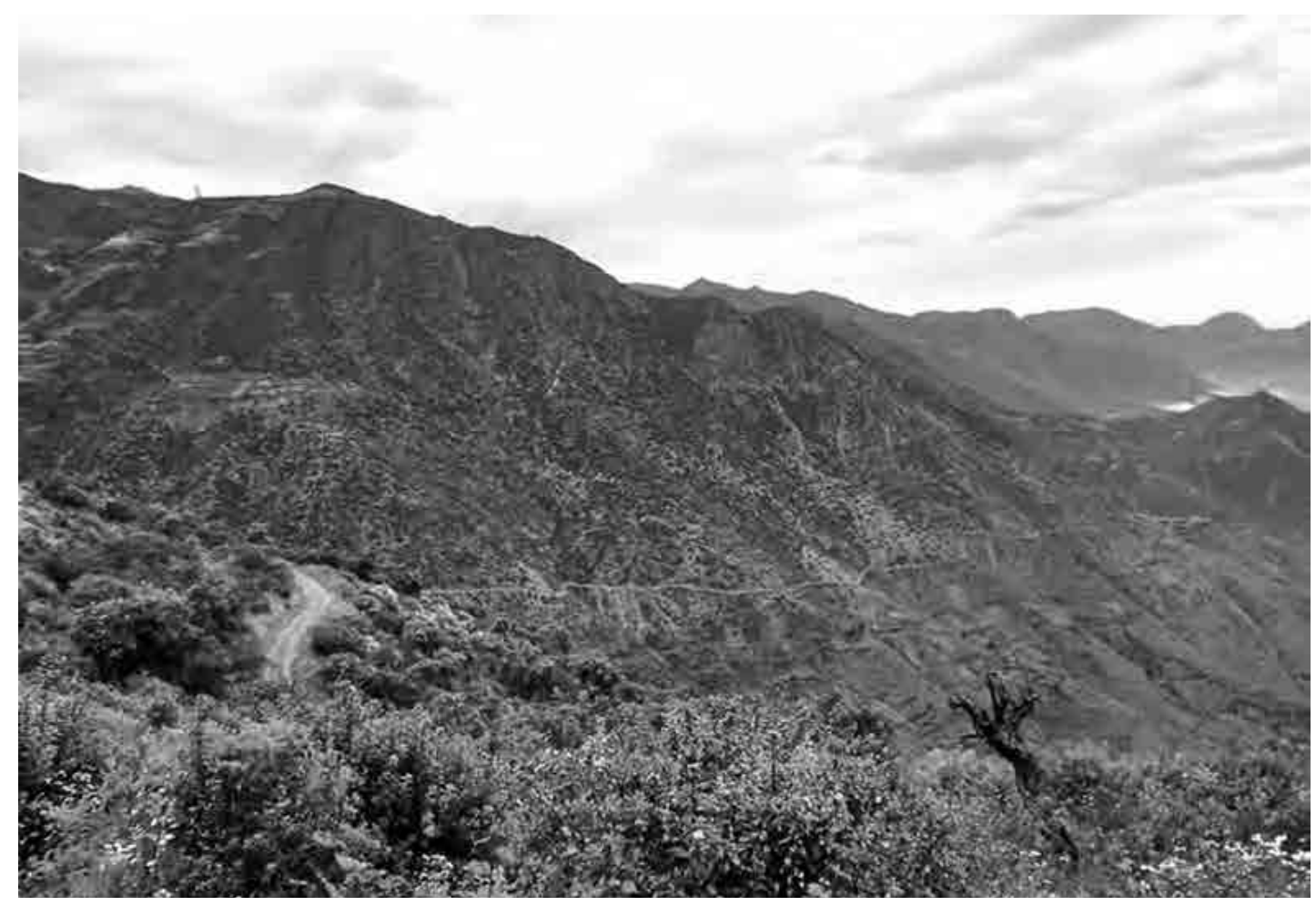

Figura 1: vista panorámica del sitio Pintashkaka (vista desde el lado noroeste).

\section{3.- Sitios CON ARTE RUPESTRE EN YAMOR}

\section{A.- PINTASHKAKA (INTIKAKA)}

Ubicación: se encuentra ubicado en las faldas y ladera media del cerro Kasuela Punta, a la margen izquierda del riachuelo Qechqa, al norte del cerro Uskas Punta, al noreste del anexo de Qarachakra, hacia el sur de la comunidad de Yamor. Políticamente está situado en la jurisdicción del anexo de Qarachakra, comunidad de Yamor, distrito Antonio Raymondi, Provincia de Bolognesi, departamento de Ancash. El sitio se localiza en las coordenadas UTM: 8869637N, 0228320E y a 2751 metros sobre el nivel del mar (sistema WGS-84, al igual que todos los demás sitios registrados).

Acceso: el acceso al sitio se realiza por el lado norte a través una trocha que va en dirección de la comunidad de Yamor hacia el anexo de Qarachakra, aproximadamente 3 kilómetros, llegado a este punto se toma un desvío por un camino de herradura, desde el cual se camina un promedio de 20 minutos, una distancia aproximada de 1 kilómetro desde la trocha.

Tipo de sitio: Paisaje Cultural Arqueológico (abrigos rocosos asociado a chullpas y pinturas rupestres).

Filiación cultural: Arcaico, Formativo e Intermedio Tardío.

Estado de conservación: el sitio se encuentra en regular estado de conservación. Las afectaciones diagnosticadas son principalmente desplome y derrumbe de paredes, causado por acción de los animales por la intensa actividad pastoril (pastoreo de ovinos y caprinos).

Descripción del sitio: El sitio ha sido dividido en 6 sectores, considerando para ello la ubicación y la configuración espacial de los mismos. 
I.- Sector A: Se encuentra ubicado en las faldas y ladera media del cerro Kasuela Punta; entre las coordenadas UTM: 8869637N, 0228320E y a 2751 metros sobre el nivel del mar. Este sector se caracteriza por presentar abundante vegetación propia de un bosque tropical, de tamaño regular entre árboles, arbustos y plantas espinosas. Se trata de un conjunto de abrigos rocosos de tipo andesita, con las paredes completamente pintadas de color rojo óxido, que se extiende de noreste a sureste, de 10 metros de altura por 40 metros de largo aproximadamente, asociado a pinturas rupestres con diferentes motivos y estructuras funerarias; en la abertura orientada hacia el oeste.

Las pinturas rupestres se encuentran en la parte media y plana de la pared norte y oeste del abrigo a unos 3 metros aproximadamente teniendo en cuenta el piso del abrigo. Está compuesto de 5 motivos definidos:

Motivo 1: figura de forma de círculo con punto concéntrico, en buen estado de conservación. Ambos de color rojo óxido sobre fondo natural de la roca (grisáceo). El circulo que encierra al punto central tiene 0.90 metros de diámetro y 0.20 metros de grosor.

Motivo 2: figura conformada por 2 círculos concéntricos, de color blanco sobre un fondo rojo óxido, en mal estado de conservación, al encontrarse por la mitad. Tiene unos 0.40 metros de diámetro y 0.10 metros de grosor.

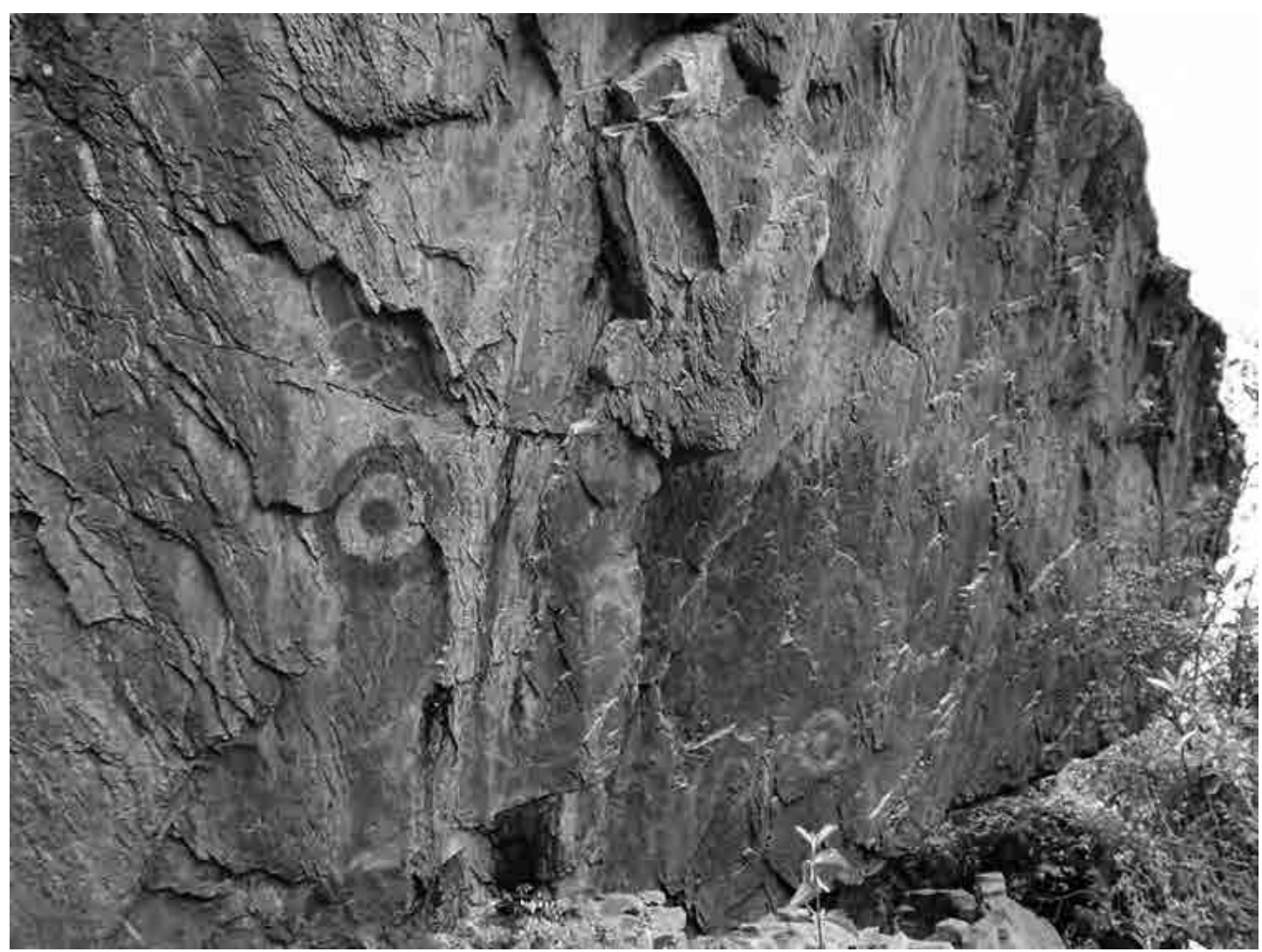

Figura 2: vista panorámica de la pintura rupestre presente en la pared de un abrigo en el sector A, del sitio Pintashkaka. 

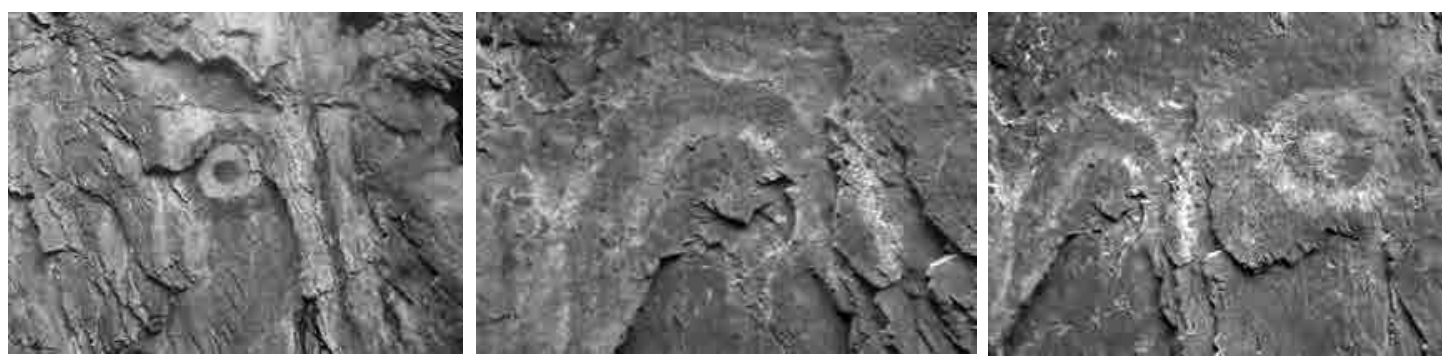

Figura 3 (izquierda): detalle del motivo 1. Figura 4 (central): vista en detalle del motivo 2. Figura 5 (derecha): vista panorámica del motivo 2 y 3. Sitio Pintashkaka, sector A.

Motivo 3: figura formado por un círculo con punto concéntrico, de color anaranjado, en regular estado de conservación. Ambos pintados sobre un fondo rojo. Tiene 0.60 metros de diámetro, 0.55 metros de altura y 0.10 metros de grosor.

Motivo 4: figura formada por 2 puntos de color rojo hechos sobre fondo natural de la roca (grisáceo), en buen estado de conservación. Tiene 0.13 y 0.14 metros de diámetro respectivamente.

Motivo 5: figura de dos círculos unidos por sus extremos, de color rojo. Ambos hechos sobre un fondo natural de la roca (grisáceo). Tienen $0.50 \mathrm{~cm}$ de largo, $0.30 \mathrm{~cm}$ de ancho y 0.06 metros de grosor.
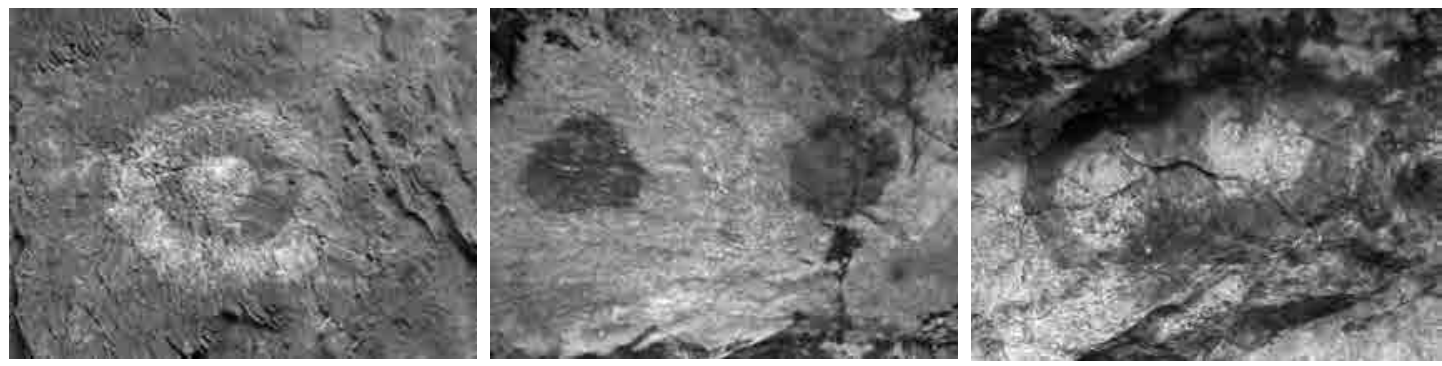

Figura 6 (izquierda): detalle del motivo 3. Figura 7 (central): toma en detalle del motivo 4. Figura 8 (derecha): foto en detalle del motivo 5. Sitio Pintashkaka, sector A.

Las estructuras funerarias se encuentran al pie del abrigo rocoso, asociadas a las pinturas, distribuidos de norte a suroeste, son:

Estructura funeraria 1: se encuentra hacia el norte del abrigo, debajo de una roca que fue acondicionada para depositar los cuerpos. Esta estructura funeraria es de planta ovalada, de $5 \mathrm{~m}$ de profundidad y con muros edificados con piedras canteadas de una sola hilera unidas con argamasa, en regular estado de conservación. El acceso tiene forma cuadrangular siendo sus dimensiones: $1.10 \mathrm{~m}$ de ancho y $0.60 \mathrm{~m}$ de altura. En el interior se observa un cráneo asociado a material botánico (mate, sogas de maguey), textil y fragmentería cerámica.

Estructura funeraria 2: se encuentra al suroeste de la primera estructura funeraria. Tiene planta cuadrangular adosada a la pared del abrigo rocoso, cuyas longitudes son: $2.10 \mathrm{~m}$ de largo, $1.80 \mathrm{~m}$ de ancho y $1.20 \mathrm{~m}$ de altura, en regular estado de conservación con derrumbe de la cubierta. Está edificado con muros de doble hilera de piedras canteadas unidas con argamasa, de $0.50 \mathrm{~m}$ de grosor. La cubierta es de forma abovedada, edificado a base de piedras planas y alargadas. En el interior se observan restos óseos de aproximadamente 3 individuos ( 3 cráneos) asociados a material botánico (sogas de maguey) y textiles. 
Pieter van Dalen Luna, Hamilton Obregón y Daniel Allende / El Arte rupestre de Yamor...
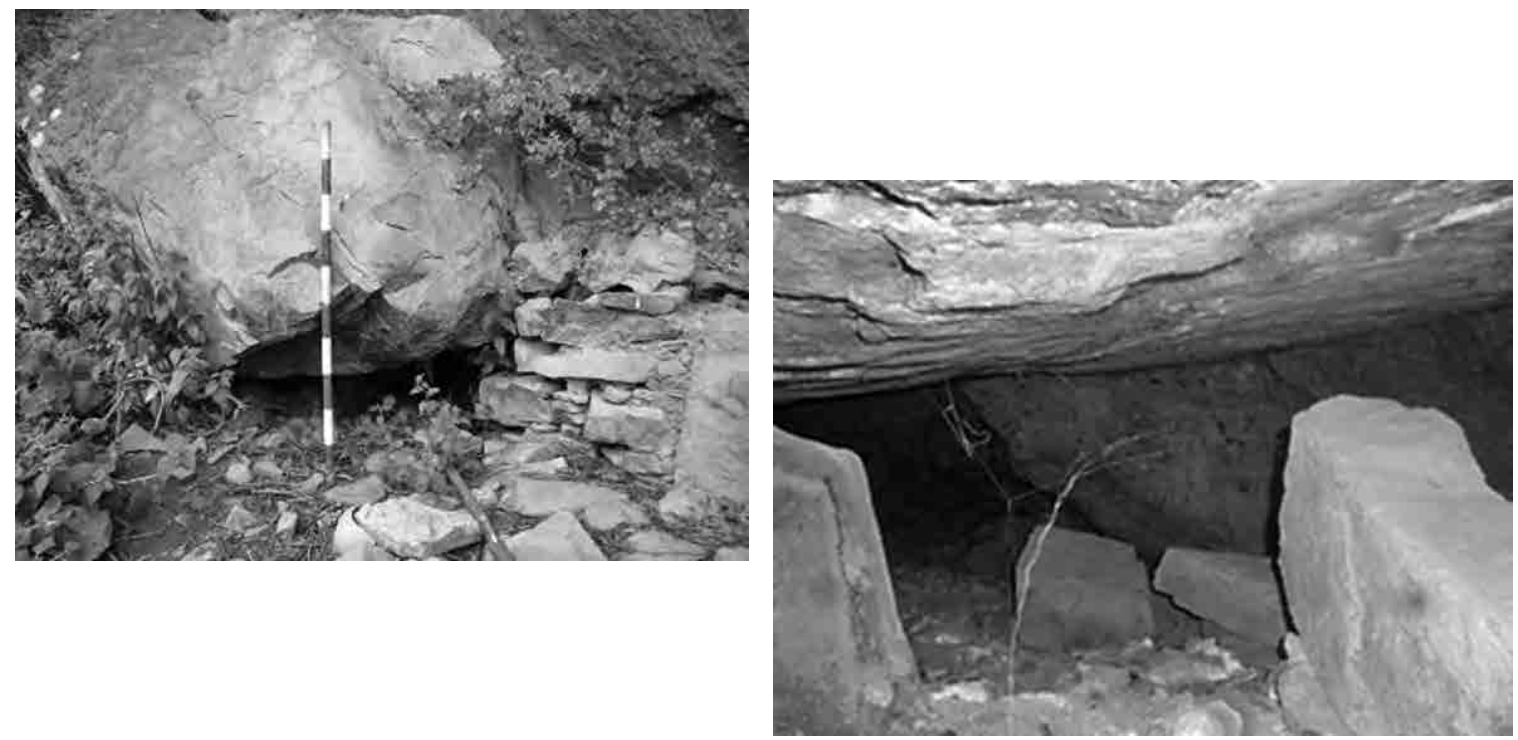

Figura 9 (izquierda): vista panorámica de la parte externa de la estructura funeraria 1. Figura 10 (derecha): vista en detalle del acceso de la estructura funeraria 1. Sitio Pintashkaka, sector A.
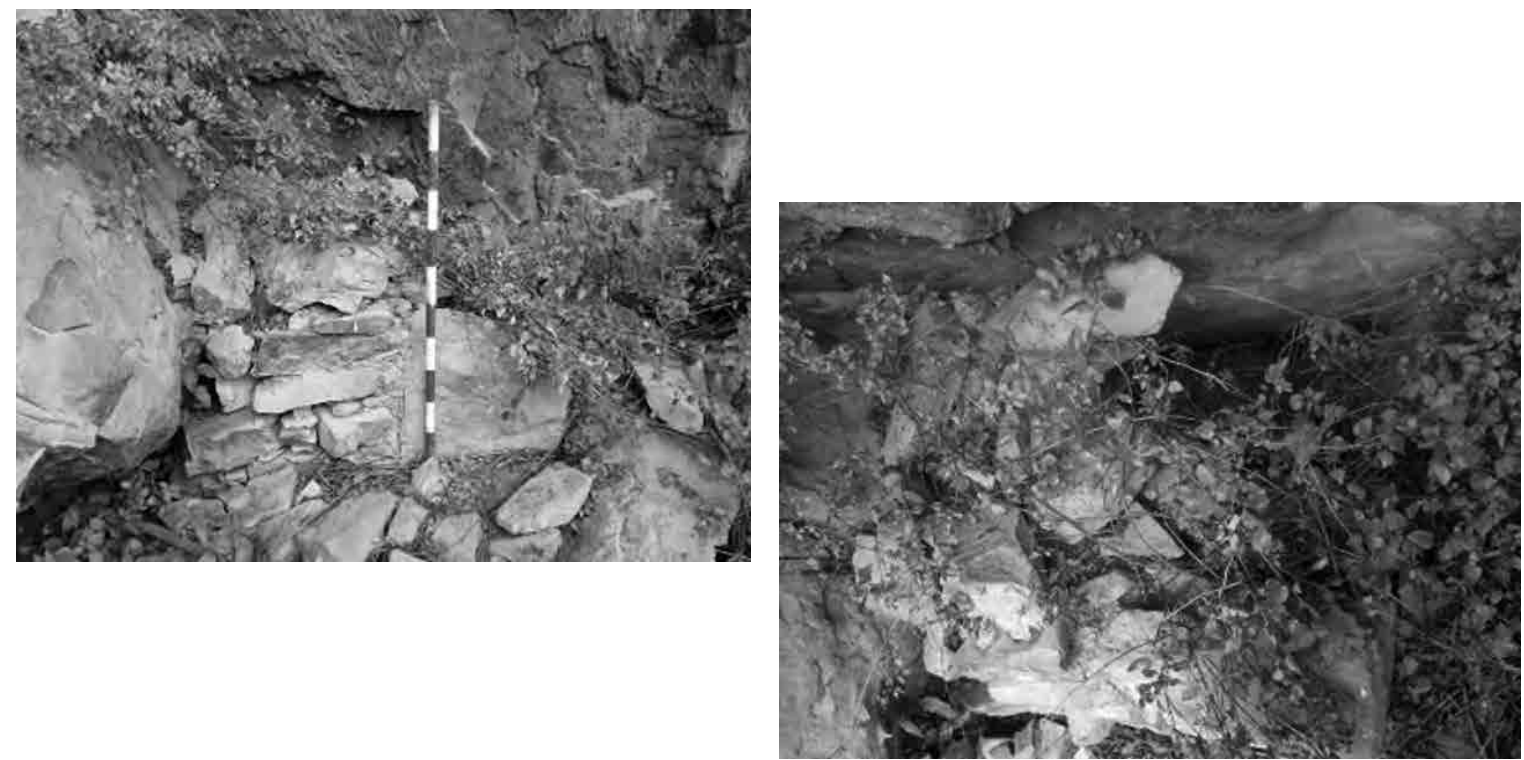

Figura 11 (izquierda): vista panorámica de la parte externa de la estructura funeraria 2. Figura 12 (derecha): vista en detalle de la cubierta de la estructura funeraria 2. Sitio Pintashkaka, sector A. 
Estructura funeraria 3: está ubicada al suroeste y adosada a la estructura funeraria 2. Tiene planta cuadrangular, cuyas dimensiones son: $1.70 \mathrm{~m}$ de largo, $1.40 \mathrm{~m}$ de ancho y una altura que varía de 0.80 a $1.10 \mathrm{~m}$; en regular estado de conservación. Presenta 2 cámaras con muros de doble hilera de piedra canteada, de 0.30 a $0.40 \mathrm{~m}$ de grosor. El paramento interno y externo se encuentran pintados de color rojo. La primera cámara no presenta acceso. El acceso a la segunda cámara es a través de primera cámara, que tiene planta cuadrangular de $0.40 \mathrm{~m}$ de largo y $0.50 \mathrm{~m}$ de altura. La cubierta es plana, edificado a base de piedras alajadas, planas y alargadas. En el interior de las cámaras se observan restos óseos, botánico (mate) y cerámica.
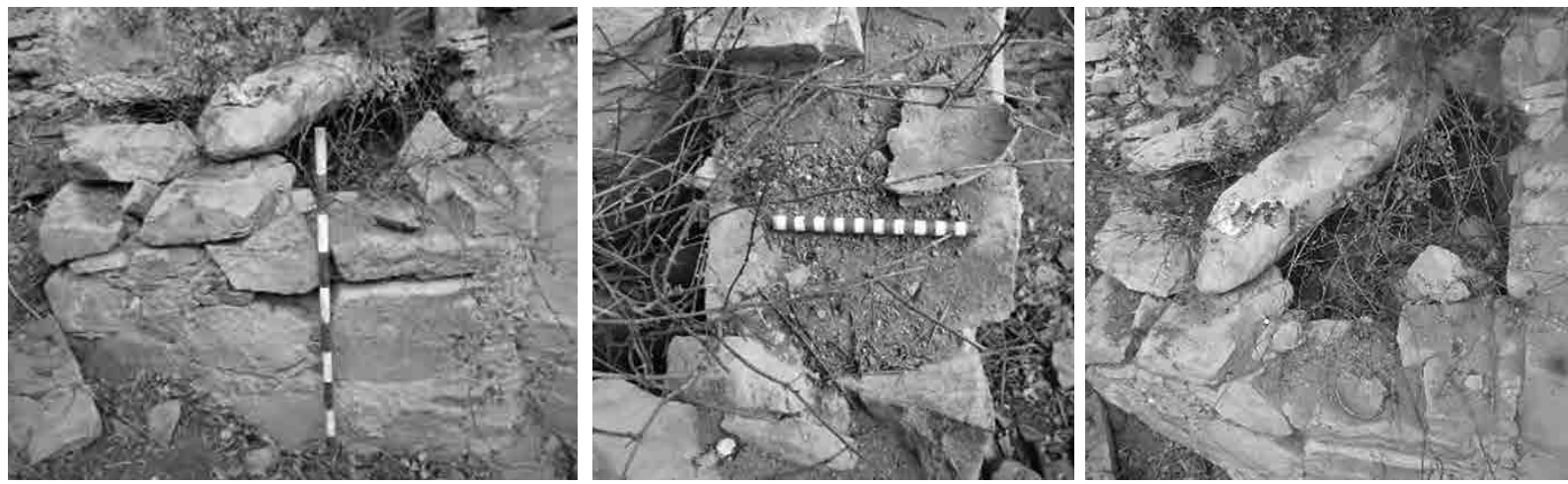

Figura 13 (izquierda): vista panorámica de la parte externa de la estructura funeraria 3. Figura 14 (superior): vista en detalle del muro norte de la estructura funeraria 3. Figura 15 (inferior): vista panorámica de la cubierta de la estructura funeraria 3. Sitio Pintashkaka, sector A.

Estructura funeraria 4: está ubicado al suroeste y adosado a la estructura funeraria 3. Presenta dos niveles con cámaras funerarias superpuestas. Solo se conserva la cámara inferior. La cámara superior se encuentra derrumbada. La cámara inferior tiene forma cuadrangular de $1.80 \mathrm{~m}$ de largo y $1.75 \mathrm{~m}$ de ancho, y $1 \mathrm{~m}$ de altura, en regular estado de conservación. Está edificada con muros de una sola hilera de piedras canteadas unidas con argamasa, de $0.40 \mathrm{~m}$ de grosor. El paramento externo se encuentra pintado de color rojo. La cámara inferior presenta un acceso que va hacia la pared del abrigo rocoso, de forma cuadrangular con $0.50 \mathrm{~m}$ de altura y $0.40 \mathrm{~m}$ de largo. La cubierta es de forma abovedada a base de piedras planas y alargadas (lajas). En el interior se observa restos óseos, botánicos (soguillas) y textiles.
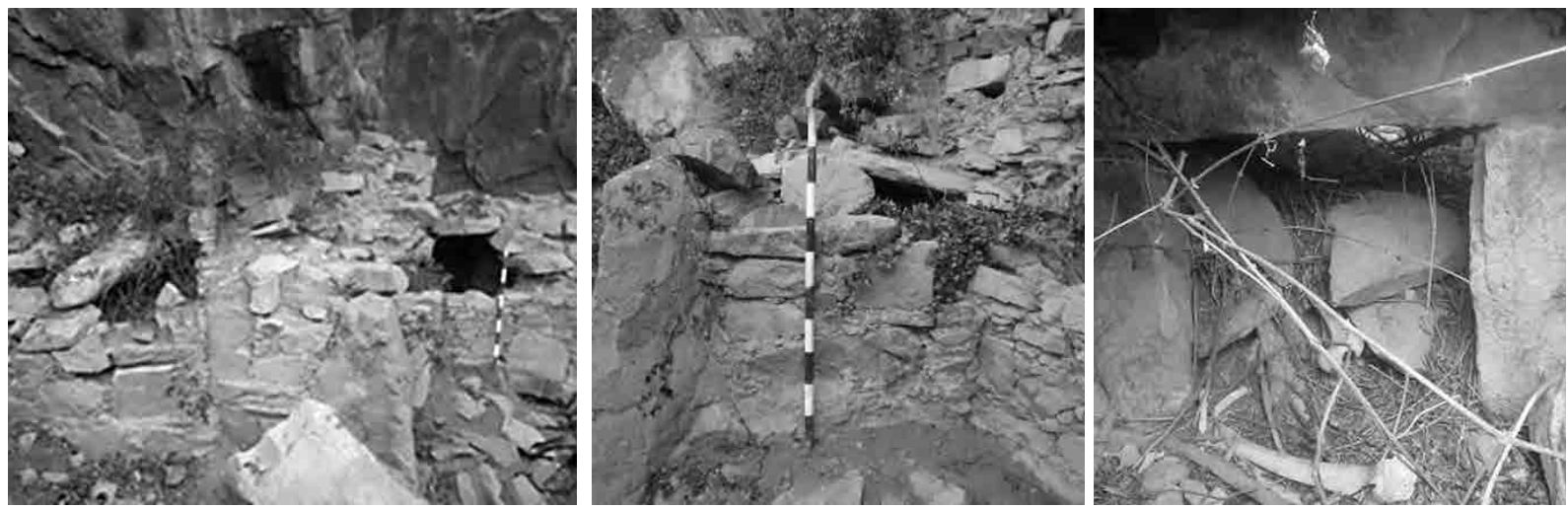

Figura 16 (izquierda): vista panorámica de la parte externa de las estructuras funerarias 3 y 4. Figura 17 (centro): vista en detalle de la parte externa norte de la estructura funeraria 4 . Figura 18 (derecha): vista panorámica de la parte interna de la estructura funeraria 4. Sitio Pintashkaka, sector A. 
Estructura funeraria 5: está ubicada al suroeste y adosado a la estructura funeraria 4. Tiene forma irregular de $1.60 \mathrm{~m}$ de ancho, $1.90 \mathrm{~m}$ de largo y $1.20 \mathrm{~m}$ de altura, en mal estado de conservación. Está edificado con muros de una sola hilera de piedra canteada unidos con argamasa, de $0.30 \mathrm{~m}$ de grosor. El paramento externo se encuentra pintado de color rojo. Tiene un acceso que va hacia la pared del abrigo rocoso, de forma cuadrangular, con $0.30 \mathrm{~m}$ de altura y $0.40 \mathrm{~m}$ de ancho. La cubierta es de forma plana a base de piedras planas y alargadas, con un $50 \%$ desplomado. En el interior se observan restos óseos (5 individuos), botánicos (soguillas), textiles y cerámica.
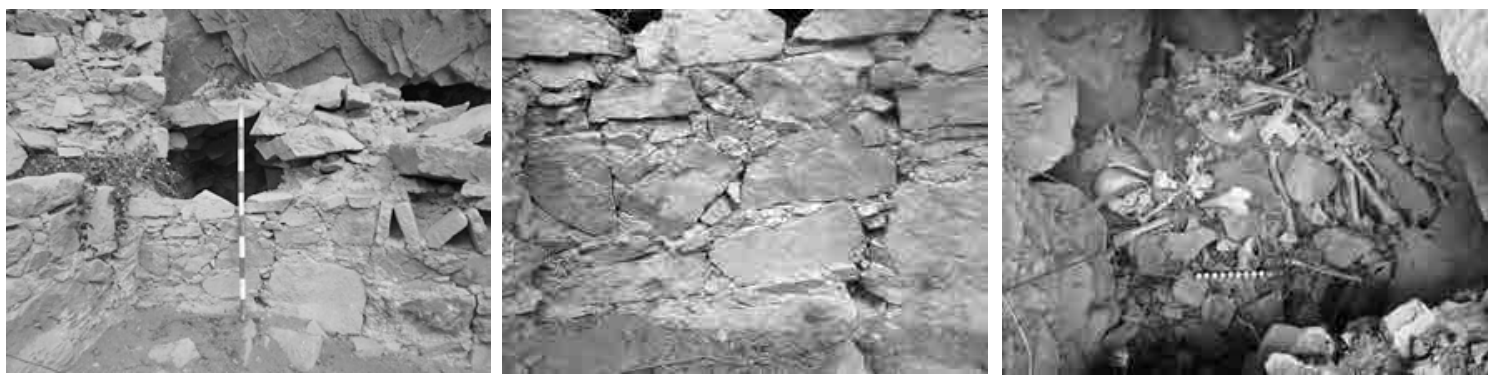

Figura 19 (izquierda): vista panorámica de la parte externa de la estructura funeraria 5. Figura 20 (central): vista en detalle del paramento norte de la estructura funeraria 5. Figura 21 (derecha): vista panorámica de la parte interna de la estructura funeraria 5. Sitio Pintashkaka, sector A.

Estructura funeraria 6: está ubicada al suroeste y adosada a la estructura funeraria 5. Tiene forma cuadrangular, compuesta de dos cámaras, cuyas dimensiones son: la primera cámara tiene $1.84 \mathrm{~m}$ de ancho, $2.00 \mathrm{~m}$ de largo, y $1.50 \mathrm{~m}$ de altura. La segunda cámara es de planta en media luna de $1.85 \mathrm{~m}$ de ancho, $1.90 \mathrm{~m}$ de largo y $1.40 \mathrm{~m}$ de altura. Ambos en regular estado de conservación. Están edificados con muros de doble hilera de piedra canteada unidos con argamasa, de $0.40 \mathrm{~m}$ de grosor. El paramento interno y externo se encuentran pintados de color rojo. El paramento externo (pared norte) muestra en la parte superior un conjunto de frisos de piedra (en zigzag) que representan motivos geométricos. En el paramento interno se observa dos nichos de forma cuadrangular. Presenta un acceso de forma cuadrangular de $0.50 \mathrm{~m}$ de ancho por $0.40 \mathrm{~m}$ de altura. La cubierta es plana, edificada a base de piedras planas y alargadas, con un $80 \%$ desplomado. En el interior se observa restos óseos (6 individuos), botánicos (soguillas, resto de maguey y tusas de maíz), textiles y cerámica.
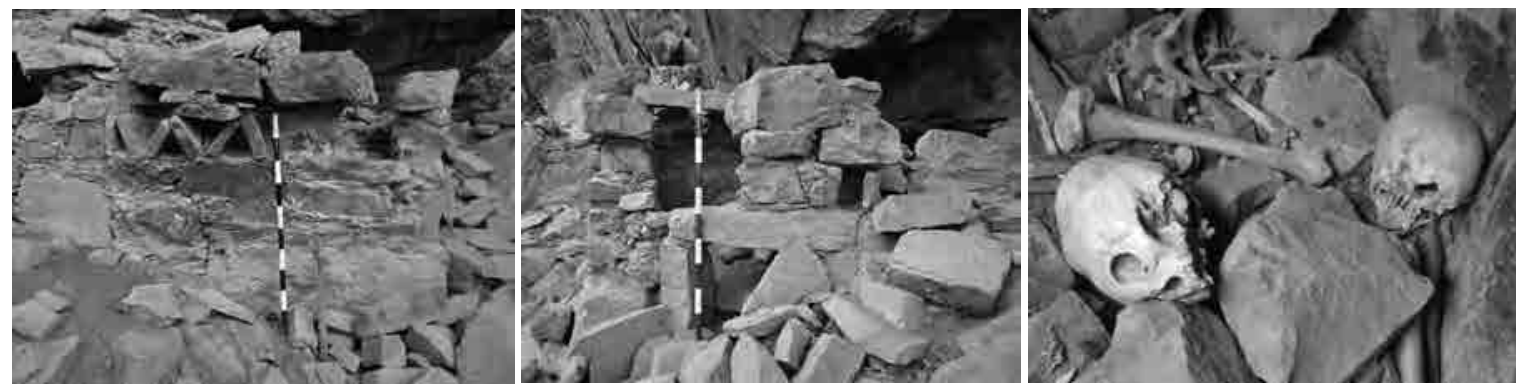

Figura 22 (izquierda): vista panorámica de la parte externa (lado norte) de la estructura funeraria 6.

Figura 23 (central): vista panorámica del paramento oeste de la estructura funeraria 6.

Figura 24 (derecha): vista en detalle de los restos óseos asociados en el interior de la estructura funeraria 6. Sitio Pintashkaka, sector A. 
Estructura funeraria 7: está ubicado al suroeste y adosado a la estructura funeraria 6, que intruye a la cubierta de la estructura funeraria 8 , sobre una roca de regular tamaño. Tiene planta irregular de $2.80 \mathrm{~m}$ de largo y $1.80 \mathrm{~m}$ de ancho, en mal estado de conservación (disturbado). Está edificado con muros de doble hilera de piedra canteada unidos con argamasa, de $0.30 \mathrm{~m}$ de grosor. El paramento externo se encuentra pintado de color rojo. En el interior se observan restos óseos y botánicos (mate y madera).
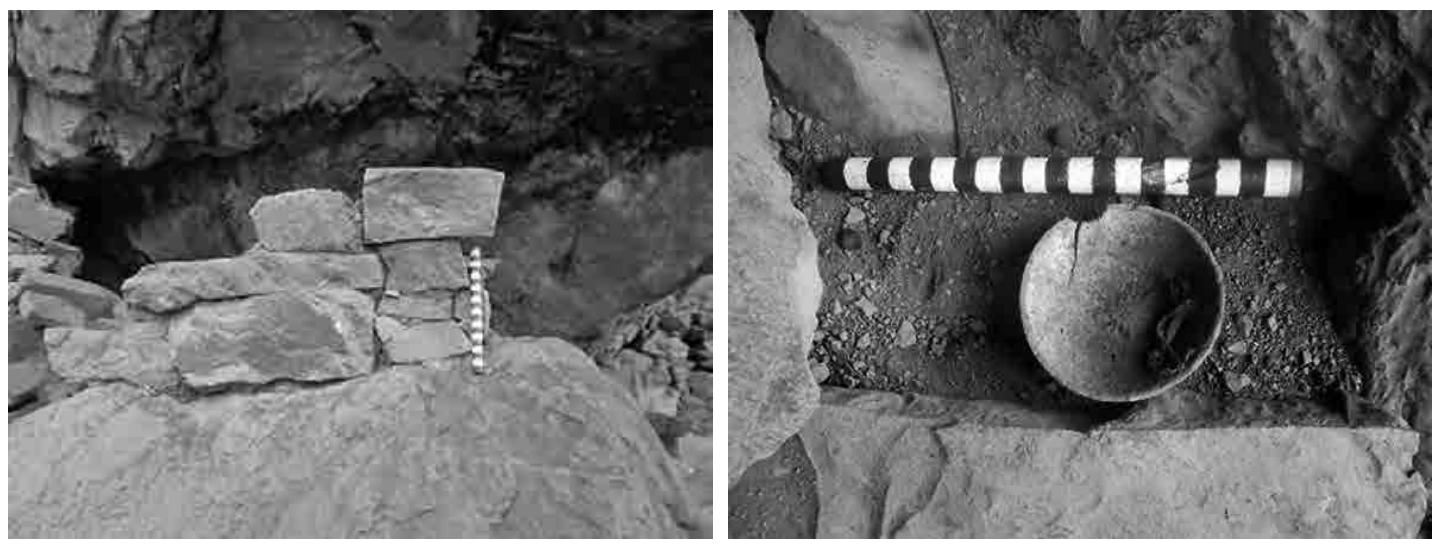

Figura 25 (izquierda): vista de la parte externa de la estructura funeraria 7.

Figura 26: (derecha): vista en detalle de los restos botanicos (mate) utilizado como plato y asociado a los individuos disturbados del interior de la estructura funeraria 7. Sitio Pintashkaka, sector A.

Estructura funeraria 8: está ubicado al sur de la estructura funeraria 7. Tiene forma cuadrangular, compuesta de dos cámaras, cuyas dimensiones son: la primera cámara tiene $1.30 \mathrm{~m}$ de ancho, 1.70 $\mathrm{m}$ de largo, y $1.20 \mathrm{~m}$ de altura; la segunda cámara tiene de $1.10 \mathrm{~m}$ de ancho, $1.80 \mathrm{~m}$ de largo y $0.80 \mathrm{~m}$ de altura. Ambos se encuentran en regular estado de conservación. Están edificados con muros de doble hilera de piedra canteada unidos con argamasa, de $0.30 \mathrm{~m}$ de grosor. El paramento externo se encuentra pintado de color rojo. A la altura de la cubierta presenta voladizo. Presenta un acceso de forma cuadrangular orientado al lado oeste. La cubierta plana está edificada a base de piedras planas y alargadas, con $90 \%$ desplomado. En el interior se observa restos óseos y textiles.

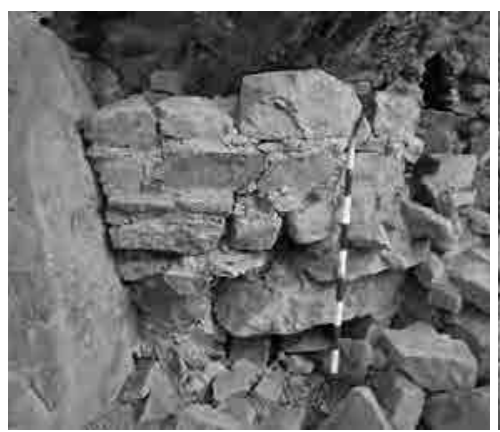

Figura 27 (izquierda): vista frontal de la parte externa de la estructura funeraria 8. Figura 28: (centro): vista panorámica de la estructura funeraria 8 desde el oeste. Figura 29 (derecha): vista en detalle de la cubierta de la estructura funeraria 8. Sitio

Pintashkaka, sector A.
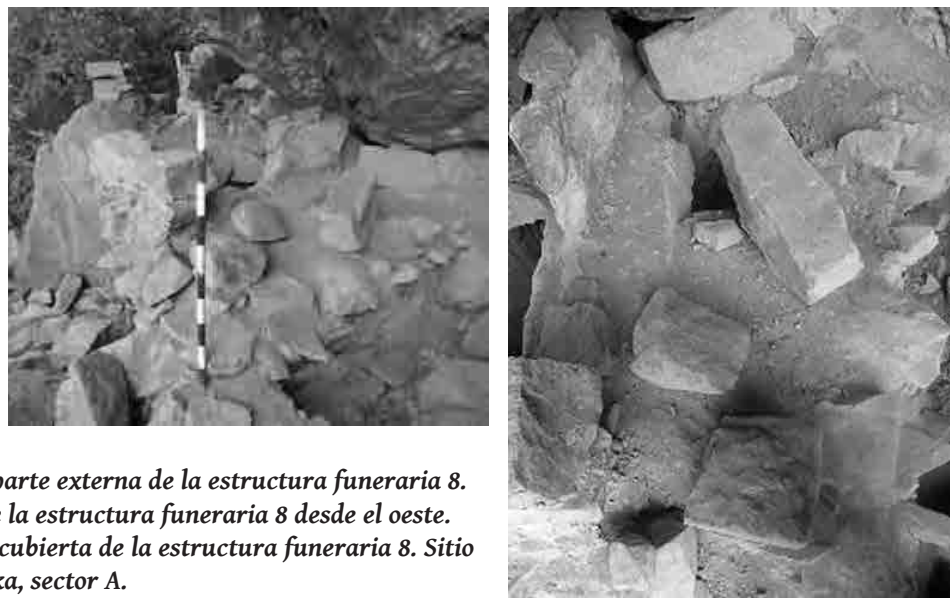
Estructura funeraria 9: está ubicado al sur y adosado a la estructura funeraria 8. Tiene forma rectangular, de $1.60 \mathrm{~m}$ de ancho, $1.70 \mathrm{~m}$ de largo, y $0.70 \mathrm{~m}$ de altura; en mal estado de conservación. Está edificado con muros de una hilera de piedras canteadas unidas con argamasa, de $0.30 \mathrm{~m}$ de grosor. Acceso no identificado. La cubierta es plana edificado a base de lajas de piedra, con un $50 \%$ desplomado. En el interior se observan restos óseos (posiblemente 1 individuo).
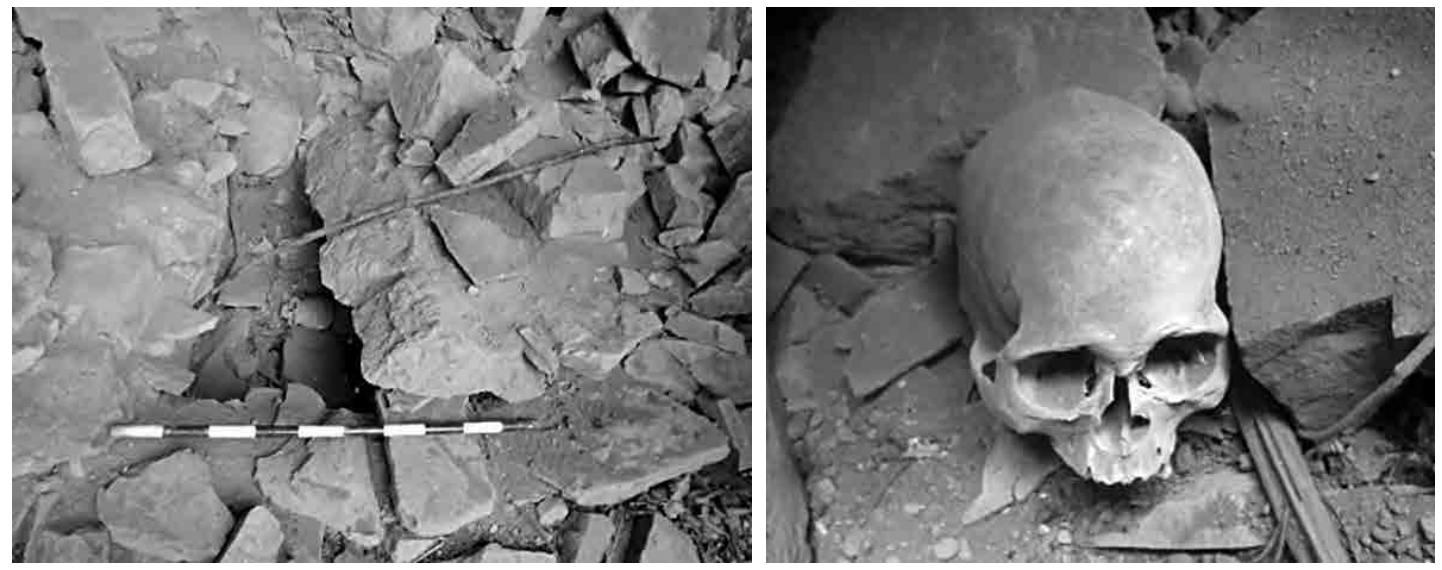

Figura 30 (izquierda): detalle de la cubierta de la estructura funeraria 9. Figura 31 (derecha): vista en detalle de los restos óseos asociados en el interior de la estructura funeraria 9. Sitio Pintashkaka, sector A.

Estructura funeraria 10: está ubicado al sur de la estructura funeraria 9, adosado a la pared del abrigo rocoso. Tiene forma en media luna, de $3.00 \mathrm{~m}$ de largo y $2.30 \mathrm{~m}$ de profundidad, en regular estado de conservación. Está edificado con muros de una hilera de piedras canteadas unidos con argamasa, de $0.50 \mathrm{~m}$ de grosor. En el interior se observa: restos óseos (6 individuos), botánicos (soguillas, maguey) y textiles.
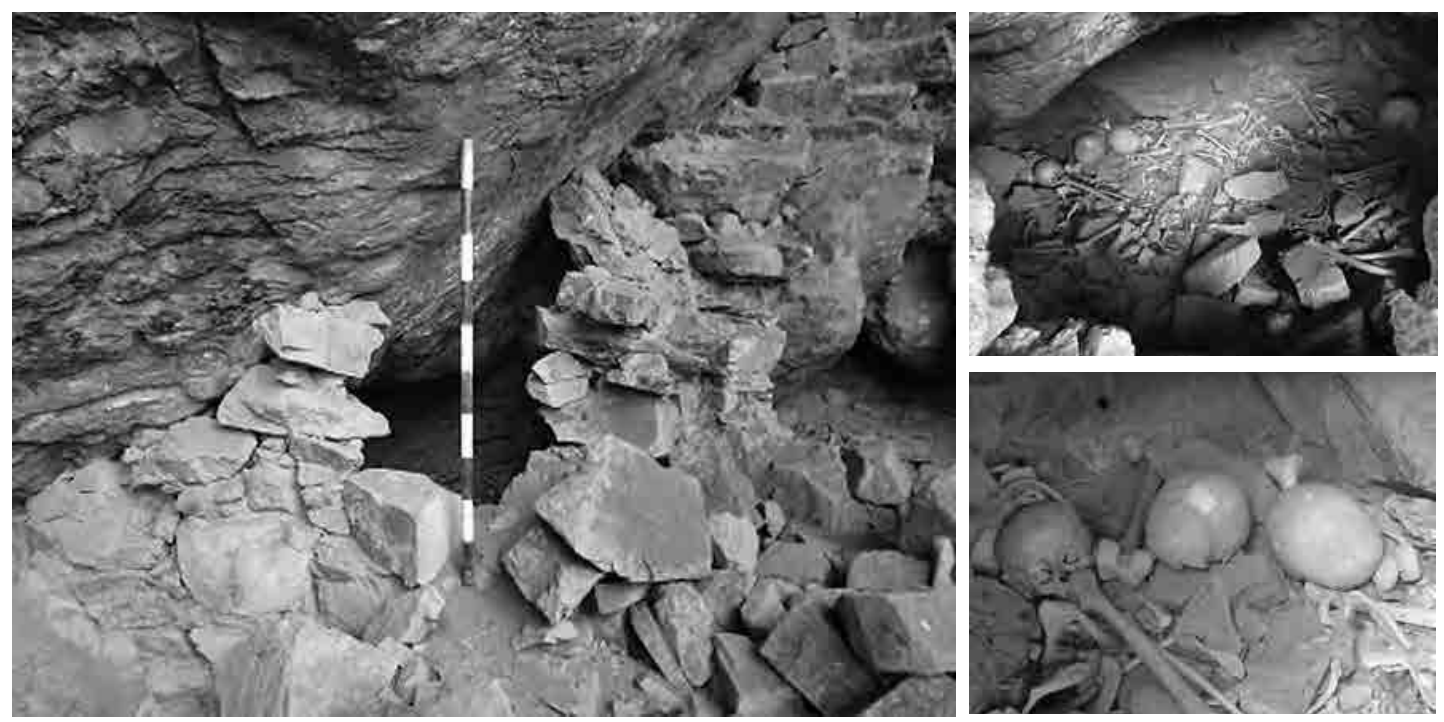

Figura 32 (izquierda): vista panorámica de la parte externa de la estructura funeraria 10.

Figura 33 (derecha arriba): vista del interior de la estructura funeraria 10 (nótese la presencia de restos óseos).

Figura 34 (derecha abajo): vista en detalle de los restos óseos en el interior de la estructura funeraria. Sitio Pintashkaka, sector A. 
Estructura funeraria 11: está ubicado al sur y en la parte superior de la estructura funeraria 10, adosado a la pared del abrigo rocoso. Tiene forma cuadrangular, cuyas dimensiones son: $1.35 \mathrm{~m}$ de ancho, $2.40 \mathrm{~m}$ de largo, y $3.50 \mathrm{~m}$ de profundidad, en regular estado de conservación. Está edificado con muros de doble hilera de piedras canteadas unidos con argamasa, de $0.30 \mathrm{~m}$ de grosor. El acceso no pudo ser identificado. En el interior se observa restos óseos (4 individuos) y textiles.
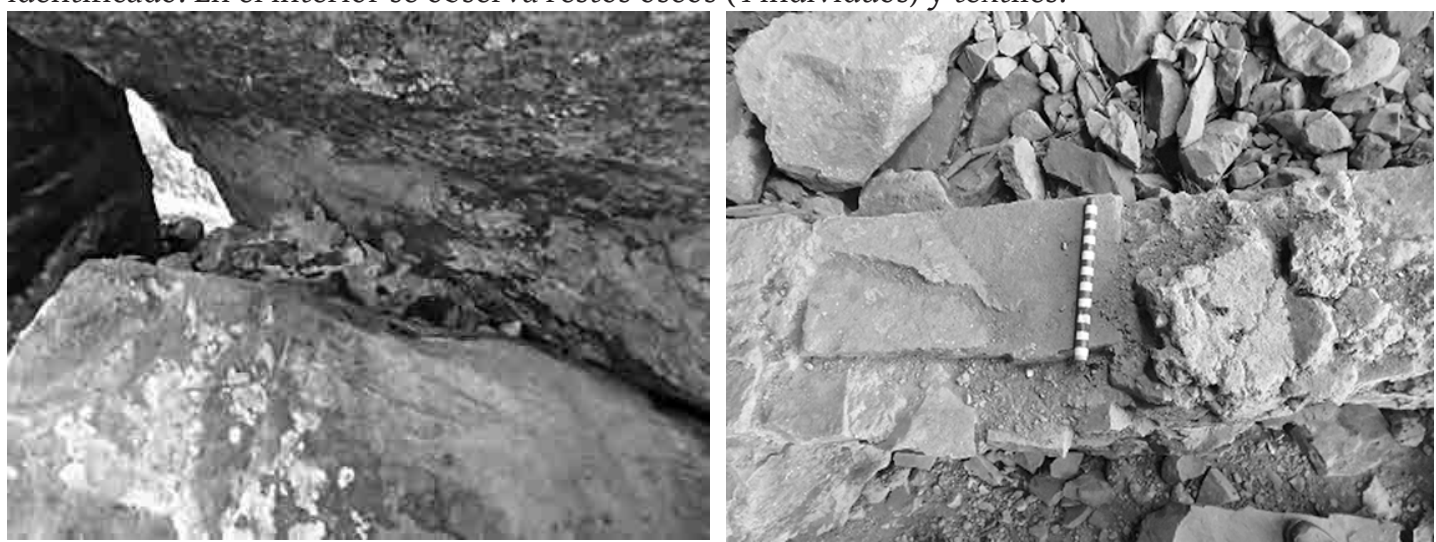

Figura 35 (izquierda): vista panorámica de la estructura funeraria 12. Figura 36 (derecha): detalle del muro de la estructura funeraria 11. Sitio Pintashkaka, sector A.

Estructura funeraria 12: está ubicado al sur de la estructura funeraria 11, en la parte superior y sobre una roca de gran tamaño pintada de color verde. Tiene planta en media luna, no se pudo determinar las medidas por su difícil acceso y su ubicación. En regular estado de conservación. Está edificado con muros de doble hilera de piedra canteada unidos con argamasa. El paramento externo se encuentra pintado de color verde.

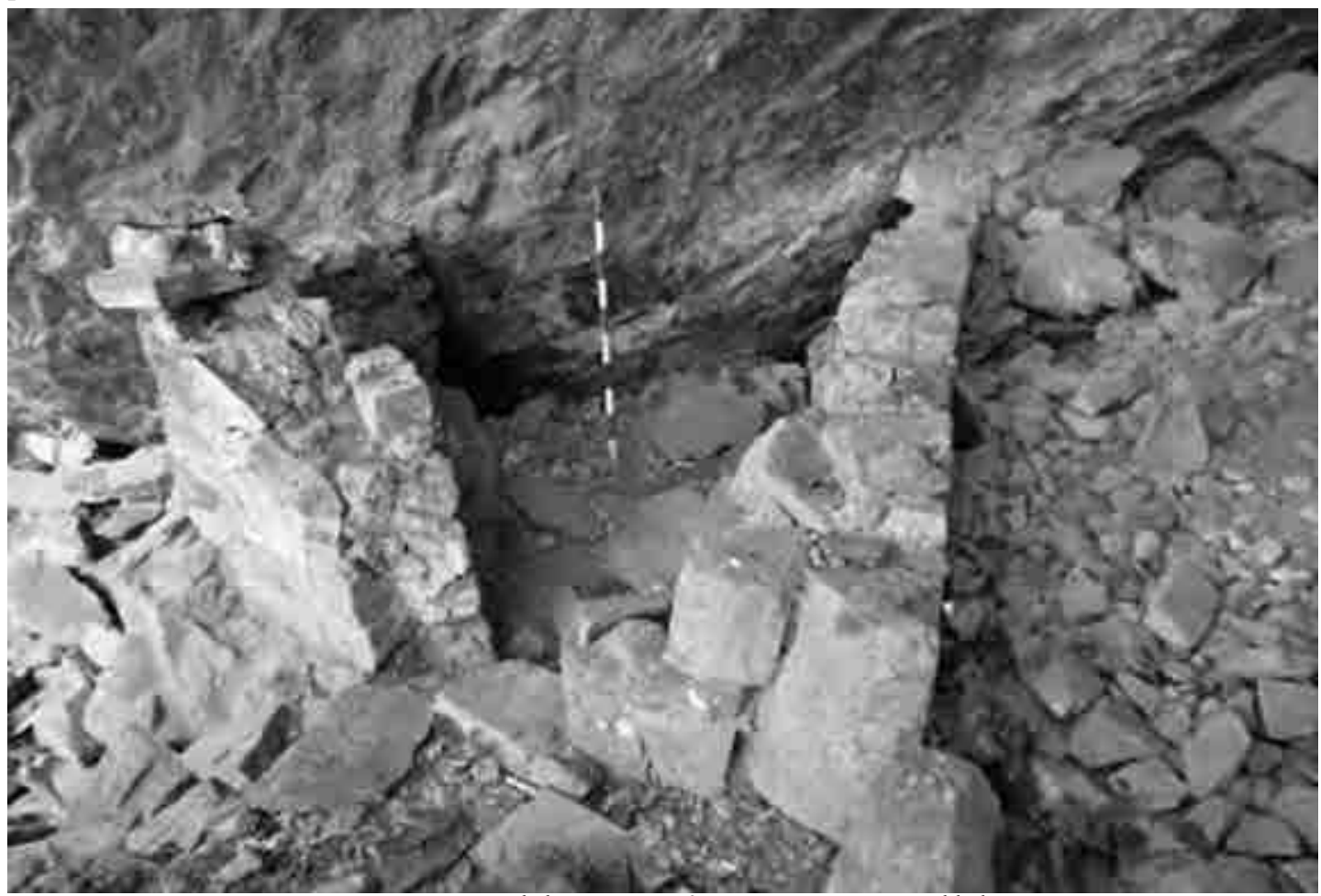

Figura 37: vista panorámica de la estructura funeraria 11. Sitio Pintashkaka, sector A. 
Estructura funeraria 13: está ubicado al oeste de la estructura funeraria 12, al pie de una roca pintada de verde, adosada a la pared del abrigo rocoso. Tiene planta cuadrangular de $1.40 \mathrm{~m}$ de ancho, $1.80 \mathrm{~m}$ de largo, y $1.90 \mathrm{~m}$ de diámetro, en regular estado de conservación. Está edificado con muros de doble hilera de piedras canteadas unidas con argamasa, de $0.40 \mathrm{~m}$ de grosor. Presenta un acceso de forma cuadrangular de $0.50 \mathrm{~m}$ de ancho por $0.40 \mathrm{~m}$ de altura, orientado hacia el noroeste. En el interior se observa restos óseos (1 individuo) y botánicos (resto de maguey). En la parte externa se observa restos óseos (cráneos con deformación craneana), textiles, cerámica y restos botánicos (soguillas, restos de maguey).
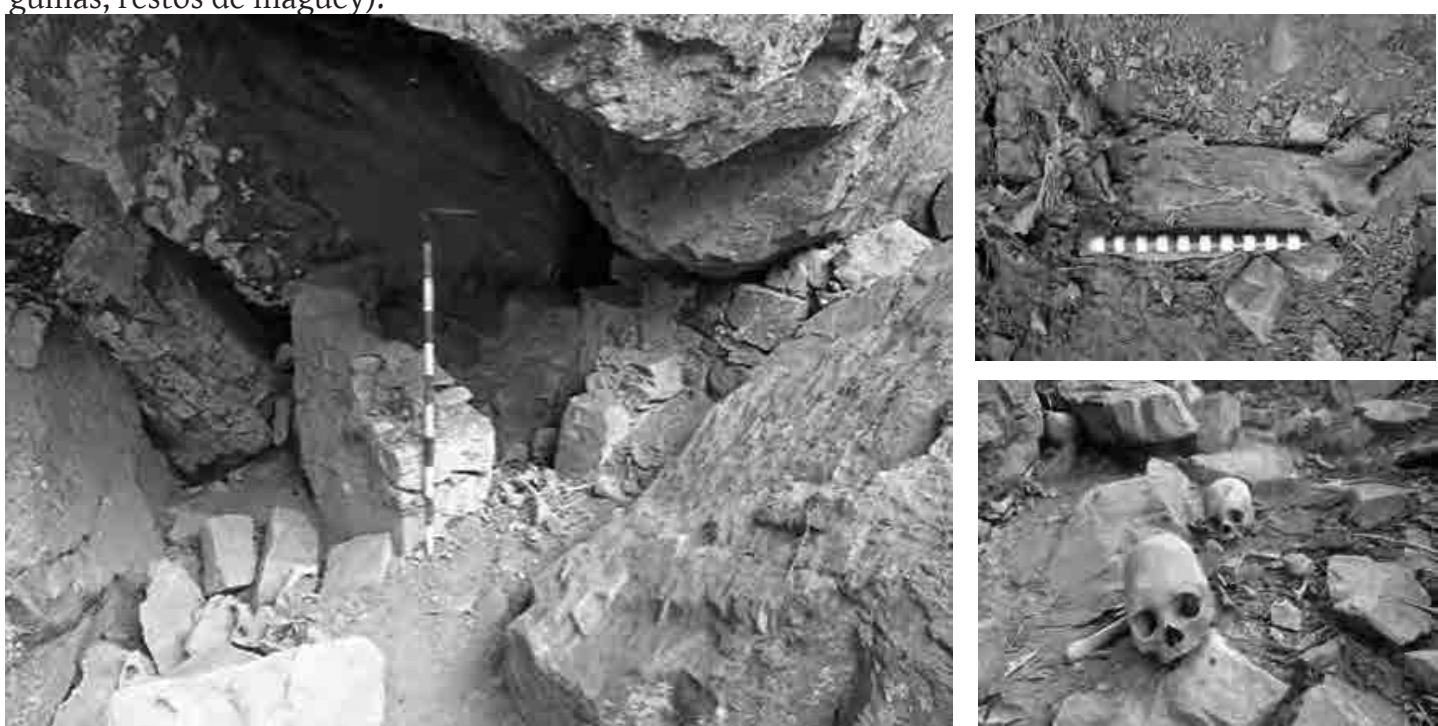

Figura 38 (izquierda): vista panorámica de la estructura funeraria 13. Figura 39 (superior derecha): material textil en el exterior de la estructura funeraria 13. Figura 40 (inferior derecha): detalle de los restos óseos en el exterior de la estructura funeraria 13. Sitio Pintashkaka, sector A.

Estructura funeraria 14: está ubicado al sur y adosado a la estructura funeraria 13, intruye por debajo del abrigo rocoso. Tiene planta cuadrangular, de $1.30 \mathrm{~m}$ de ancho y $1.30 \mathrm{~m}$ de largo; en regular estado de conservación. Está edificado con muros de doble hilera de piedras canteadas unidas con argamasa, de $0.40 \mathrm{~m}$ de grosor. Presenta un acceso de forma cuadrangular de $0.50 \mathrm{~m}$ de ancho por $0.40 \mathrm{~m}$ de altura, orientado al oeste. La cubierta es plana a base de piedras planas y alargadas, con $80 \%$ desplomado. En el interior se observa restos óseos (1 individuo), botánicos (soguillas y resto de maguey), textiles y cerámica.
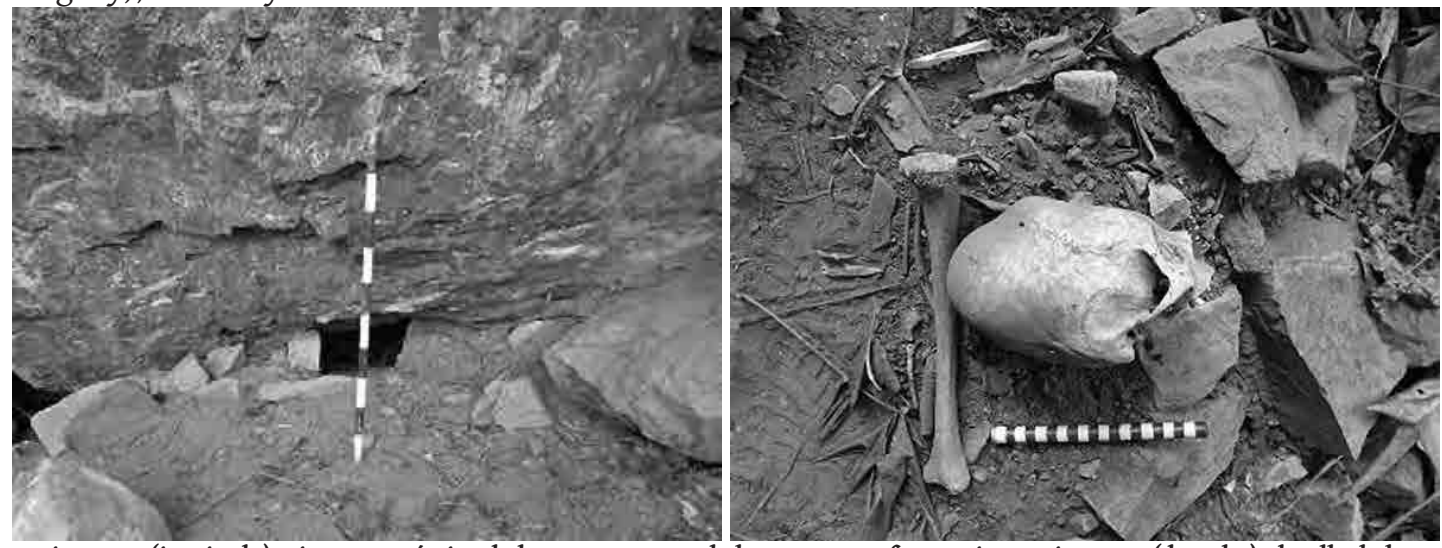

Figura 41 (izquierda): vista panorámica de la parte externa de la estructura funeraria 14. Figura 42 (derecha): detalle de los restos óseos asociados en el exterior de la estructura funeraria 14. Sitio Pintashkaka, sector A. 
II.- Sector B: Se encuentra ubicado en las faldas y ladera media del cerro Kasuela Punta; entre las coordenadas UTM: 8869628N, 0228335E y a 2758 metros sobre el nivel del mar, al lado oeste del sector A. Al igual que el sector A se caracteriza por presentar abundante vegetación propia de un bosque tropical, de tamaño regular entre árboles, arbustos y plantas espinosas. Se trata de un conjunto de abrigos rocosos de tipo andesita, con las paredes completamente pintadas de color rojo óxido, que se extiende de noreste a suroeste, de 8 metros de altura por 32 metros de largo aproximadamente, asociado a pinturas rupestres con diferentes motivos y estructuras funerarias (tipo chullpa).

Las pinturas rupestres se encuentran en la parte media inferior de las paredes norte y oeste del abrigo, a unos 2.50 metros aproximadamente de altura con respecto al piso del abrigo. Está compuesto de 3 motivos definidos:

Motivo 1: pintura de forma de 2 semi-círculos concéntricos, en regular estado de conservación. Ambos elaborados mediante la técnica de pintura negativa, de color natural del abrigo rocoso (grisáceo), debajo de un fondo rojo. El semi-círculo mayor tiene $0.50 \mathrm{~m}$ de alto por $0.60 \mathrm{~m}$ de ancho, y 0.10 $m$ de grosor.

Motivo 2: pintura de forma geométrica (4 motivos cóncavos) en mal estado de conservación. Ambos elaborados mediante la técnica de pintura negativa, de color natural del abrigo rocoso (grisáceo), debajo de un fondo rojo, ubicado por debajo del motivo 1 . Tiene $0.16 \mathrm{~m}$ de alto por $0.80 \mathrm{~m}$ de ancho.

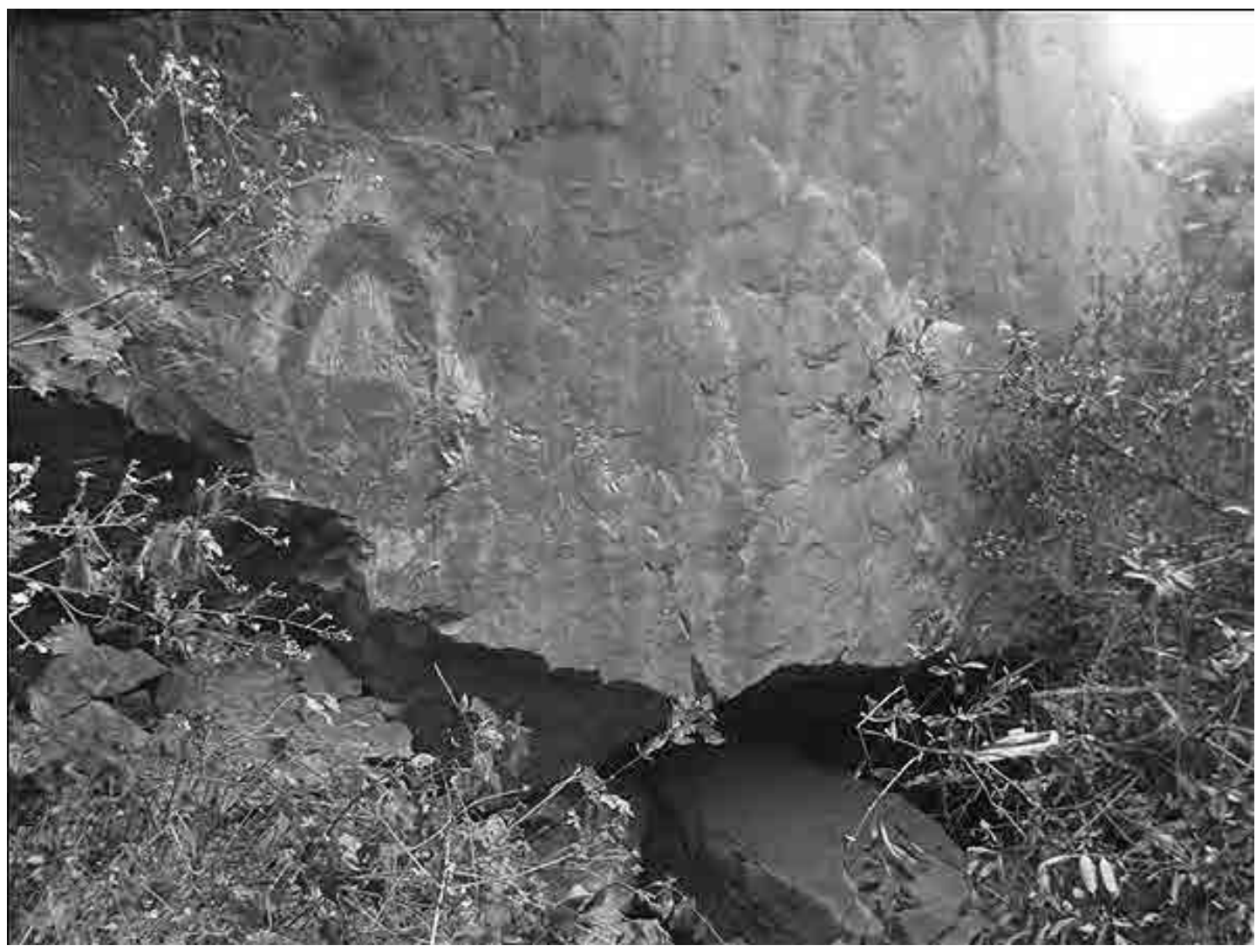


Motivo 3: pintura de dos semi-círculos concéntricos en mal estado de conservación. Ambos elaborados mediante la técnica de pintura negativa, de color natural del abrigo rocoso (grisáceo), debajo de un fondo rojo. Los semi-círculos tienen $0.60 \mathrm{~m}$ de alto por $0.80 \mathrm{~m}$ de ancho, y $0.15 \mathrm{~m}$ de grosor.
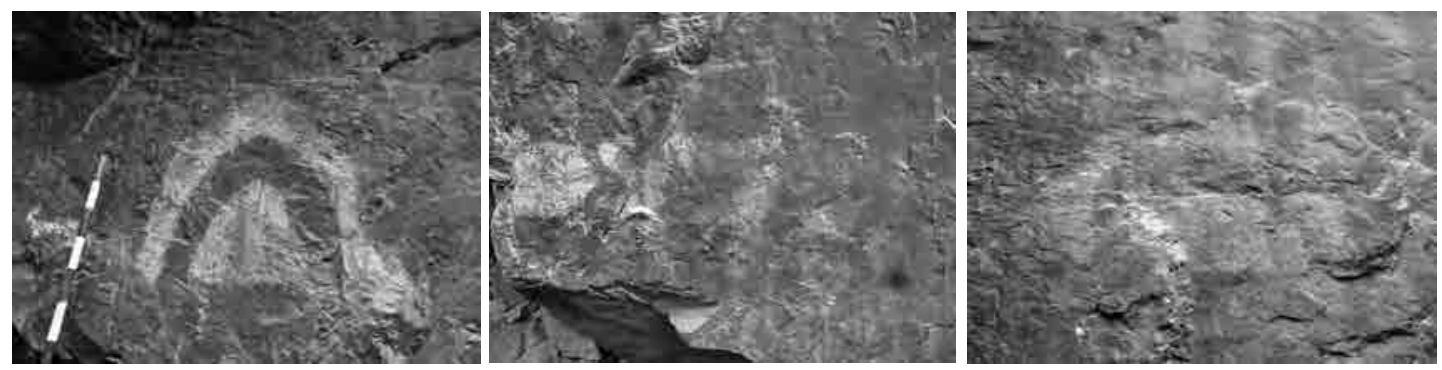

Figura 44 (izquierda): detalle del motivo 1. Figura 45 (centro): detalle del motivo 2. Figura 46 (derecha): detalle del motivo 3. Sitio Pintashkaka, sector B.

Las estructuras funerarias se encuentran al pie del abrigo rocoso, distribuidos de noreste a suroeste, ubicados al oeste del sector A.

Estructura funeraria 1: está ubicada al lado norte del abrigo rocoso. Tiene planta semicircular, cuyas dimensiones son: $1.34 \mathrm{~m}$ de ancho, $1.70 \mathrm{~m}$ de largo, $1.10 \mathrm{~m}$ de altura y $1.70 \mathrm{~m}$ de profundidad, en regular estado de conservación. Está edificado con muros de una hilera, de piedras canteadas unidas con argamasa, de $0.30 \mathrm{~m}$ de grosor. El paramento externo (pared norte) muestra en la parte superior un conjunto de piedras voladizas a media altura. En el interior se observa restos óseos (1 individuo).

Estructura funeraria 2: está ubicada al suroeste y adosado a la estructura funeraria 1. Tiene forma semicircular, cuyas dimensiones son: $2.10 \mathrm{~m}$ de ancho, $2.00 \mathrm{~m}$ de largo, y $0.77 \mathrm{~m}$ de altura, en mal estado de conservación, con muros totalmente derrumbados. Está edificado con muros de una hilera de piedras canteadas unidas con argamasa, de $0.54 \mathrm{~m}$ de grosor. En el interior se observa algunos restos óseos muy dispersos.

Estructura funeraria 3: está ubicada al sur y a un nivel superior de la estructura funeraria 2. Corresponde a un acondicionamiento del espacio en forma de media luna, cuyas dimensiones son: $1.10 \mathrm{~m}$ de ancho, $2.40 \mathrm{~m}$ de largo, y $0.50 \mathrm{~m}$ de altura. Está edificado con muros de doble hilera de piedra canteada unidos con argamasa, de $0.30 \mathrm{~m}$ de grosor, en parte está pintado de color verde. En su interior no está asociado a ningún material cultural.
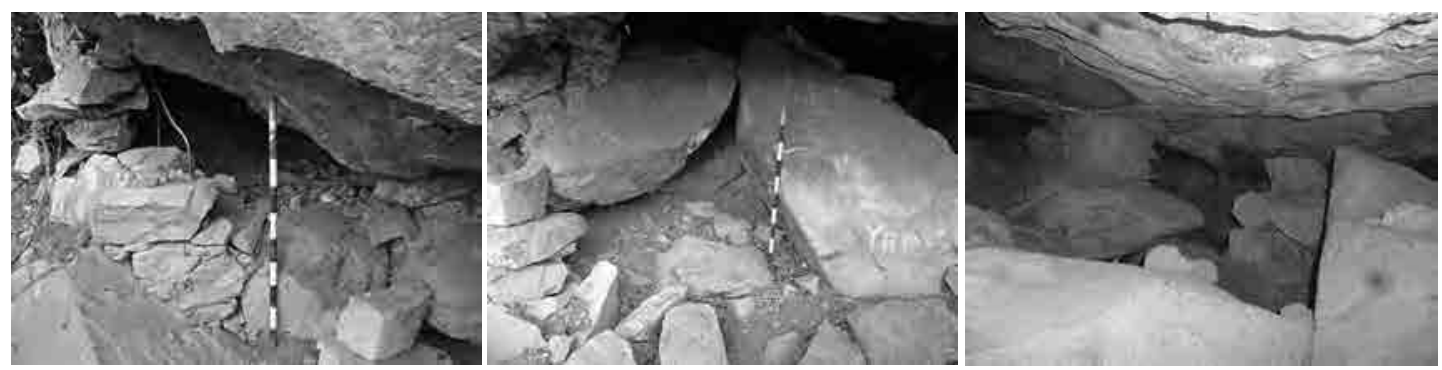

Figura 47 (izquierda): vista panorámica de la estructura funeraria 1. Figura 48 (centro): vista panorámica de la estructura funeraria 2. Figura 49 (derecha): vista panorámica de la estructura funeraria. Sitio Pintashkaka, sector B. 
Estructura funeraria 4: está ubicada al suroeste y adosado a la estructura funeraria 3, situado sobre una piedra plana pintada de color verde. Tiene forma en media luna, cuyas dimensiones son: $1.65 \mathrm{~m}$ de ancho, $1.50 \mathrm{~m}$ de profundidad, y $0.60 \mathrm{~m}$ de altura; en regular estado de conservación. Está edificado con muros de doble hilera de piedras canteadas unidas con argamasa, de $0.75 \mathrm{~m}$ de grosor. El paramento interno se encuentra pintado de color verde. En el interior se observa algunos restos óseos muy dispersos.

Estructura funeraria 5: está ubicada al noroeste de la estructura funeraria 4. Tiene forma semi-circular, compuesta de dos cámaras, cuyas dimensiones son: la primera cámara tiene $1.80 \mathrm{~m}$ de ancho, $1.20 \mathrm{~m}$ de largo, y $1.20 \mathrm{~m}$ de altura. La segunda cámara tiene de $1.10 \mathrm{~m}$ de ancho, $2.20 \mathrm{~m}$ de largo y 1.20 $m$ de altura. Ambos en regular estado de conservación. Están edificadas con muros de doble hilera de piedras canteadas unidas con argamasa, de $0.40 \mathrm{~m}$ de grosor. La cámara 2 presenta un acceso sellado de forma cuadrangular, orientado al suroeste. En el interior se observa algunos restos óseos, botánicos (soguillas y resto de maguey) y textiles.

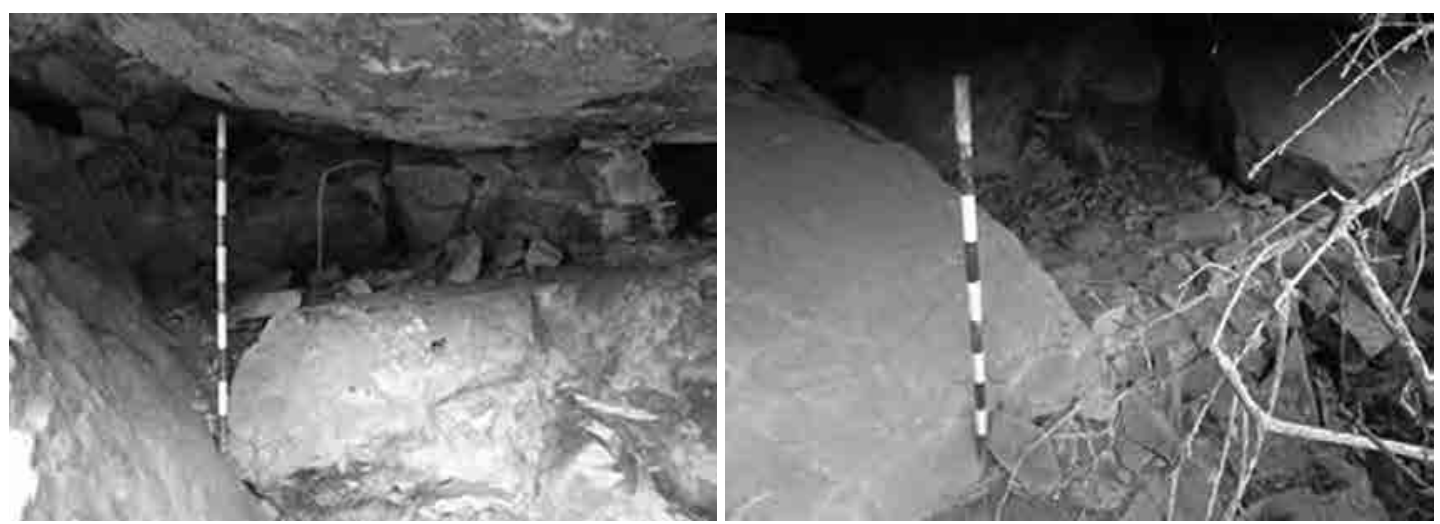

Figura 50 (izquierda): vista panorámica de la estructura funeraria 4.

Figura 51 (derecha): vista panorámica de la estructura funeraria 5. Sitio Pintashkaka, sector B.

III.- Sector C: Se encuentra ubicado en las faldas y ladera media del cerro Kasuela Punta; entre las coordenadas UTM: 8869613N, 0228272E y a 2769 metros sobre el nivel del mar, al lado oeste de los sectores A y B. Al igual que estos sectores (A y B), se caracterizan por presentar abundante vegetación propia de un bosque tropical, de tamaño regular entre árboles, arbustos y plantas espinosas, que imposibilita en gran manera el acceso. Corresponde a un conjunto de abrigos rocosos con las paredes pintadas de color rojo óxido, asociado a 3 estructuras funerarias adosadas a las paredes:

Estructura funeraria 1: está ubicado al lado norte del abrigo rocoso. Tiene planta rectangular de 1.70 $\mathrm{m}$ de ancho, $1.60 \mathrm{~m}$ de largo, y una altura que varía de 0.90 a $1.10 \mathrm{~m}$. Se encuentra en mal estado de conservación. Está edificado con muros de doble hilera de piedras canteadas unidas con argamasa, de $0.30 \mathrm{~m}$ de grosor. Presenta un acceso de forma cuadrangular orientado al oeste. La cubierta es plana a base de piedras lajas, con 90\% desplomado. No está asociado a ningún material en su interior. 

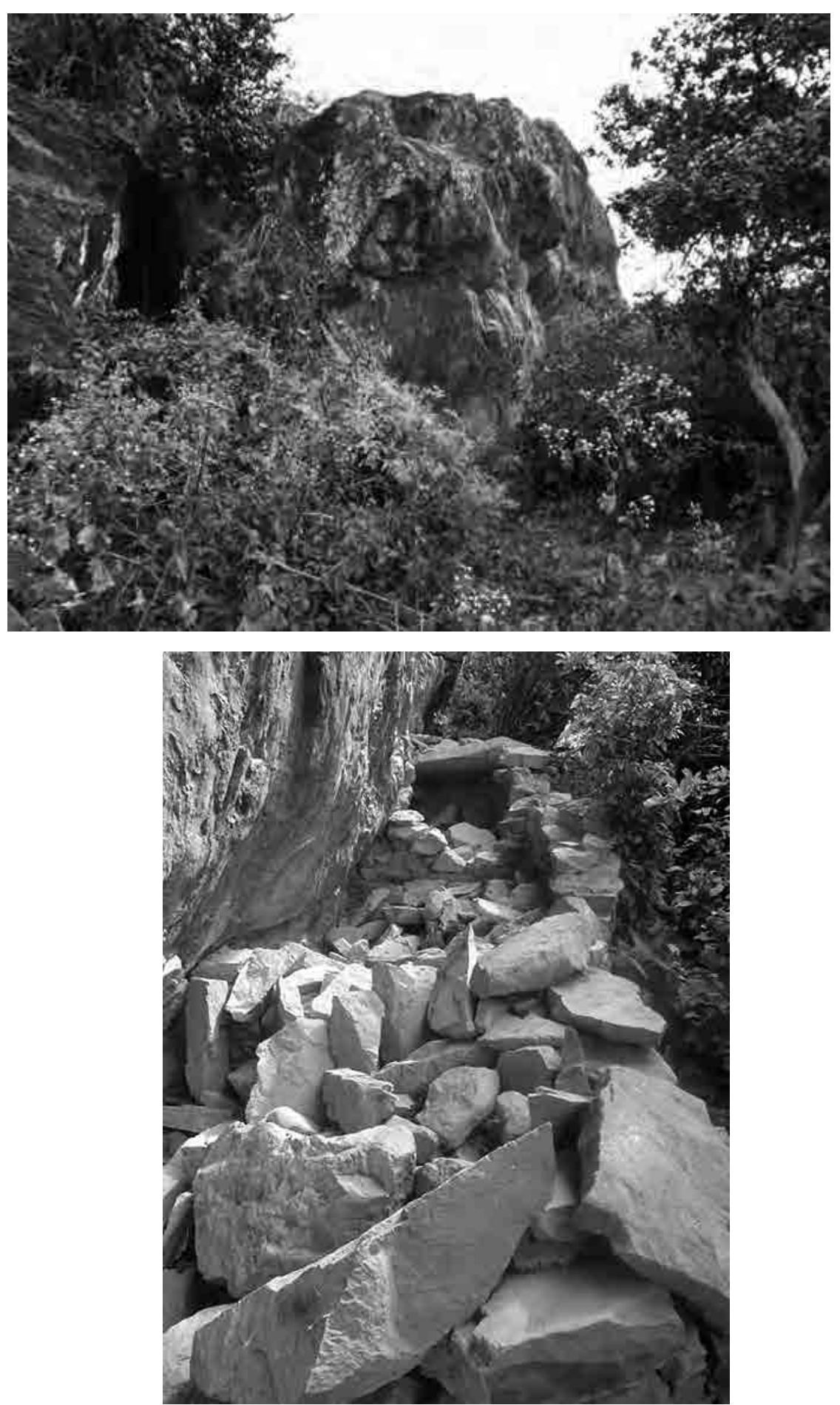

Figura 52 (arriba): vista panorámica del abrigo rocoso del sector C. Figura 53 (abajo): vista panorámica de las estructuras funerarias al pie del abrigo rocoso. Sitio Pintashkaka, sector C. 

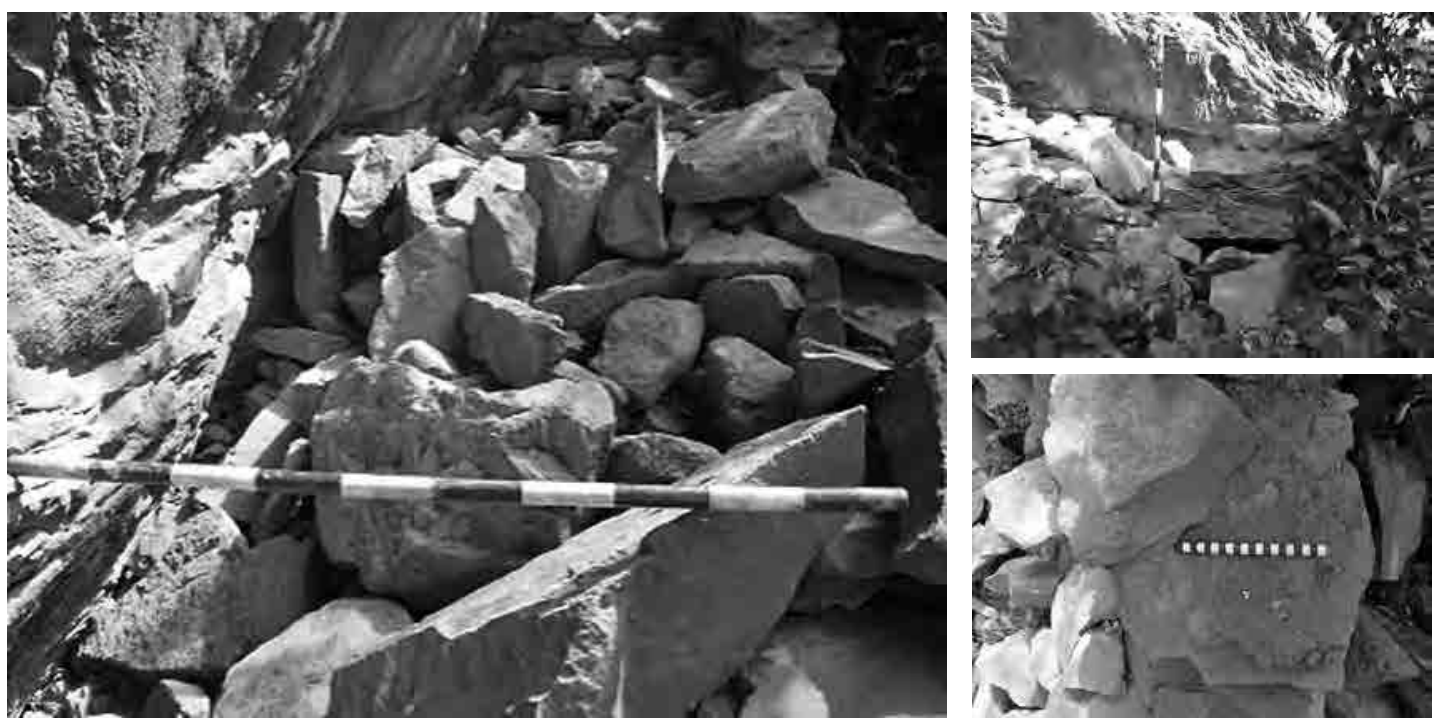

Figura 54 (izquierda): vista panorámica de la estructura funeraria 1. Figura 55 (derecha superior): del acceso de la estructura funeraria 1. Figura 56 (derecha inferior): detalle del muro de la estructura funeraria 1. Sitio Pintashkaka, sector C.

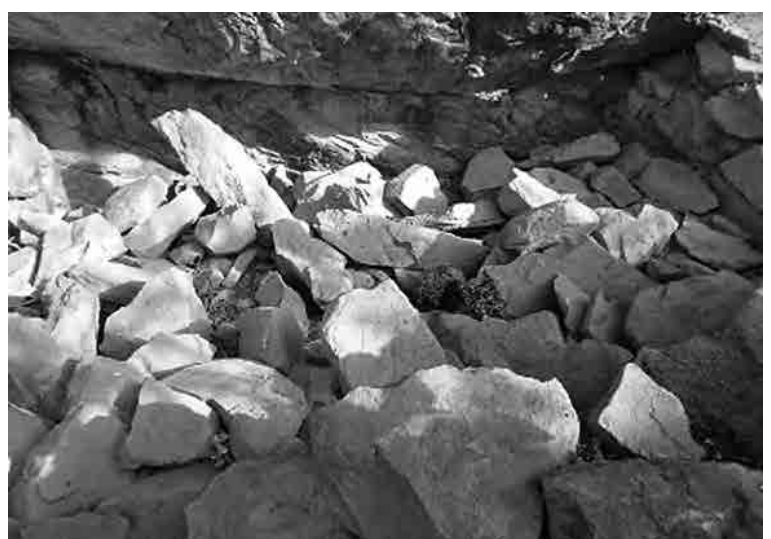

Estructura funeraria 2: está ubicado al suroeste y adosado a la estructura funeraria 1. Tiene planta rectangular de $1.80 \mathrm{~m}$ de ancho, $3.20 \mathrm{~m}$ de largo, y $0.90 \mathrm{~m}$ de altura. Se encuentra en mal estado de conservación. Está edificado con muros de doble hilera de piedras canteadas unidas con argamasa, con un grosor que varía de 0.40 a $0.50 \mathrm{~cm}$. Presenta un acceso de forma cuadrangular orientado al oeste. La cubierta es plana a base de lajas de piedra, totalmente derrumbado. No está asociado a ningún material en su interior.
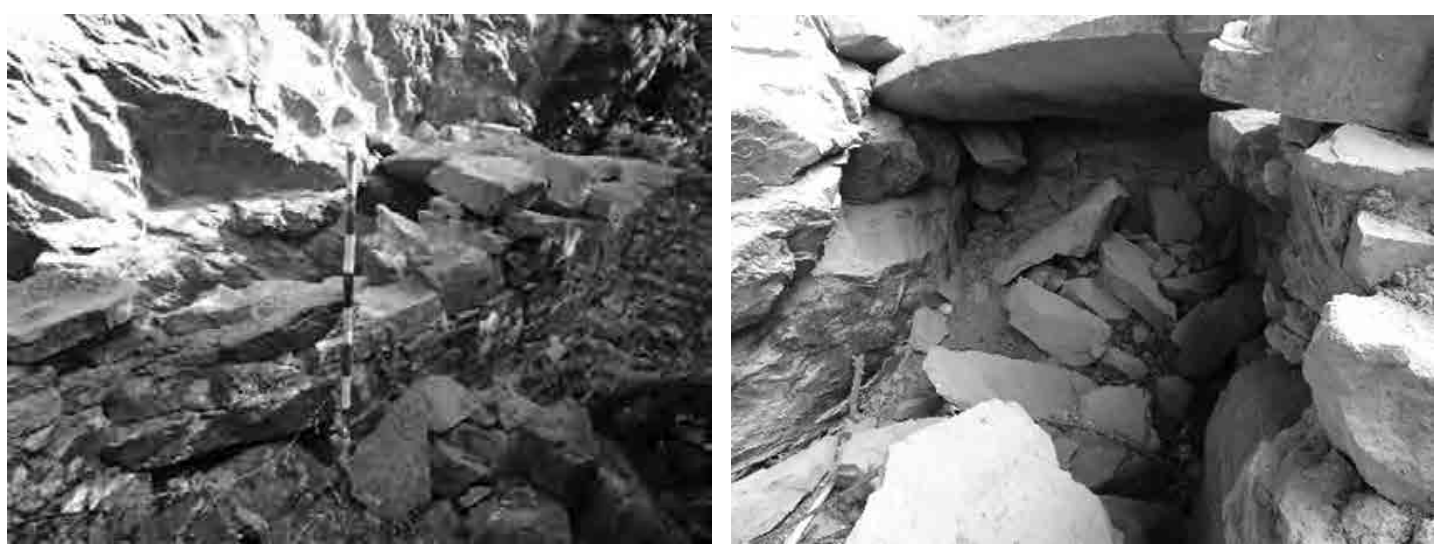

Figura 57: izquierda: detalle del interior de la estrutura funeraria 2. Figura 58 (izquierda inferior): vista panorámica de la estructura funeraria 3. Figura 59 (derecha): detalle del interior de la estructura funeraria 3. Sitio Pintashkaka, sector C. 
Estructura funeraria 3: está ubicado al lado suroeste y adosado a la estructura funeraria 2 . Tiene planta rectangular de $1.60 \mathrm{~m}$ de ancho, $3.60 \mathrm{~m}$ de largo, y una altura que varía de $1.00 \mathrm{a}$ $1.10 \mathrm{~m}$. Se encuentra en mal estado de conservación. Está edificado con muros de una hilera de piedras canteadas unidas con argamasa, con un grosor que varía de 0.35 a $0.40 \mathrm{~m}$. Al igual que la estructura funeraria 1 y 2 , presenta un acceso de forma cuadrangular orientado al oeste. La cubierta es plana a base de lajas de piedra, con $100 \%$ desplomado. No está asociado a ningún material cultural en su interior.

IV.- Sector D: Se encuentra ubicado en las faldas y ladera media del cerro Kasuela Punta; entre las coordenadas UTM: 8869592N, 0228312E y a 2777 metros sobre el nivel del mar, hacia el sur de los sectores A, B y C. Al igual que los demás sectores está rodeado de una densa vegetación que imposibilita el acceso. Corresponde a un conjunto de abrigos rocosos con las paredes pintadas de color rojo óxido, asociado a 4 estructuras funerarias adosados:

Estructura funeraria 1: ubicado al lado suroeste del abrigo rocoso. Tiene planta semicircular adosada a las paredes del abrigo rocoso, de $1.50 \mathrm{~m}$ de ancho y $2.10 \mathrm{~m}$ de profundidad. Se encuentra en mal estado de conservación. Está edificada con muros de doble hilera de piedras canteadas unidas con argamasa, de $0.40 \mathrm{~m}$ de grosor. No está asociado a ningún material cultural en su interior.

Estructura funeraria 2: ubicado al lado norte de la estructura funeraria 1. Corresponde a un acondicionamiento del espacio donde se ha edificado la construcción de planta irregular, adosada a las paredes del abrigo rocoso, de $2.10 \mathrm{~m}$ de ancho y $1.80 \mathrm{~m}$ de profundidad. Se encuentra en mal estado de conservación. Ha sido edificada con muros de doble hilera de piedra canteada unidos con argamasa. Está asociado a algunos restos óseos dispersos en el interior.
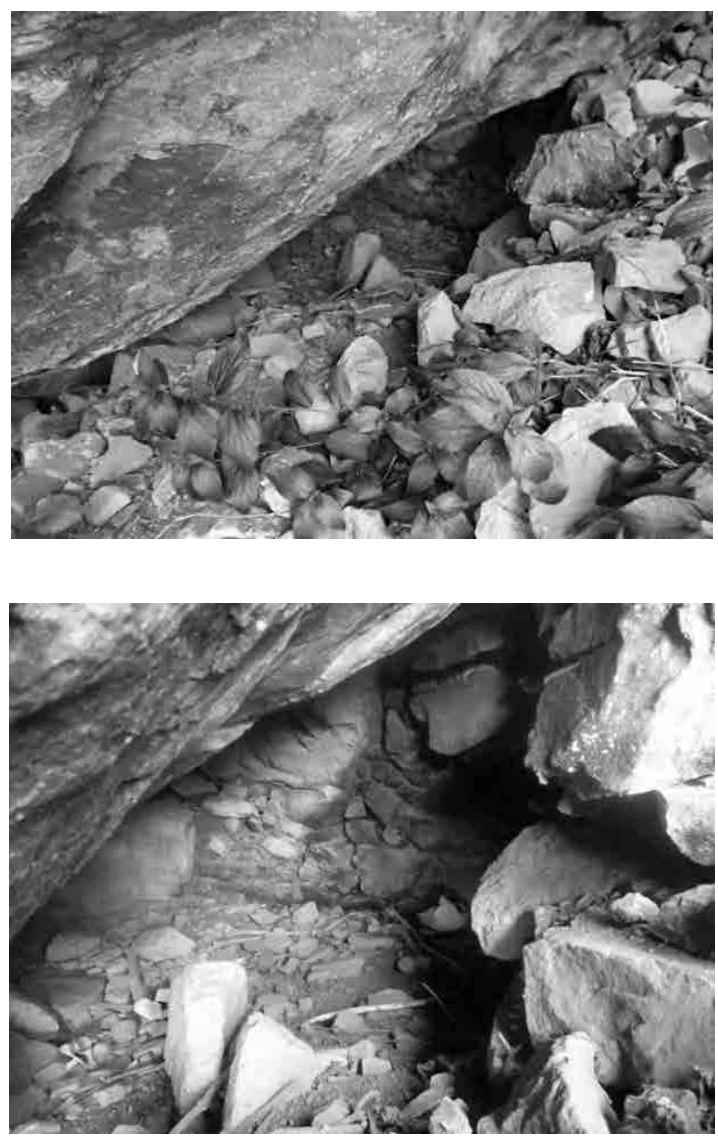

Figura 60 (superior): vista panorámica de la estructura funeraria 1. Figura 61 (inferior): detalle del interior de la estructura funeraria 1. Sitio Pintashkaka, sector D.

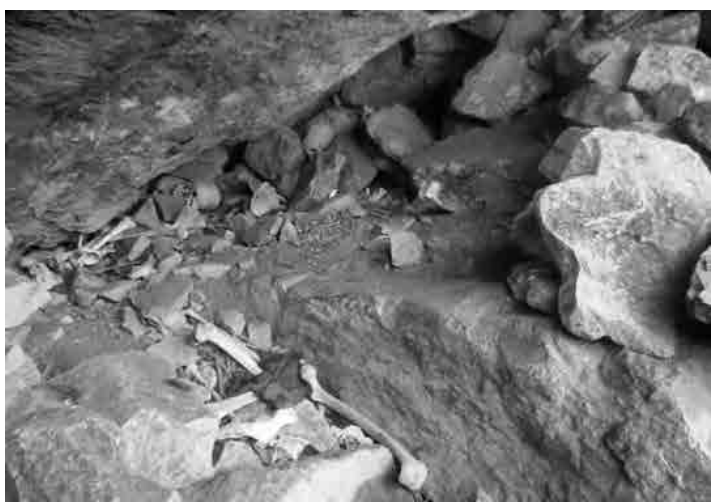

Figura 62: vista panorámica de la estructura funeraria 2. Sitio Pintashkaka, sector D. 
Estructura funeraria 3: ubicado al lado noreste de la estructura funeraria 2. Tiene planta semicircular, adosada a las paredes del abrigo rocoso, de $3.10 \mathrm{~m}$ de ancho y $2.50 \mathrm{~m}$ de profundidad. Se encuentra en mal estado de conservación. Está edificado con muros de doble hilera de piedra canteada unidas con argamasa, de $0.40 \mathrm{~m}$ de grosor, parte del muro está derrumbado. Está asociado a algunos restos óseos dispersos en el interior.
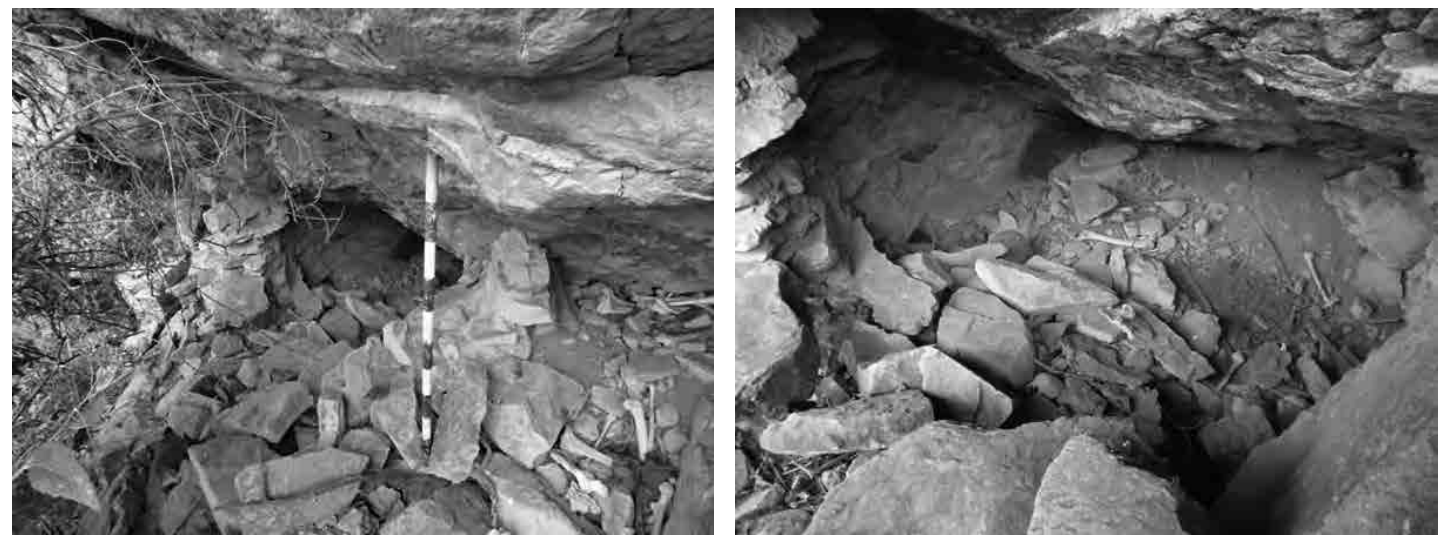

Figura 63: izquierda: vista panorámica de la estructura funeraria 3. Figura 64: derecha: detalle del interior de la estructura funeraria 3. Sitio Pintashkaka, sector D.

Estructura funeraria 4: ubicada al lado noreste y adosada a la estructura funeraria 3. Tiene planta cuadrangular adosada a las paredes del abrigo rocoso, de $1.80 \mathrm{~m}$ de ancho y $1.60 \mathrm{~m}$ de profundidad. Se encuentra en mal estado de conservación. Está edificado con muros de una hilera de piedras canteadas unidas con argamasa, de $0.40 \mathrm{~m}$ de grosor. Está asociado a algunos restos óseos (1 individuo) en el interior.
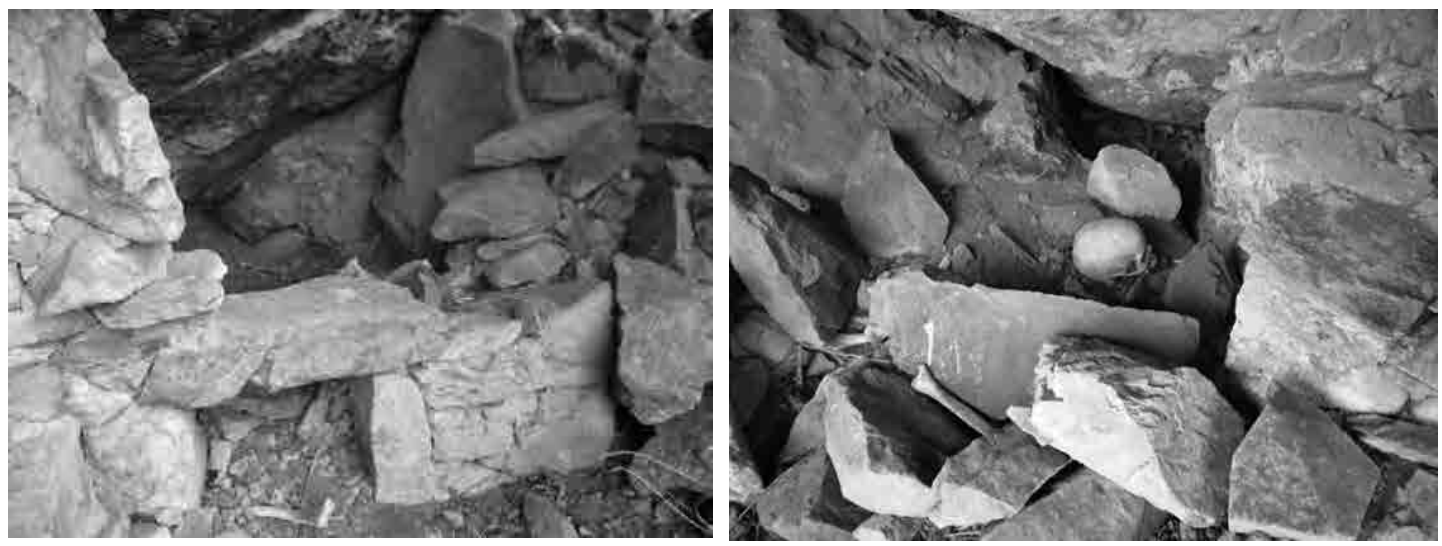

Figura 65 (izquierda): vista panorámica de la estructura funeraria 4.

Figura 66 (derecha): detalle del interior de la estructura funeraria 4. Sitio Pintashkaka, sector D. 
V.- SECTOR E: Se encuentra ubicado en las faldas y ladera media del cerro Kasuela Punta; entre las coordenadas UTM: 8869592N, 0228312E y a 2777 metros sobre el nivel del mar, al Sur de los sectores A, B y C. Corresponde a un abrigo rocoso de roca granito de color gris claro con la abertura del acceso orientado al norte. Debajo del farallón se han acondicionado un conjunto de estructuras funerarias de planta cuadrangular, en mal estado de conservación, edificadas con muros de doble hilera unidas con argamasa de unos $0.30 \mathrm{~m}$ de grosor. En el interior se observan restos óseos dispersos y fragmentería cerámica.

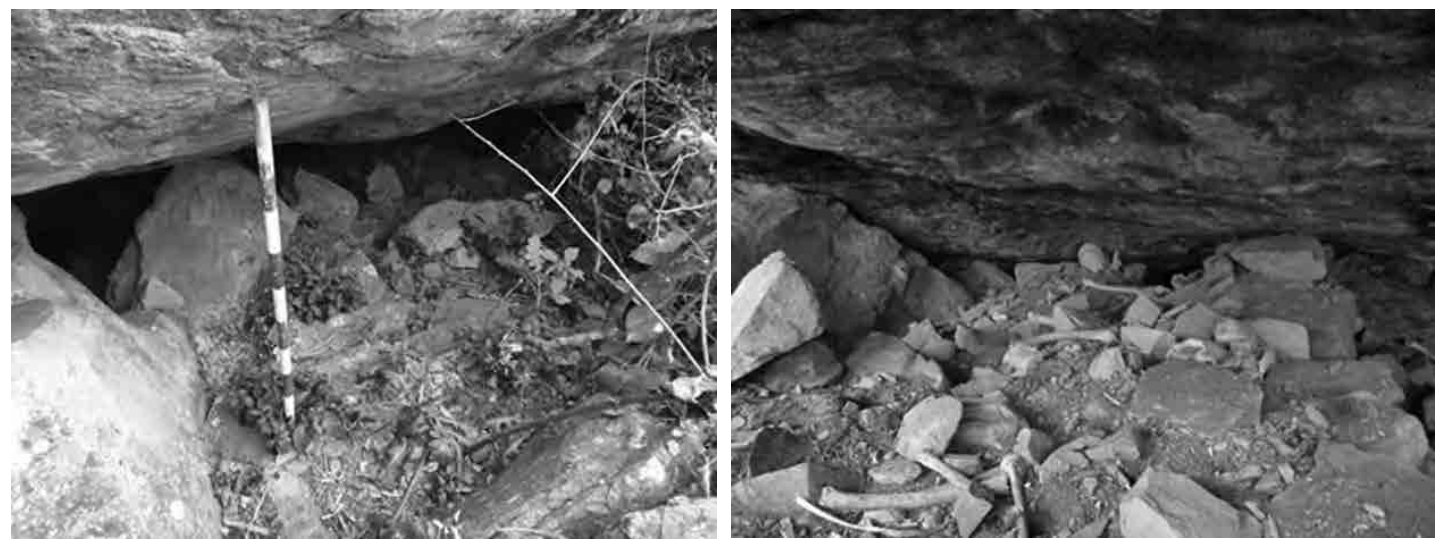

Figura 67 (izquierda): vista panorámica del abrigo rocoso del sector $E$.

Figura 68 (derecha): detalle del interior del abrigo rocoso del sector E. Sitio Pintashkaka.

\section{B.- GALLO QAQA}

Ubicación: se encuentra ubicado hacia el noroeste de la comunidad de Yamor, a unos 5 km aproximadamente, sobre un conjunto de despeñaderos y roquedales, en la margen derecha de la quebrada Qashpawarar y la margen izquierda de las quebradas Suquranra y Lucmaruri. Situado políticamente en la jurisdicción de la comunidad campesina de Yamor, distrito Antonio Raymondi, Provincia de Bolognesi, departamento de Ancash. El sitio se localiza entre las coordenadas UTM: 8871753N, 0226618E y a 2778 metros sobre el nivel del mar.

Acceso: desde la comunidad de Yamor, se toma un camino de herradura con dirección al sitio de Rurun Pukru, por un tramo de 30 minutos, para luego tomar un desvío hacia una pendiente donde se encuentran los abrigos rocosos.

Tipo de sitio: Paisaje Cultural Arqueológico (abrigos rocosos con pinturas rupestres y estructuras funerarias).

Filiación cultural: intermedio tardío.

Estado de conservación: el sitio se encuentra en regular estado de conservación. Las afectaciones diagnosticadas son principalmente por excesivo pastoreo de ganado ovino y caprino, y la presencia abundante de plantas herbáceas y arbustivas.

Descripción del sitio: El sitio ha sido dividido en 10 sectores, considerando para ello la ubicación y la configuración espacial de los mismos.

I.- Sector A: Se encuentra ubicado al lado noroeste de la comunidad de Yamor, a unos $5 \mathrm{~km}$ aproximadamente, en la margen derecha de la quebrada Qashpawarar y margen izquierda de la quebrada 
Suquranra y Lucmaruri, en la parte más alta y pronunciada de la pendiente, entre las coordenadas UTM: $8871753 \mathrm{~N}, 0226618 \mathrm{E}$ y a 2778 metros sobre el nivel del mar. Presenta abundante vegetación arbórea, arbustiva y cactácea. Corresponde a un conjunto de abrigos rocosos de tipo andesita, con las paredes completamente pintadas de color rojo óxido, que se extiende de este a oeste, asociado a tres estructuras funerarias. La abertura del abrigo está orientado hacia el norte. Estas estructuras funerarias se encuentran en mal estado de conservación, con muros completamente derrumbados por la presencia de pastoreo de ganado ovino y caprino.
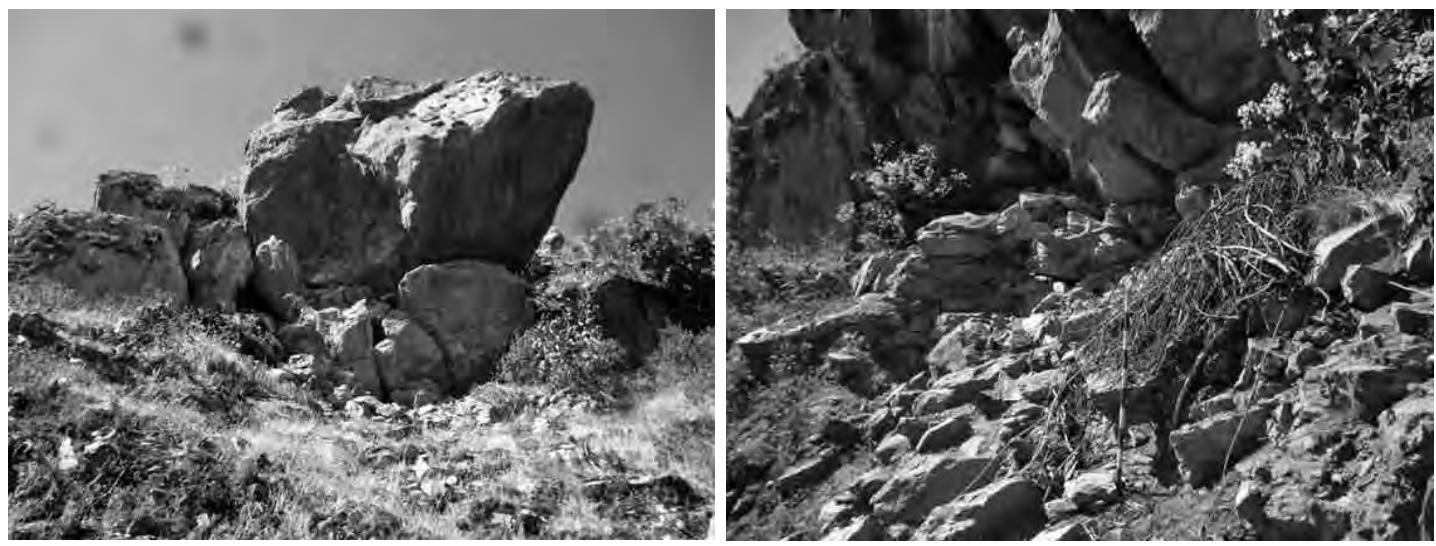

Figura 69 (izquierda): vista panorámica del abrigo rocoso del sector A.

Figura 70 (derecha): detalle de las estructuras funerarias derrumbados. Sitio Gallo Qaqa, sector A.

II.- Sector B: Llamado también sector Patapampa. Se encuentra ubicado a unos $200 \mathrm{~m}$ aproximadamente al este del sector A, entre las coordenadas UTM: $8871753 \mathrm{~N}, 0226618 \mathrm{E}$ y a 2778 metros sobre el nivel del mar. Este sector corresponde a un conjunto de abrigos rocosos de roca granítica, con la abertura que se extiende de este a oeste. Está asociado a un panel de pinturas rupestres de color rojo sobre fondo natural de la roca (grisáceo).
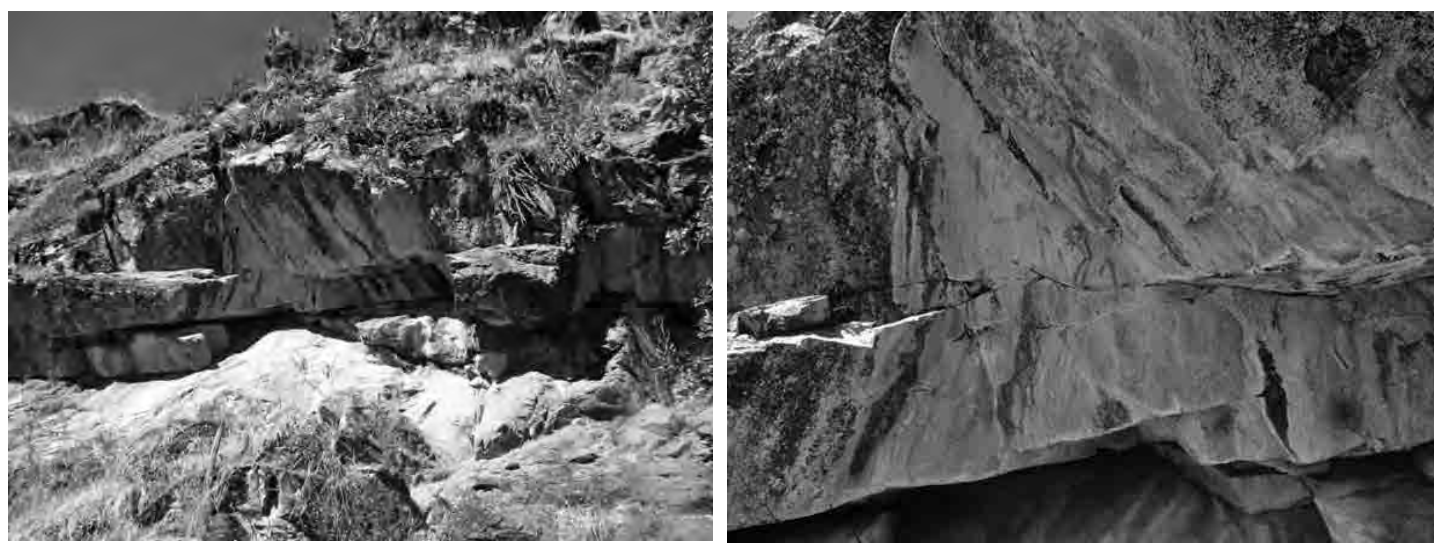

Figura 71 (izquierda): vista panorámica del farallón donde se ubican las pinturas rupestres. Figura 72 (derecha): detalle del panel donde estan las pinturas rupestres. Sitio Gallo Qaqa, sector B. 
Motivo 1: pintura de forma geométrica (una línea vertical y varios puntos de color rojo) en mal estado de conservación, ubicado en la parte más alta del panel. Ambos de color rojo sobre fondo natural de la roca (grisáceo). El motivo tiene $0.25 \mathrm{~m}$ de alto por $0.20 \mathrm{~m}$ de ancho.

Motivo 2: pintura de forma geométrica (cuadrangular con líneas paralelas de forma horizontal en el interior) en mal estado de conservación, de color rojo sobre fondo natural de la roca (grisáceo). El motivo tiene $0.15 \mathrm{~m}$ de altura por $0.20 \mathrm{~m}$ de ancho.

Motivo 3: pintura de con forma de una línea en forma de "S", de color rojo sobre fondo natural de la roca (grisáceo), ubicado al lado derecho del motivo 2. En mal estado de conservación. Tiene $25 \mathrm{~cm}$ de altura por $12 \mathrm{~cm}$ de ancho.
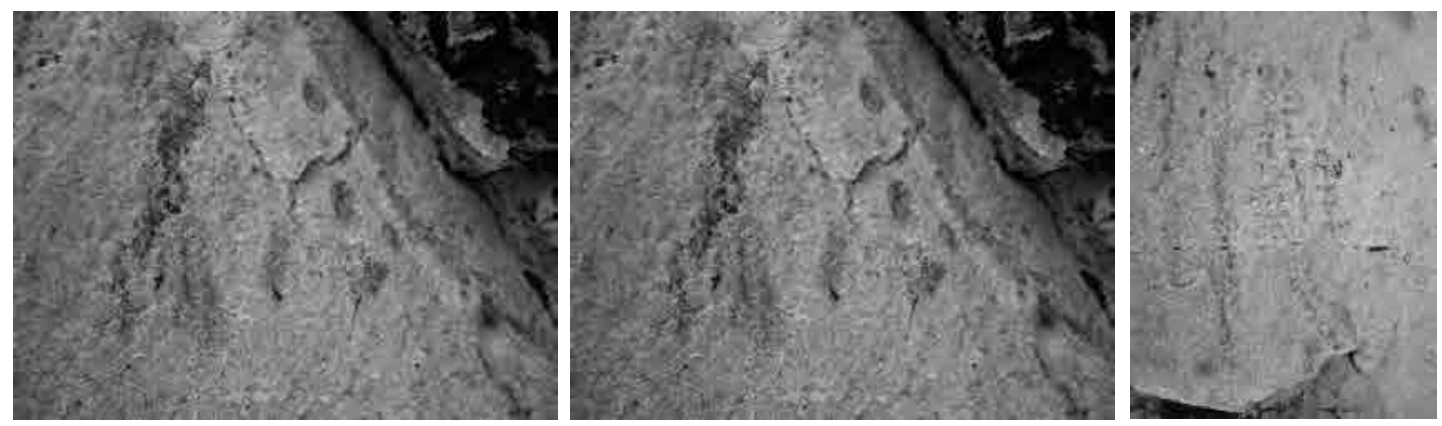

Figura 73 (izquierda): detalle del motivo 1. Figura 74 (centro): detalle del motivo 2. Figura 75 (derecha): detalle del motivo 3. Sitio Gallo Qaqa, sector B.

Motivo 4: pintura de forma zoomorfa (serpiente estilizada) con unas líneas oblicuas que adornan su cabeza. Está hecho de color rojo sobre un fondo natural de la roca (grisáceo), en buen estado de conservación. Tiene $25 \mathrm{~cm}$ de altura por $20 \mathrm{~cm}$ de ancho.

Motivo 5: pintura de forma geométrica (rectangular con líneas paralelas de forma horizontal en el interior) en mal estado de conservación, de color rojo sobre fondo natural de la roca (grisáceo). El motivo tiene $0.15 \mathrm{~m}$ de altura por $0.25 \mathrm{~m}$ de ancho.

Motivo 6: pintura de forma zoomorfa (al parecer una serpiente) de color rojo sobre fondo natural de la roca (grisáceo), en mal estado de conservación. Tiene $0.30 \mathrm{~m}$ de altura por $0.25 \mathrm{~m}$ de ancho.
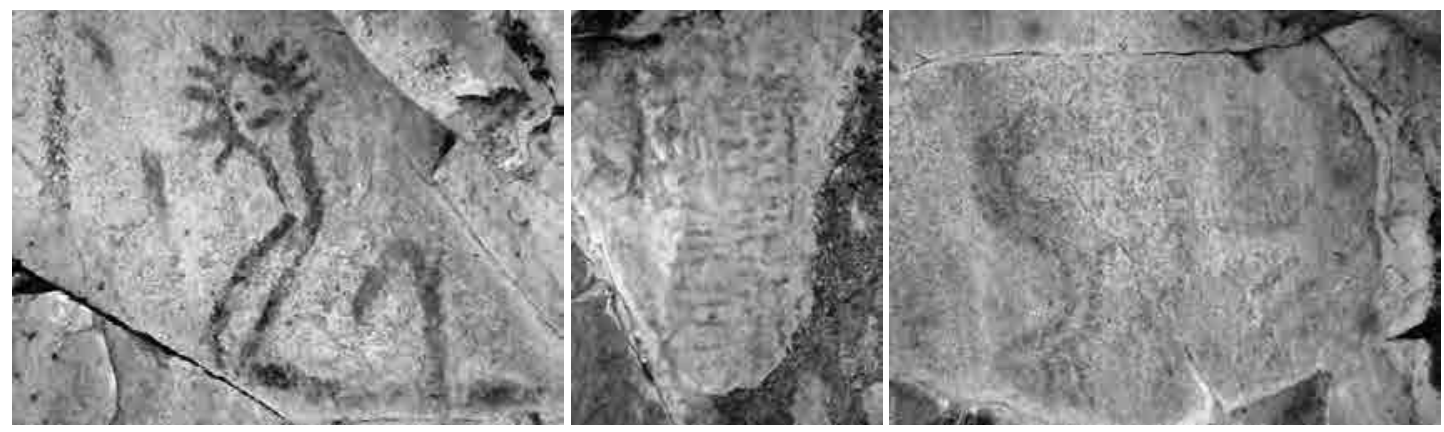

Figura 76 (izquierda): detalle del motivo 4. Figura 77 (centro): detalle del motivo 5. Figura 78 (derecha): detalle del motivo 6. Sitio Gallo Qaqa, sector B. 
Motivo 7: pintura de forma geométrica (especie de una flor estilizada) de color rojo sobre fondo natural de la roca (grisáceo), de $0.05 \mathrm{~m}$ de diámetro, en mal estado de conservación.

Motivo 8: corresponde a una pintura de forma ilegible (mancha), de color rojo sobre fondo natural de la roca (grisáceo), en mal estado de conservación. Tiene $0.07 \mathrm{~m}$ de altura por $0.05 \mathrm{~m}$ de ancho.
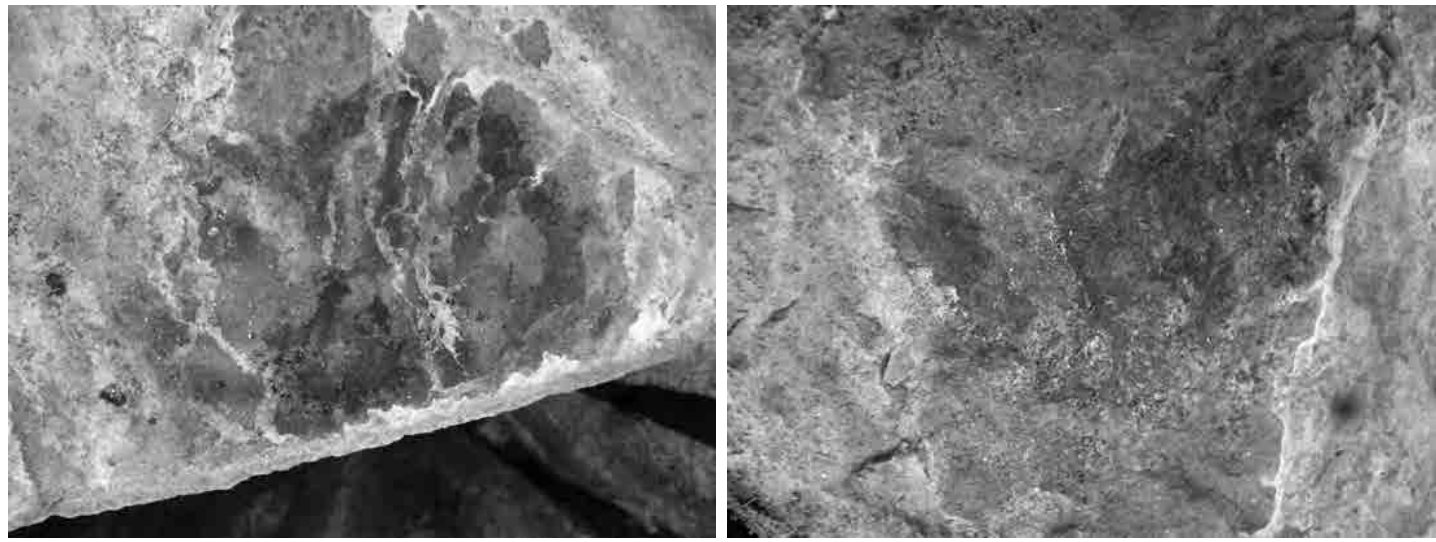

Figura 79 (izquierda): detalle del motivo 7. Figura 80 (derecha): detalle del motivo 8. Sitio Gallo Qaqa, sector B.

III.- Sector C: Se encuentra ubicado a unos $150 \mathrm{~m}$ aproximadamente al noreste del sector B, entre las coordenadas UTM: $8871842 \mathrm{~N}, 0226252 \mathrm{E}$ y a 2682 metros sobre el nivel del mar.

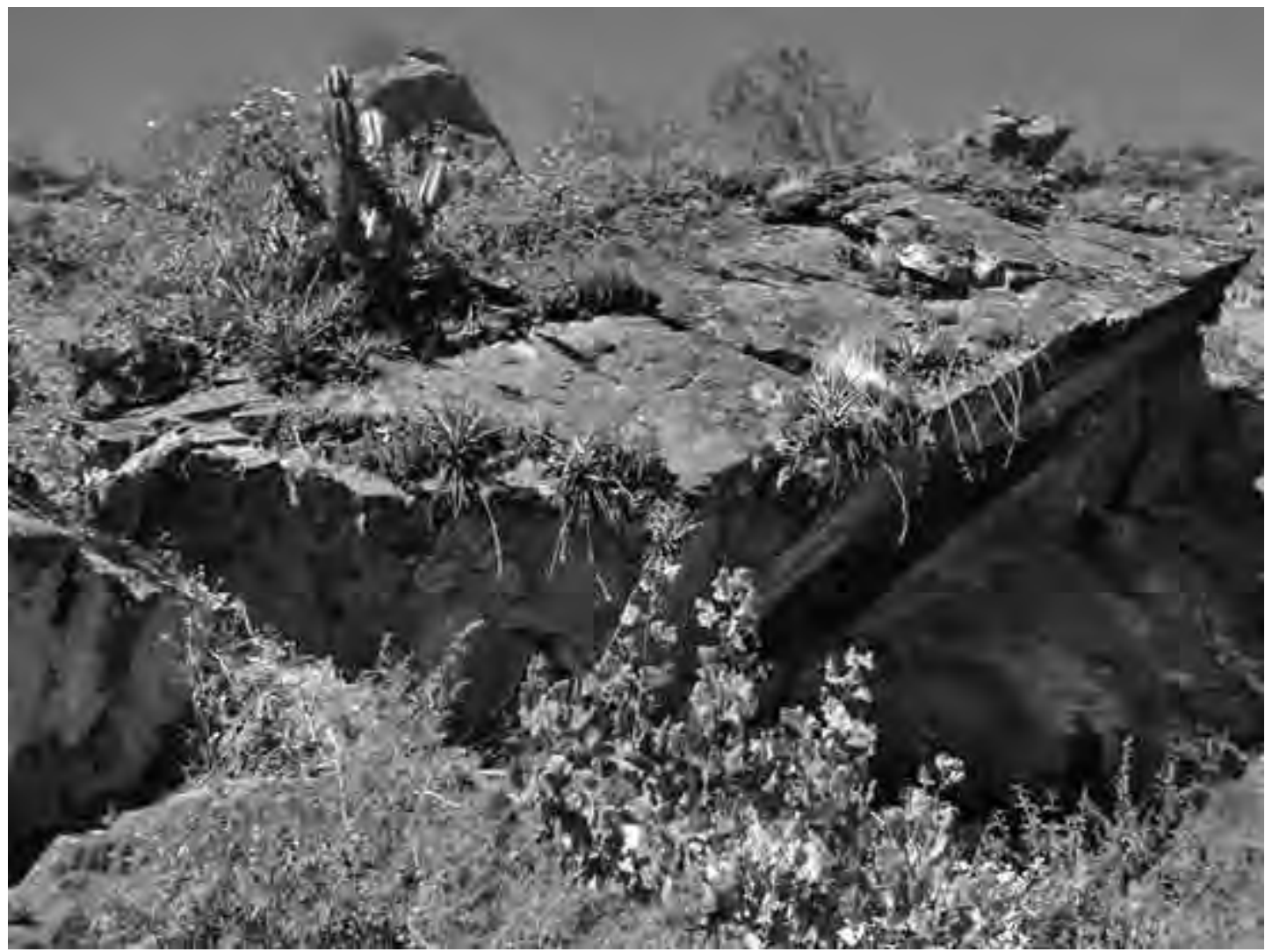

Figura 81: vista panorámica del abrigo rocoso del sector C, Sitio Gallo Qaqa. 
Este sector corresponde a una cueva con la abertura orientada al norte, que se extiende este a oeste. Está situado debajo de una roca del tipo andesita, de $30 \mathrm{~m}$ de largo por $10 \mathrm{~m}$ de altura, asociado a un conjunto de estructuras funerarias tipo chullpa y pinturas rupestres. Las paredes de la cueva están completamente pintadas de color rojo óxido.

Las pinturas rupestres (3 motivos), están situadas en la pared interna y superior de la cueva. Todos son hechos de color rojo sobre un fondo natural de la roca (grisácea), en regular estado de conservación, asociado a la estructura funeraria 4. El motivo 1 es un motivo zoomorfo estilizado (al parecer una serpiente) con 2 líneas oblicuas sobre su cabeza haciendo de antenas. Los motivos 2 y 3, son líneas verticales de color rojo sobre un fondo natural de la roca, ubicadas al lado oeste del motivo 1.
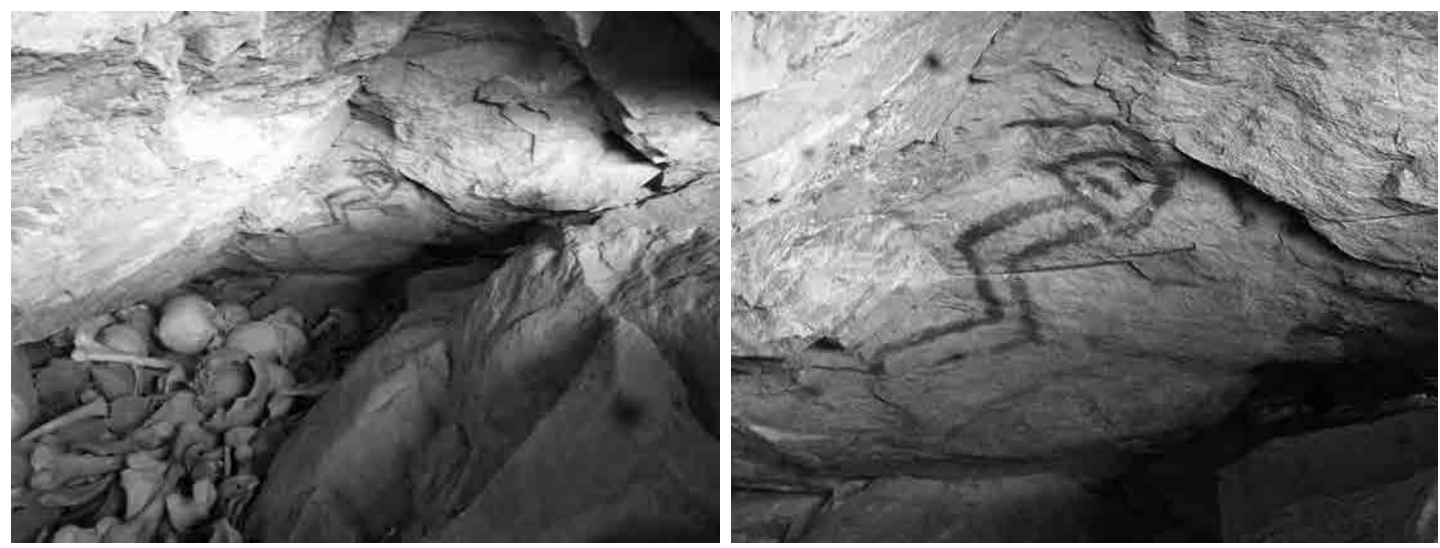

Figura 82 (izquierda): vista panorámica del panel con pintura rupestre. Figura 83 (derecha): detalle del motivo 1. Sitio Gallo Qaqa, sector $C$.

Las estructuras funerarias (tipo chullpa), están situadas en la parte externa del acceso de la cueva. Se registró 4 estructuras funerarias:

Estructura funeraria 1: está ubicado al lado más oriental de la cueva, en la parte externa y adosada a la misma. Tiene planta en media luna, de $2.88 \mathrm{~m}$ de ancho y $2.60 \mathrm{~m}$ de profundidad, de regular estado de conservación. Está edificado con muros de doble hilera de piedras canteadas unidas con argamasa, de $0.43 \mathrm{~m}$ de grosor. En el interior se observa restos óseos (11 individuos) y botánicos (soguillas trenzadas, restos de maguey y tusas de maíz).
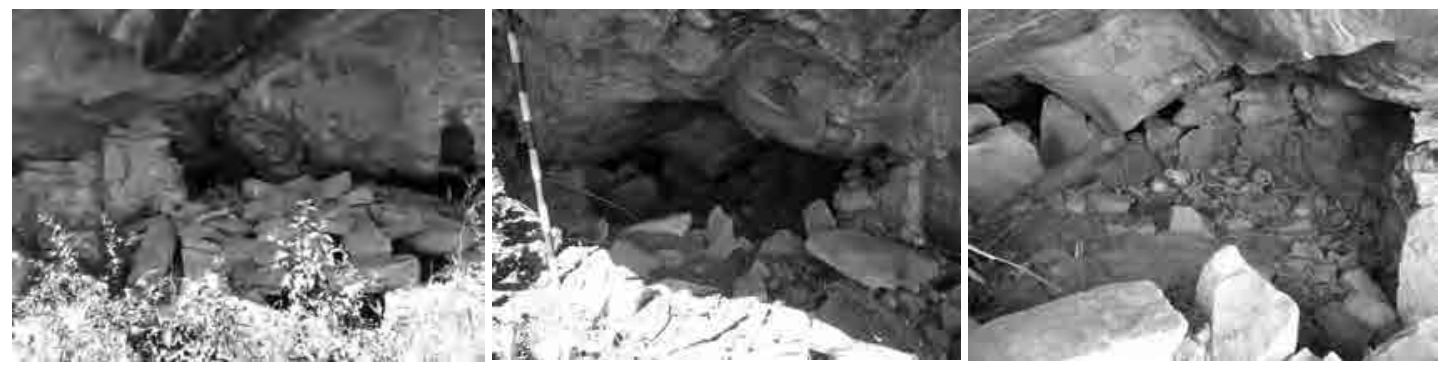

Figura 84 (izquierda): vista panorámica de la parte externa del abrigo rocoso. Figura 85: (centro): vista panorámica de la estructura funeraria 1. Figura 86 (derecha): detalle de los restos óseos asociados en el interior de la estructura funeraria 1. Sitio Gallo Qaqa, sector $C$. 
Estructura funeraria 2: está ubicado al oeste y adosado a la estructura funeraria 1. Tiene planta irregular, de $0.90 \mathrm{~m}$ de ancho, $2.10 \mathrm{~m}$ de profundidad, en mal estado de conservación, con los muros casi totalmente derrumbados, con la pared externa pintada de rojo. Está edificado con muros de doble hilera de piedras canteadas unidas con argamasa, de $0.40 \mathrm{~m}$ de grosor. En el interior no se observa ningún material cultural.

Estructura funeraria 3: está ubicado al noroeste de la estructura funeraria 2. Tiene planta ovoidal, de $3.50 \mathrm{~m}$ de ancho, $2.00 \mathrm{~m}$ de largo, y $1.10 \mathrm{~m}$ de altura (parte interna), en regular estado de conservación. Está edificado con muros de doble hilera de piedras canteadas unidas con argamasa, de $0.40 \mathrm{~m}$ de grosor. Presenta una cubierta plana a base de piedras lajas. En el interior se observa restos óseos (7 a 8 individuos), botánicos (soguillas y resto de maguey), textiles y cerámica.
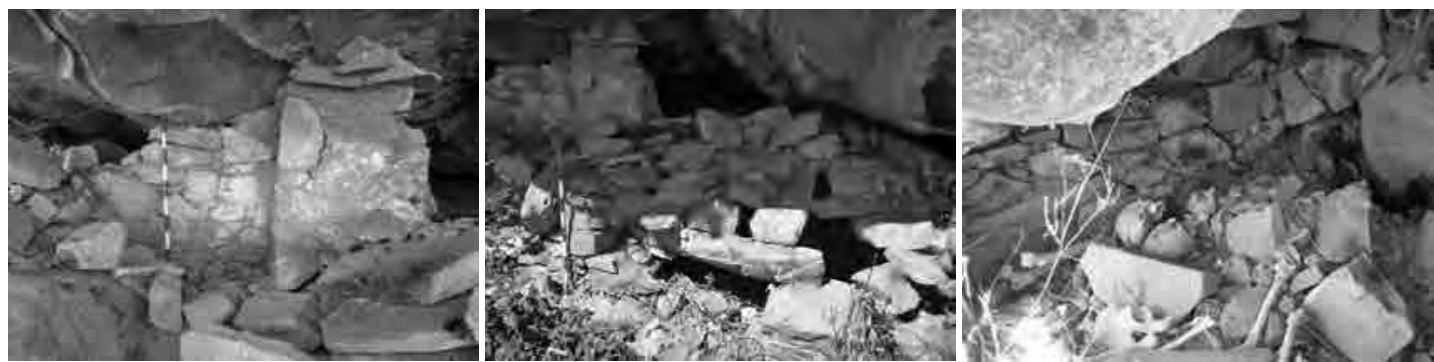

Figura 87 (izquierda): detalle de la parte externa de la estructura funeraria 2. Figura 88 (centro): vista panorámica de la parte externa de la estrutura funeraria 3. Figura 89 (derecha): detalle de la parte interna y de los restos óseos asociados a la estructura funeraria 3. Sitio Gallo Qaqa, sector C.

Estructura funeraria 4: está ubicado al suroeste y adosado a la estructura funeraria 3, en el interior de la cueva. Tiene planta irregular, fue acondicionado a la paredes internas de la cueva, de $3.70 \mathrm{~m}$ de ancho, $5.40 \mathrm{~m}$ de largo, y $1.10 \mathrm{~m}$ de altura, en regular estado de conservación. Está edificado con muros dobles de piedras canteadas unidas con argamasa, de $0.40 \mathrm{~m}$ de grosor, conservado solo en el acceso de la cueva. El paramento externo se encuentra pintado de color rojo. El acceso de la cueva tiene $3.47 \mathrm{~m}$ de ancho por $1.25 \mathrm{~m}$ de altura. En el interior se observa restos óseos en gran cantidad (se pudo identificar 40 individuos aproximadamente, enfardelados en un especie de sacos hechos con sogas de maguey trenzados planos), botánicos (soguillas y resto de maguey), textiles y cerámica.
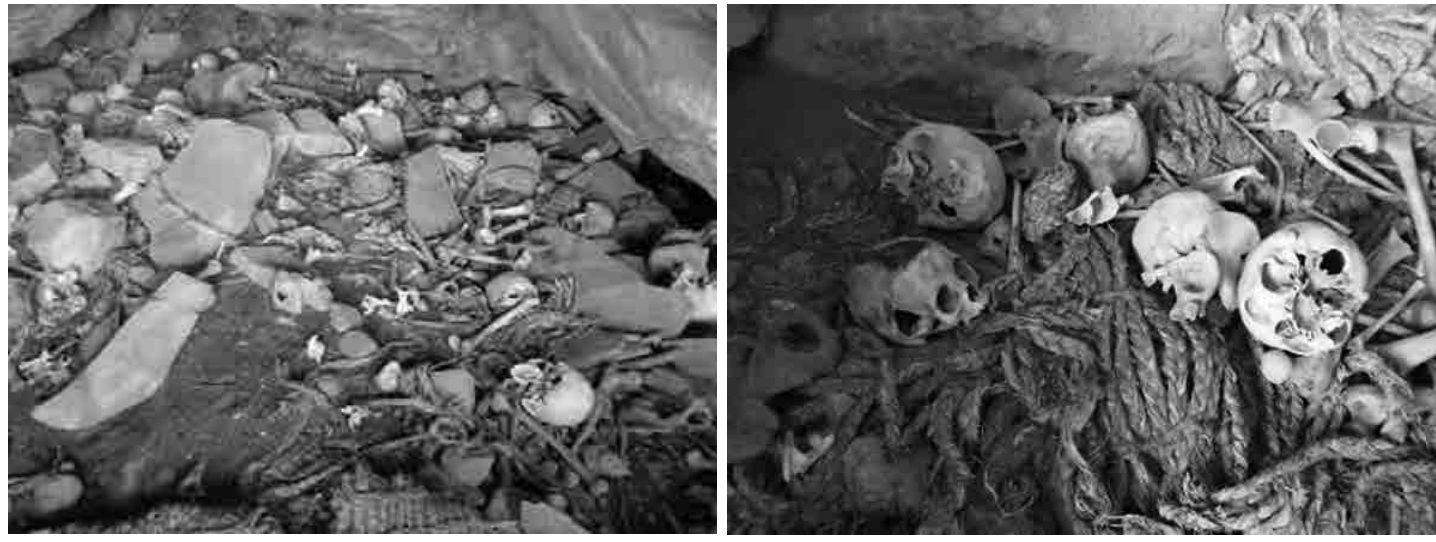

Figura 90 (izquierda): vista panorámica del interior de la estructura funeraria 4.

Figura 91: (derecha): detalle de los materiales asociados a la estructura funeraria 4. Sitio Gallo Qaqa, sector C. 
Pieter van Dalen Luna, Hamilton Obregón y Daniel Allende / El Arte rupestre de Yamor...

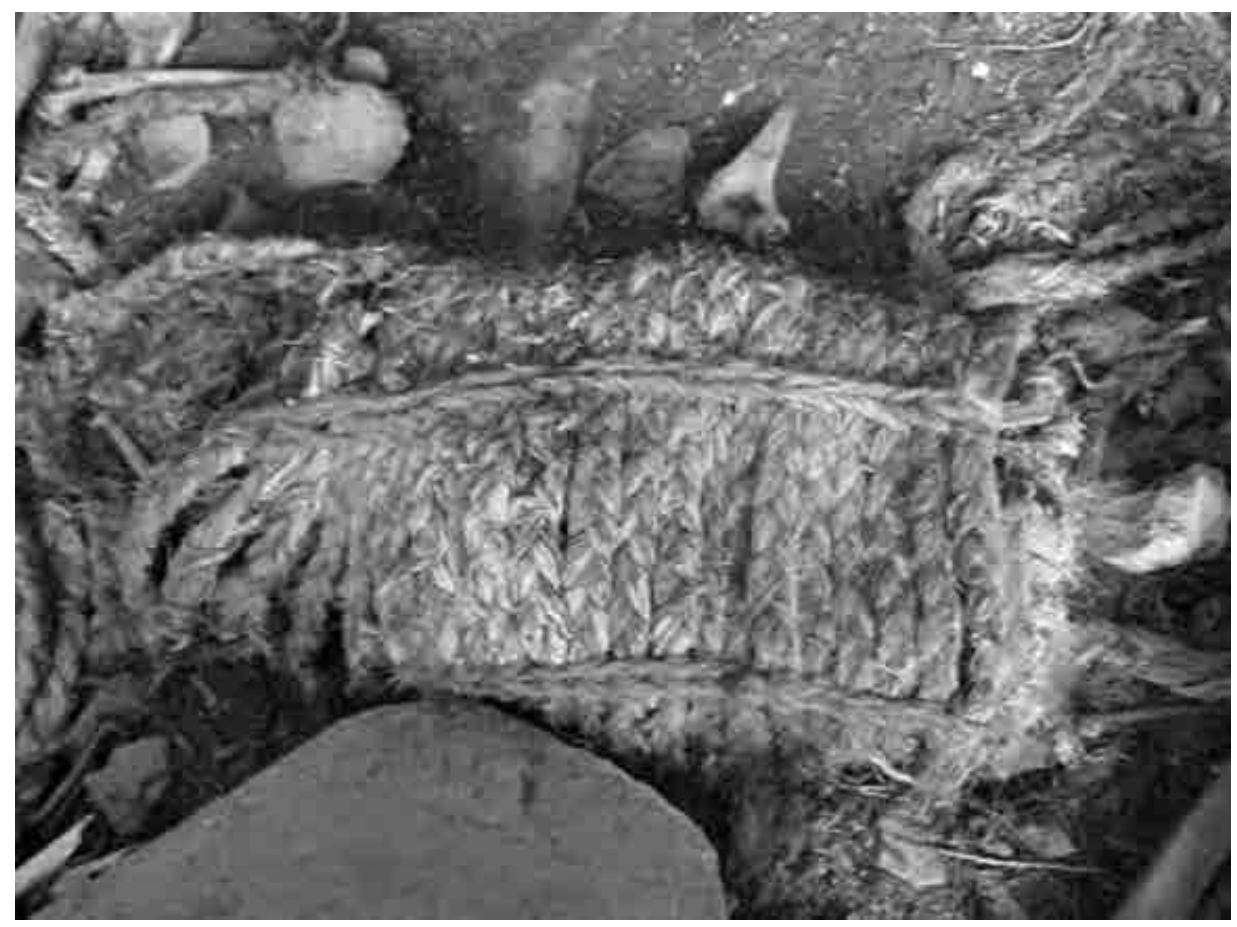

Figura 92: detalle de un fardo en el interior de la estructura funeraria 4. Sitio Gallo Qaqa, sector C.

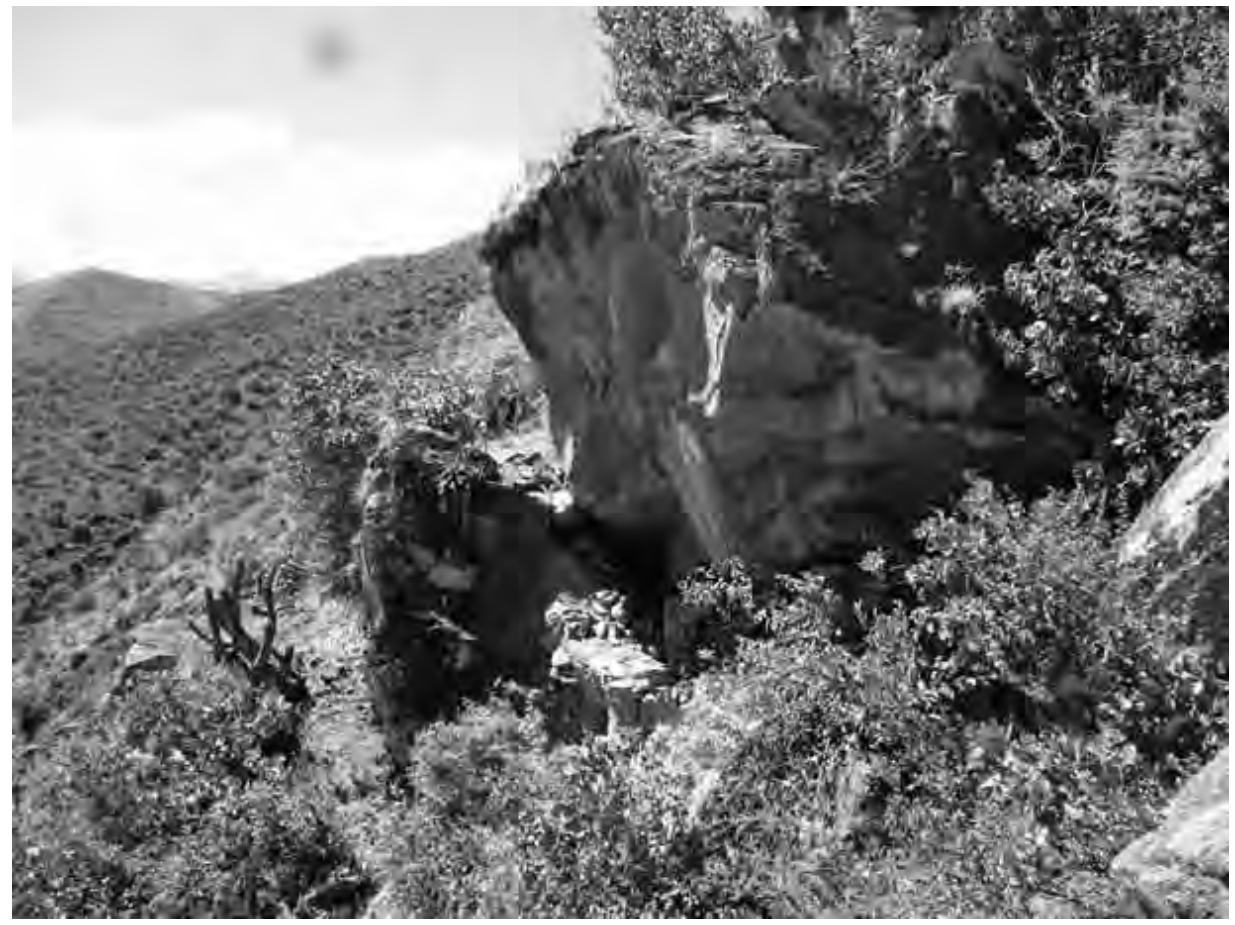

Figura 93: vista panorámica del abrigo rocoso del sector D, Sitio Gallo Qaqa. 
IV.- Sector D: Se encuentra ubicado a unos $50 \mathrm{~m}$ de al norte del sector C, entre las coordenadas UTM: $8871841 \mathrm{~N}, 0226232 \mathrm{E}$ y a 2656 metros sobre el nivel del mar. Este sector forma parte de un conjunto de abrigos rocosos, de roca del tipo andesita con la abertura del acceso orientado al suroeste de $20 \mathrm{~m}$ de largo por $20 \mathrm{~m}$ de altura. Tiene las paredes pintadas de color rojo óxido, asociado a un conjunto de 3 estructuras funerarias tipo chullpa.

Estructura funeraria 1: está ubicado al lado noroeste del abrigo rocoso. Tiene planta cuadrangular, compuesta de dos cámaras. La primera cámara se encuentra conectada mediante un vano con la segunda cámara, también de planta cuadrangular. Tiene $2.73 \mathrm{~m}$ de ancho, $2.67 \mathrm{~m}$ de largo, y $1.35 \mathrm{~m}$ de altura. Ambas cámaras están en regular estado de conservación. Está edificado con muros de doble hilera de piedras canteadas unidas con argamasa, de $0.40 \mathrm{~m}$ de grosor. El paramento interno y externo se encuentra pintado de color rojo. El paramento externo está pintado de color rojo óxido. Presenta un vano de acceso de forma cuadrangular de $0.70 \mathrm{~m}$ de ancho por $0.70 \mathrm{~m}$ de altura. La cubierta es plana a base de piedras lajas dispuestas horizontalmente apoyadas sobre maderas. En el interior se observa restos óseos (3 individuos) y botánicos (soguillas).
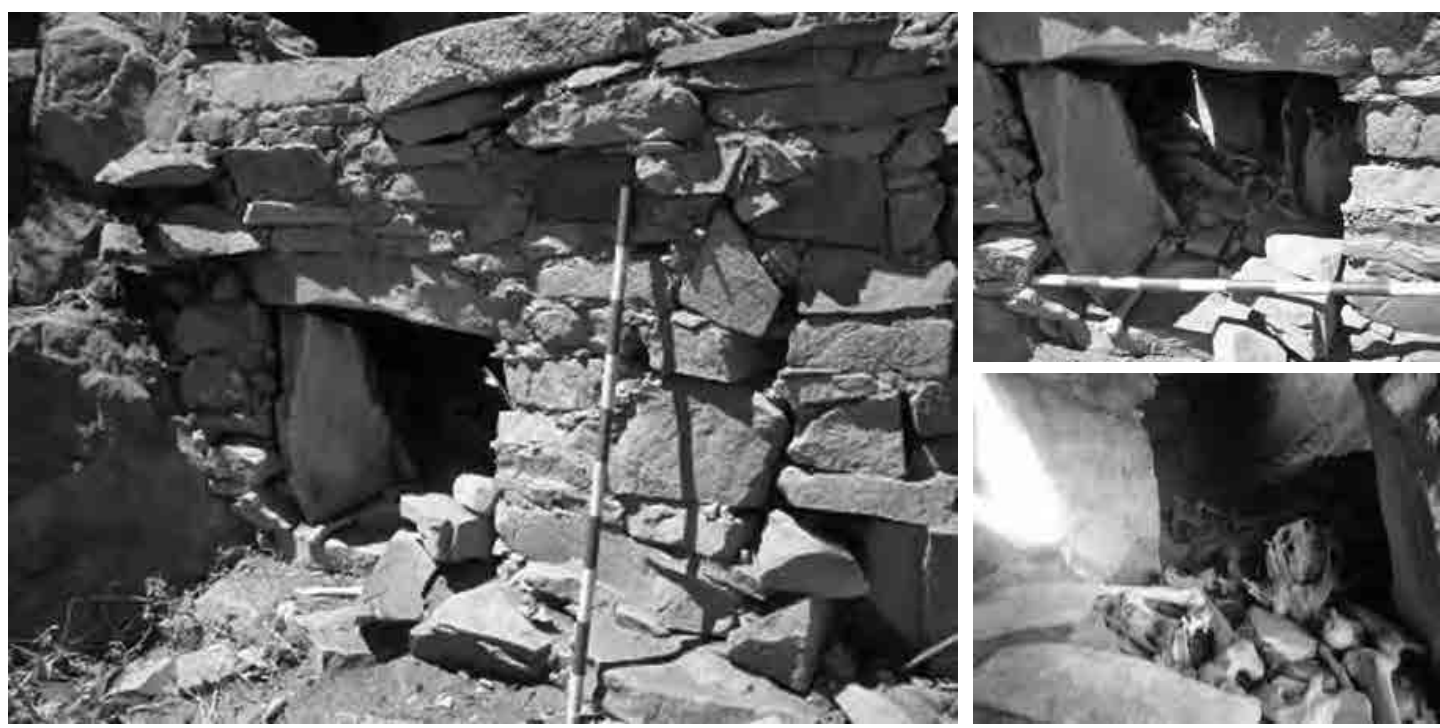

Figura 94 (izquierda): detalle de la parte externa de la estructura funeraria 1. Figura 95: (superior derecha): detalle del acceso de la estructura funeraria 1. Figura 96 (inferior derecha): detalle del interior de la estructura funeraria 1. Sitio Gallo Qaqa, sector D.

Estructura funeraria 2: está ubicado al suroeste y adosado a la estructura funeraria 2. Tiene planta irregular, de $1.61 \mathrm{~m}$ de ancho, $1.95 \mathrm{~m}$ de largo, y $1.70 \mathrm{~m}$ de altura. Está edificado con muros dobles de piedras canteadas unidas con argamasa, de $0.41 \mathrm{~m}$ de grosor. La cubierta es plana a base de lajas. En el interior se observa algunos restos óseos y botánicos.

Estructura funeraria 3: está ubicado al suroeste y debajo del abrigo rocoso, en el cual fue acondicionado. Tiene planta cuadrangular, de $2.30 \mathrm{~m}$ de ancho, $2.30 \mathrm{~m}$ de largo, y $1.10 \mathrm{~m}$ de altura; en regular estado de conservación. Está edificado con muros dobles de piedras canteadas unidas con argamasa, de $0.44 \mathrm{~m}$ de grosor. En el interior se observa restos óseos (15 individuos), botánicos (soguillas, restos de maguey y tusas de maíz) y textiles. 

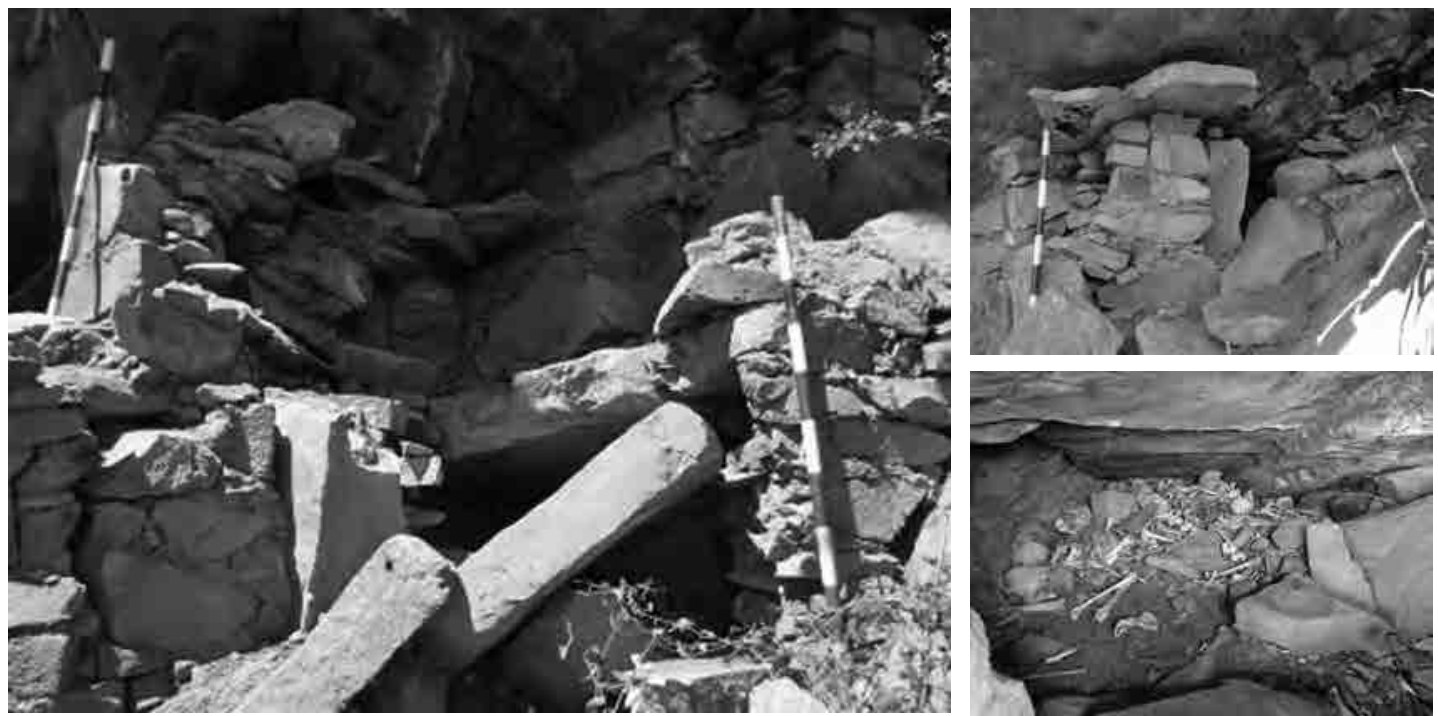

Figura 97 (izquierda): vista panorámica de la parte externa de la estructura funeraria 2. Figura 98 (superior derecha): vista panorámica de la estructura funeraria 3. Figura 99 (inferior derecha): detalle de los restos óseos asociados en el interior de la estructura funeraria 3. Sitio Gallo Qaqa, sector D.

V.- Sector E: Se encuentra ubicado a unos $400 \mathrm{~m}$ al oeste del sector D; entre las coordenadas UTM: $8871871 \mathrm{~N}, 0226049 \mathrm{E}$ y a 2664 metros sobre el nivel del mar. Este sector forma parte de un conjunto de abrigos rocosos dispuestos sobre una pequeña pendiente cerca a la confluencia de quebradas, de roca del tipo andesita, de $3.20 \mathrm{~m}$ de largo por $2.00 \mathrm{~m}$ de altura. El abrigo tiene una acceso orientado al norte de $2.30 \mathrm{~m}$ de ancho, $2.50 \mathrm{~m}$ de profundidad y $0.60 \mathrm{~m}$ de altura. En el interior presenta una estructura funeraria, al parecer en proceso de construcción (no culminada), de una sola hilera, sin argamasa. No está asociado a ningún material cultural.
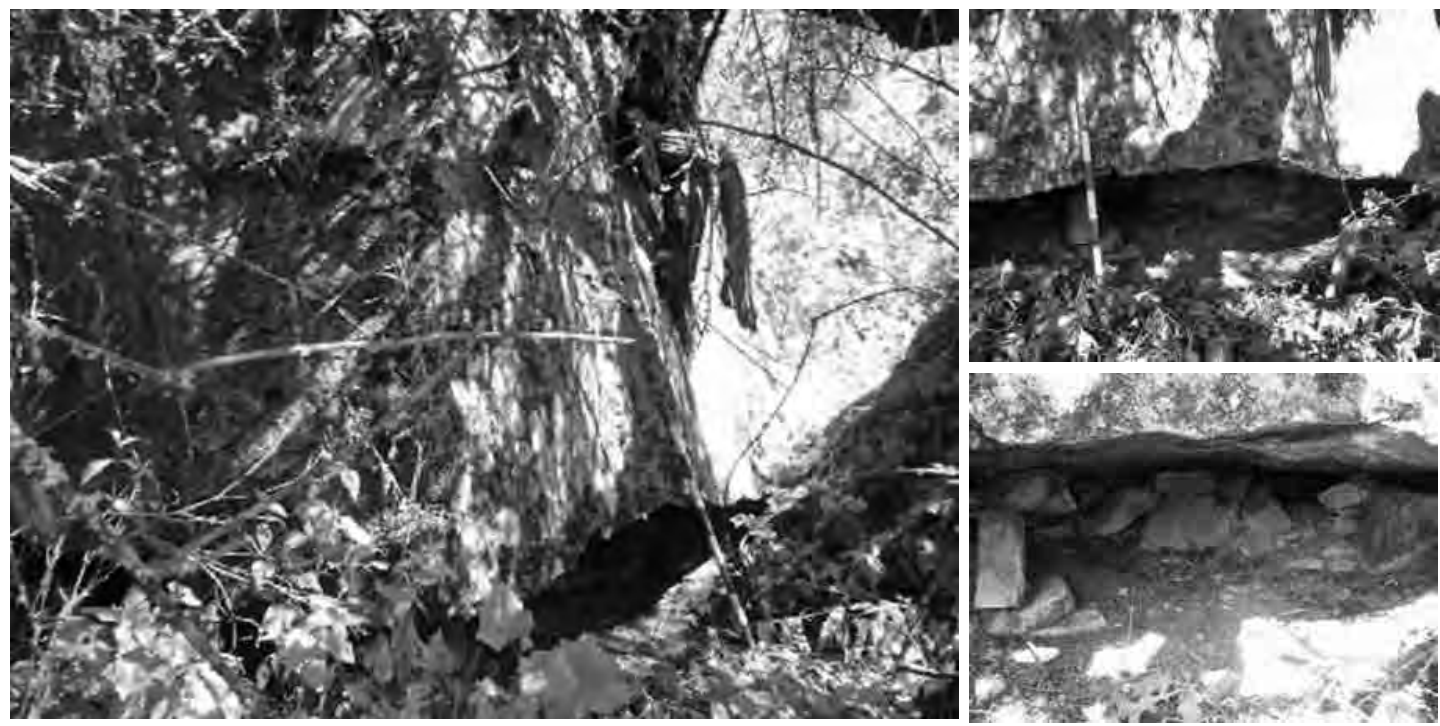

Figura 100 (izquierda): vista panorámica del abrigo rocoso del sector E. Figura 101 (centro): detalle de la abertura del acceso del abrigo rocoso del sector E. Figura 102 (derecha): detalle del interior de la estructura funeraria. Sitio Gallo Kaka, sector E. 
VI.- Sector F: Se encuentra ubicado a unos $700 \mathrm{~m}$ al sur del sector D; entre las coordenadas UTM: $8871696 \mathrm{~N}, 0225919 \mathrm{E}$ y a 2796 metros sobre el nivel del mar. Este sector corresponde a un conjunto de dos pequeños abrigos rocosos, compuesto de 2 rocas grandes del tipo andesita con las paredes pintadas completamente de anaranjado rojizo. Está asociado a estructuras funerarias tipo chullpa y pinturas rupestres en la parte baja de la abertura del abrigo.

Las pinturas rupestres antropomorfas están ubicadas en la pared interna y superior del abrigo rocoso, pintado de color rojo óxido sobre un fondo anaranjado. El motivo 1, figura antropomorfa de color rojo, con las extremidades superiores extendidas. El motivo 2, figura antropomorfa estilizada con la cabeza ovoidal y 6 dedos en las extremidades superiores. El motivo 3, figura indefinida de color rojo sobre un fondo anaranjado.

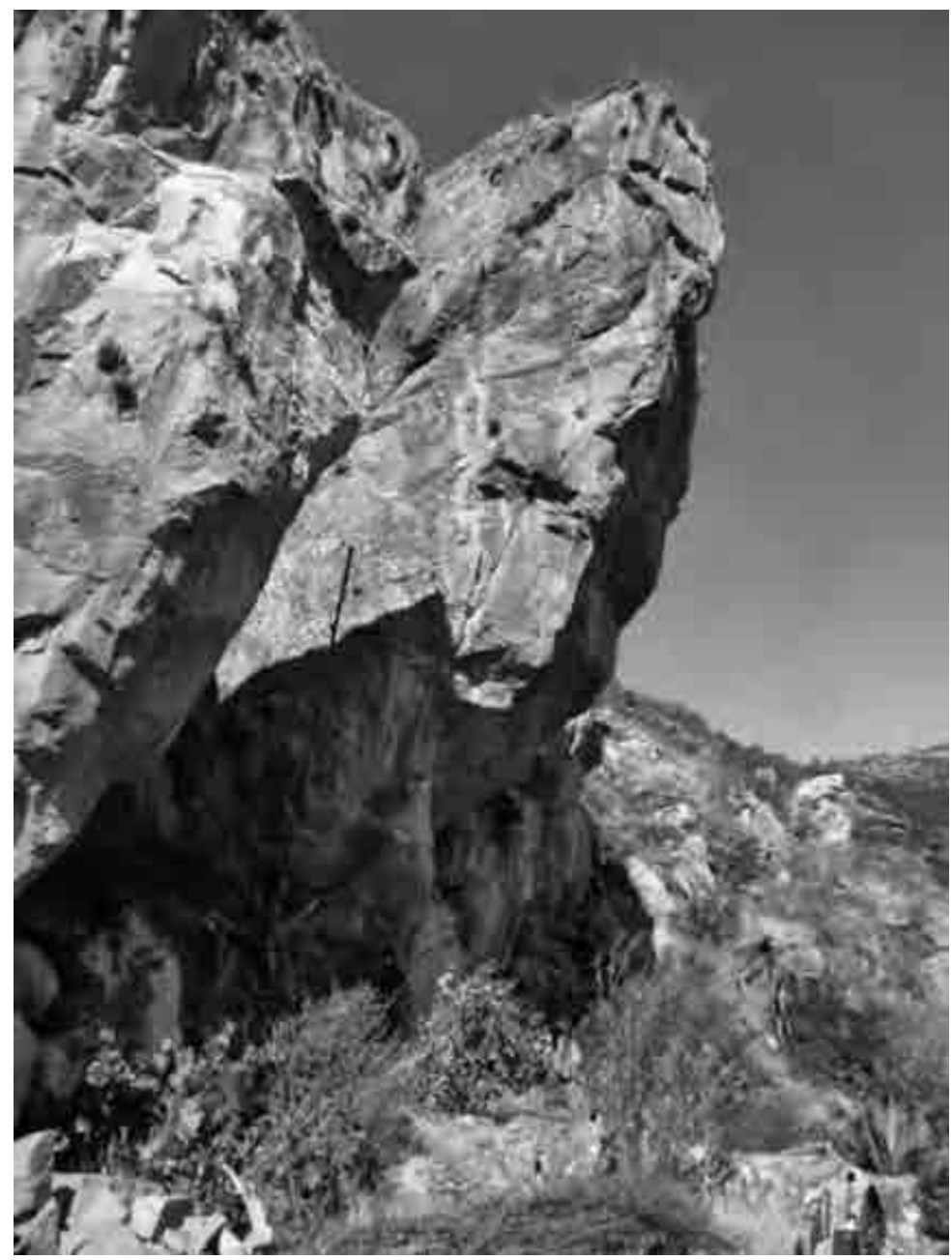

Figura 103: vista panorámica del abrigo rocoso del sector F, Sitio Gallo Qaqa. 

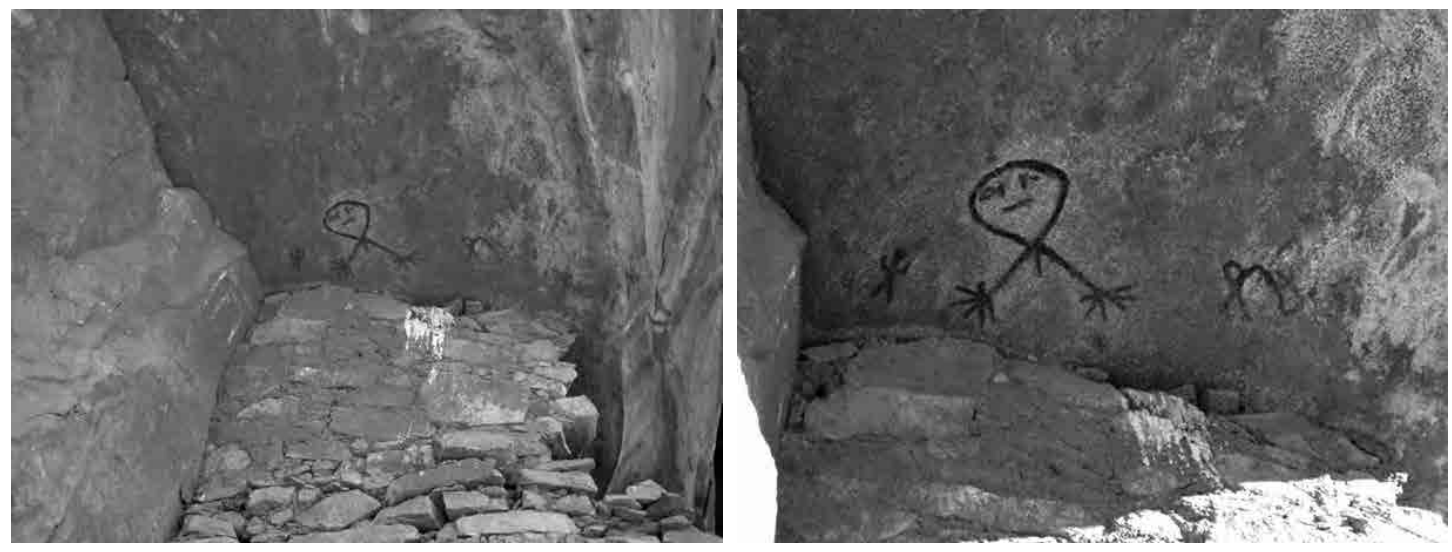

Figura 104 (izquierda): vista panorámica del techo del abrigo con el panel de pintura rupestre por encima de una estructura funeraria. Figura 105: derecha: detalle de los motivos 1, 2 y 3. Sitio Gallo Qaqa, sector F.

Las estructuras funerarias están situadas al pie de los abrigos rocosos y adosadas a ellas. El primer abrigo está asociado a una sola estructura funeraria y el otro a 4 estructuras funerarias.

Estructura funeraria 1: está ubicado al lado derecho y al pie del primer abrigo rocoso. Tiene planta cuadrangular, de $2.75 \mathrm{~m}$ de largo, $2.40 \mathrm{~m}$ de ancho, y $0.70 \mathrm{~m}$ de altura, en regular estado de conservación. Está edificado con muros dobles de piedras canteadas unidas con argamasa, de 0.38 a $0.40 \mathrm{~m}$ de grosor. En el interior se observa algunos restos óseos humanos.
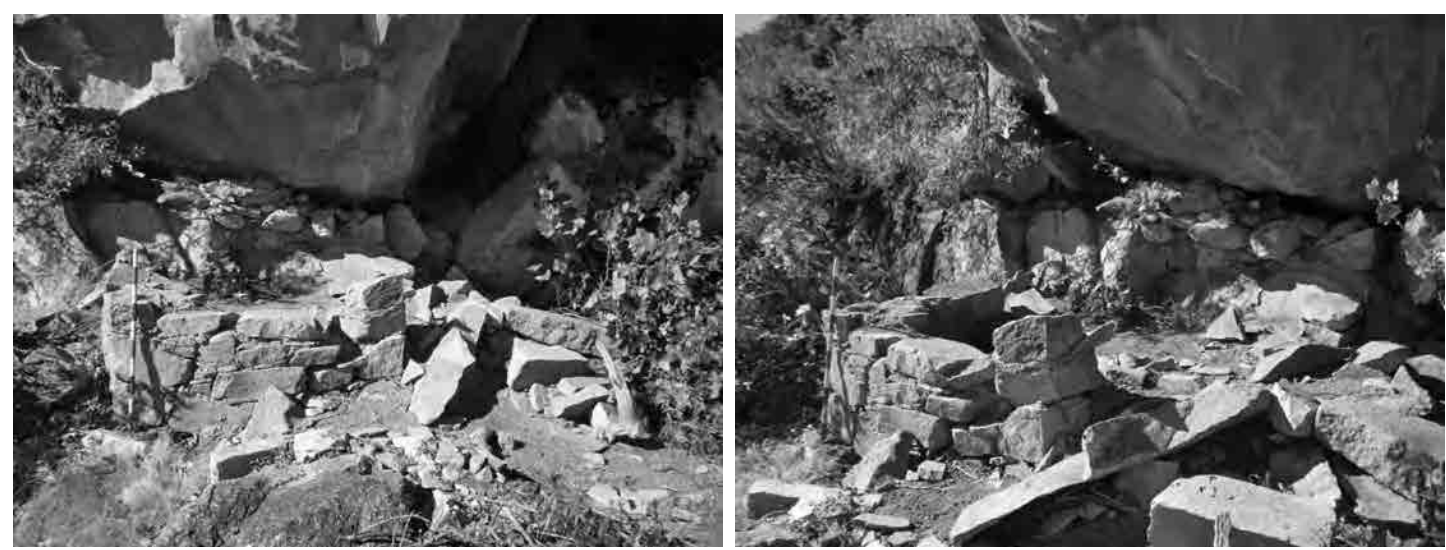

Figura 106 (izquierda): detalle de la parte externa (lado norte) de la estructura funeraria 1. Figura 107 (derecha): detalle de la parte externa (lado noroeste) de la estructura funeraria 1. Sitio Gallo Qaqa, sector F. 
Estructura funeraria 2: está ubicado al oeste de la estructura funeraria 1, al pie del segundo abrigo rocoso. Tiene forma cuadrangular, de $1.40 \mathrm{~m}$ de ancho y $1.70 \mathrm{~m}$ de largo, en mal estado de conservación. Está edificado con muros simples de piedras canteadas unidas con argamasa, de $0.30 \mathrm{~m}$ de grosor. En el interior no se identificó ningún material cultural.
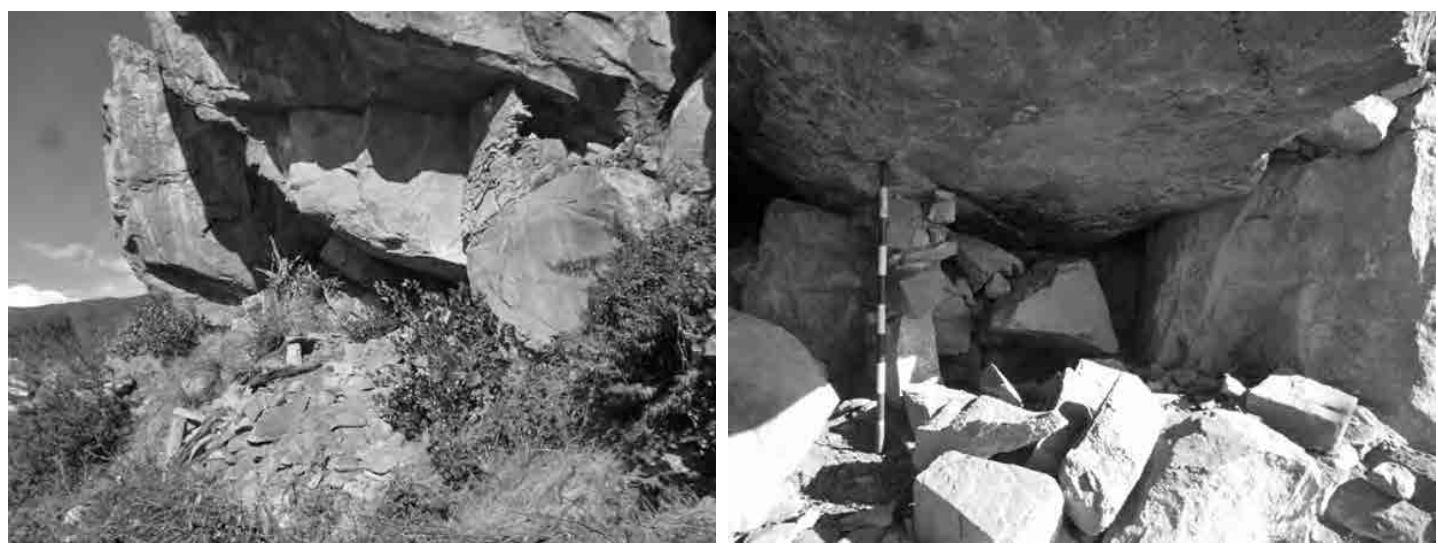

Figura 108 (izquierda): vista panorámica del segundo abrigo rocoso asociado a estructuras funerarias. Figura 109 (derecha): detalle de la estructura funeraria 2. Sitio Gallo Qaqa, sector F.

Estructura funeraria 3: está ubicado al norte y por delante de la estructura funeraria 2. Tiene planta cuadrangular, de 1.90 a $2.00 \mathrm{~m}$ de ancho, $2.00 \mathrm{~m}$ de largo, y $0.70 \mathrm{~m}$ de altura, en mal estado de conservación. Está edificado con muros de una hilera de piedras canteadas unidas con argamasa, de $0.30 \mathrm{~m}$ de grosor. El paramento externo (pared oeste) se encuentra pintado de color anaranjado. En el interior no se halló ningún material cultural.

Estructura funeraria 4: está ubicado al suroeste y adosado a la estructura funeraria 5. Tiene planta cuadrangular, compuesto de dos cámaras, cuyas dimensiones son: la primera cámara tiene $1.84 \mathrm{~m}$ de ancho, $2.00 \mathrm{~m}$ de largo, y $1.50 \mathrm{~m}$ de altura. La segunda cámara es de planta en media luna de $1.85 \mathrm{~m}$ de ancho, 1.90 m de largo y $1.40 \mathrm{~m}$ de altura. Ambas cámaras están en regular estado de conservación. Está edificado con muros dobles de piedras canteadas unidas con argamasa, de $0.40 \mathrm{~m}$ de grosor. El paramento externo (lado norte) se encuentra pintado de color anaranjado. En el interior no se identificó ningún material cultural.
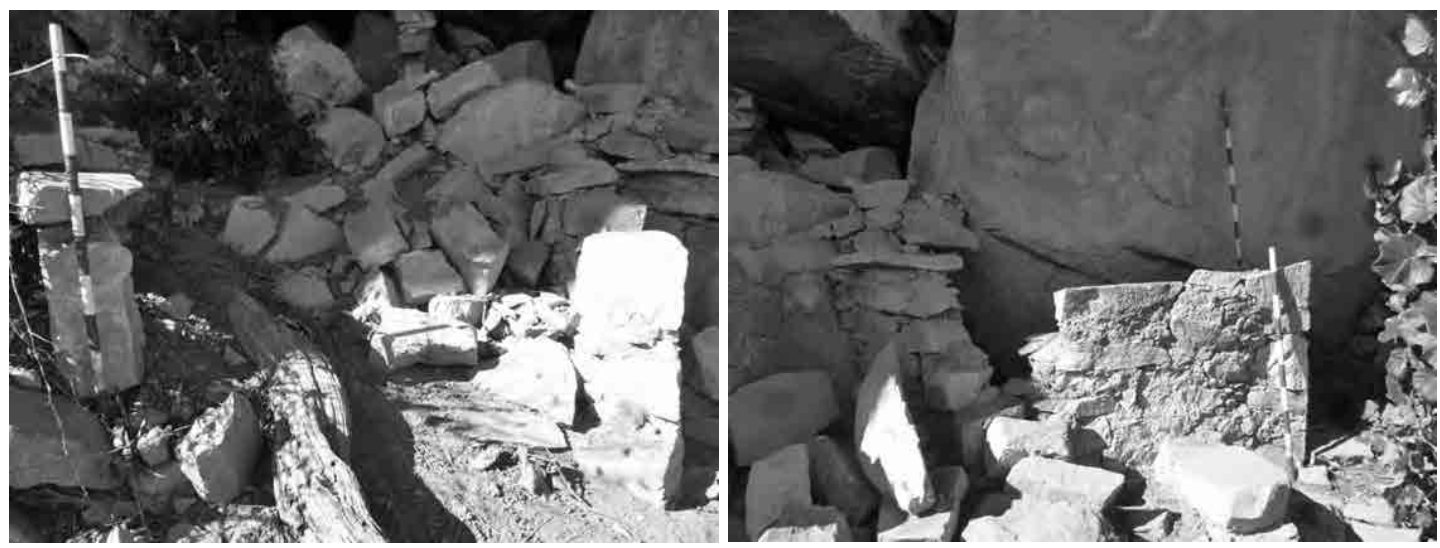

Figura 110 (izquierda): detalle de la estructura funeraria 3. Figura 111 (derecha): detalle de la estructura funeraria 4. Sitio Gallo Qaqa, sector F. 
Estructura funeraria 5: está ubicado en la parte superior del abrigo sobre una plataforma natural, debajo del panel con pintura rupestre, al suroeste de la estructura funeraria 4. Tiene planta cuadrangular, de $1.04 \mathrm{~m}$ de ancho, $2.20 \mathrm{~m}$ de largo, y $3.10 \mathrm{~m}$ de altura, en regular estado de conservación. Está edificado con muros simples de piedras canteadas unidas con argamasa, de $0.30 \mathrm{~m}$ de grosor. El paramento externo se encuentra pintado de color rojo. En el interior se observa algunos restos óseos humanos dispersos.
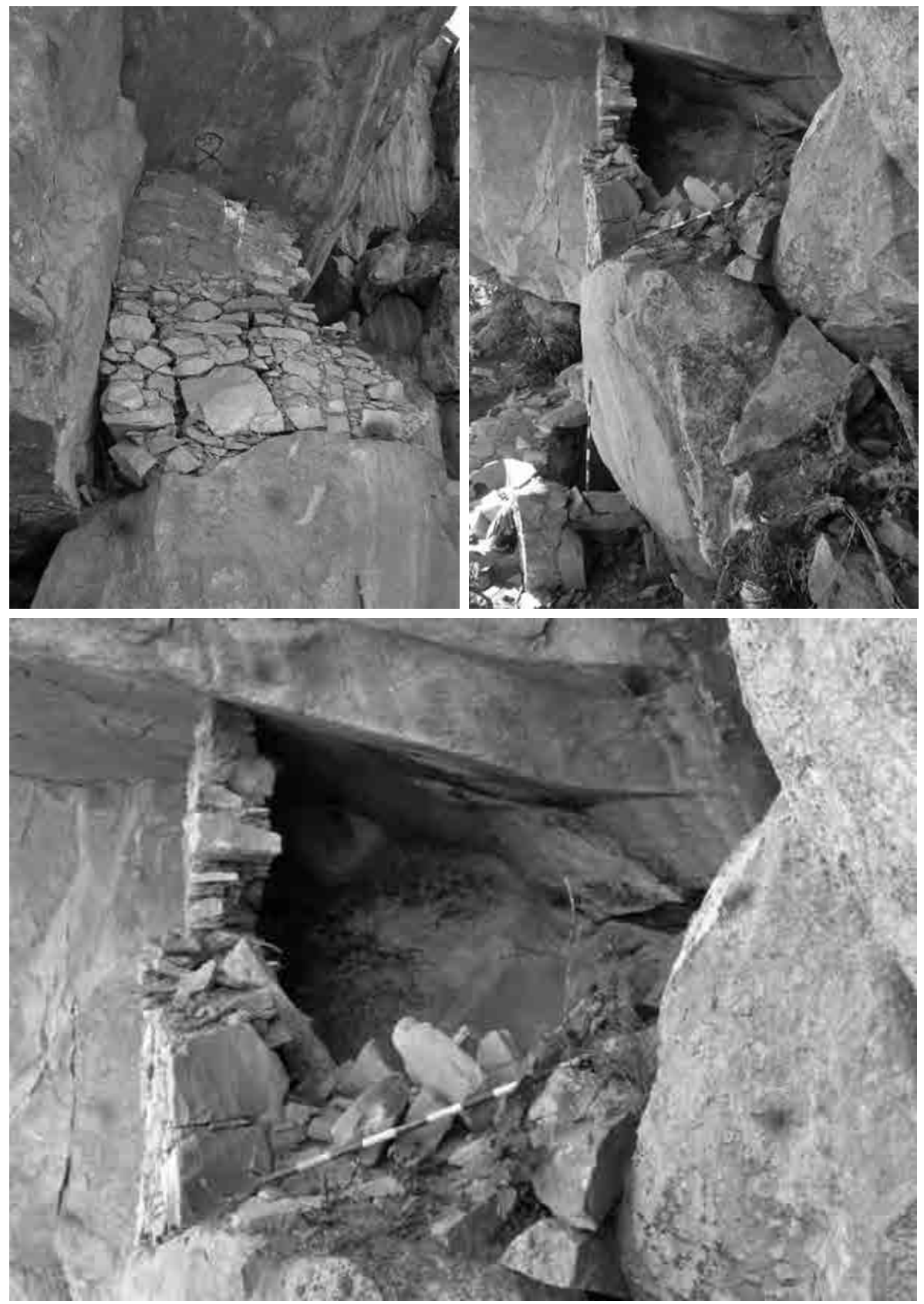

Figura 112 (superior izquierda): vista panorámica de la parte externa (lado norte) de la estructura funeraria 5. Figura 113 (superior derecha): vista panorámica de la estructura

funeraria 5 .

Figura 114 (inferior): detalle del interior de la estructura funeraria 5. Sitio Gallo Qaqa, sector F. 
VII.- Sector G: Se encuentra ubicado a unos $20 \mathrm{~m}$ del sector F, en un nivel inferior; entre las coordenadas UTM: 8871712N, 0225931E y a 2795 metros sobre el nivel del mar. Este sector corresponde a un conjunto de abrigos rocosos, en la parte baja de dos rocas grandes del tipo andesita con las paredes pintadas completamente de anaranjado. Está asociado a 3 estructuras funerarias tipo chullpa:

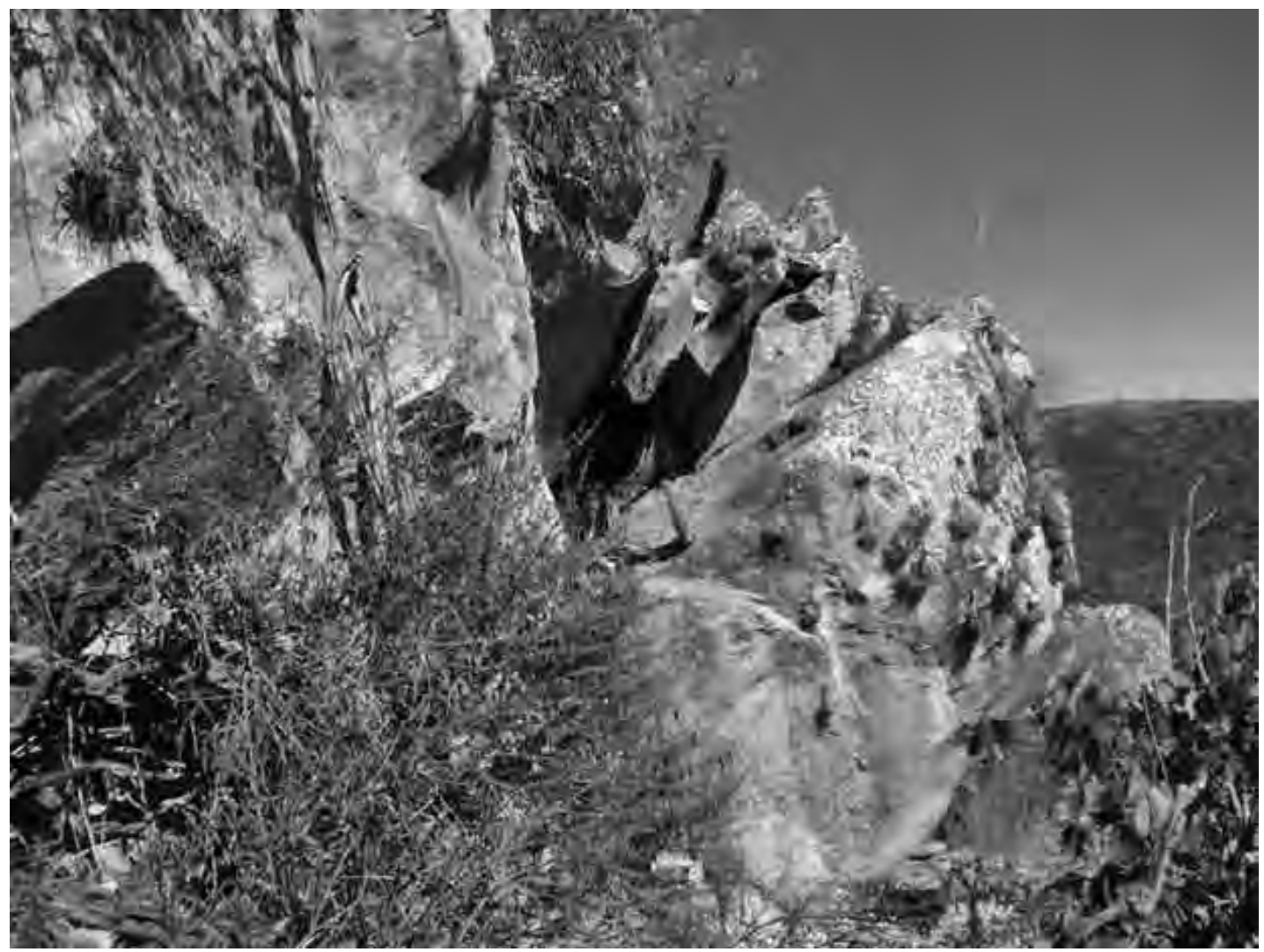

Figura 115: vista panorámica del abrigo rocoso del sector G. Sitio Gallo Qaqa.

Estructura funeraria 1: está ubicado al sureste y adosado al primer abrigo rocoso, sobre una plataforma natural a un nivel superior que la estructura funeraria 2. Tiene planta en media luna, de $1.40 \mathrm{~m}$ de largo, $0.80 \mathrm{~m}$ de ancho y $0.40 \mathrm{~m}$ de altura, en mal estado de conservación. Está edificado con muros de piedras canteadas unidas con argamasa, de $0.30 \mathrm{~m}$ de grosor. En el interior se observa algunos restos óseos (1 posible individuo).

Estructura funeraria 2: está ubicado al norte de la estructura funeraria $1 \mathrm{y}$ adosado a la pared del abrigo, en un nivel inferior, sobre una plataforma artificial construida para este fin. Tiene planta cuadrangular, de $1.10 \mathrm{~m}$ de ancho, $2.10 \mathrm{~m}$ de largo, y $1.00 \mathrm{~m}$ de altura, en mal estado de conservación. Está edificado con muros de piedras canteadas unidas con argamasa, de $0.30 \mathrm{~m}$ de grosor. En el interior no se halló ningún material cultural.

Estructura funeraria 3: está ubicado al oeste de las estructuras funerarias 1 y 2, al pie del segundo abrigo rocoso. Tiene planta cuadrangular, de 1.36 a $1.54 \mathrm{~m}$ de ancho, $1.65 \mathrm{~m}$ de largo, y $0.70 \mathrm{~m}$ de altura, en regular estado de conservación. Está edificado con muros de piedras canteadas unidas con argamasa, de $0.30 \mathrm{~m}$ de grosor. En el interior no se halló ningún material cultural. 

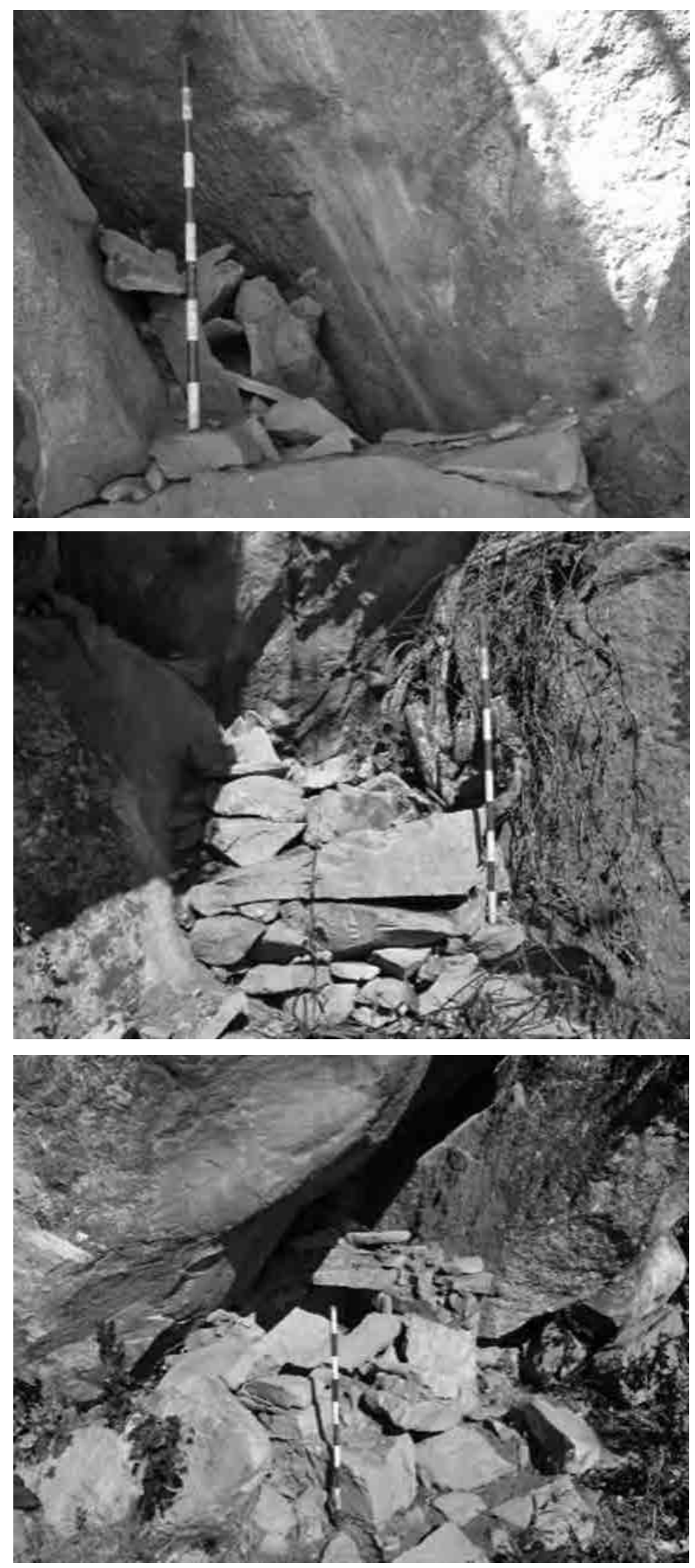

Figura 116 (arriba): detalle de la estructura funeraria 1. Figura 117 (centro): detalle estructura funeraria 2. Figura 118 (debajo): detalle de la estructura funeraria 3. Sitio Gallo Qaqa, sector G. 
VIII.- Sector H: Se encuentra ubicado al sur de los sectores D y E, a unos $100 \mathrm{~m}$ del sector G; entre las coordenadas UTM: $8871698 \mathrm{~N}, 0225833 \mathrm{E}$ y a 2795 metros sobre el nivel del mar. Comprende un abrigo rocoso de unos $4 \mathrm{~m}$ de alto por $6.20 \mathrm{~m}$ de ancho aproximadamente; con la abertura del acceso orientado al norte. Al pie de este abrigo está una estructura funeraria tipo chullpa de planta cuadrangular de 1.60 a $2.50 \mathrm{~m}$ de ancho, $1.90 \mathrm{~m}$ de largo, y $0.60 \mathrm{~m}$ de altura, en mal estado de conservación. Está edificado con muros dobles de piedras canteadas unidas con argamasa, de $0.30 \mathrm{~m}$ de grosor, sostenida en maderos de árboles propios del lugar. Por la cubierta y los muros desplomados fue imposible identificar los materiales culturales asociados.
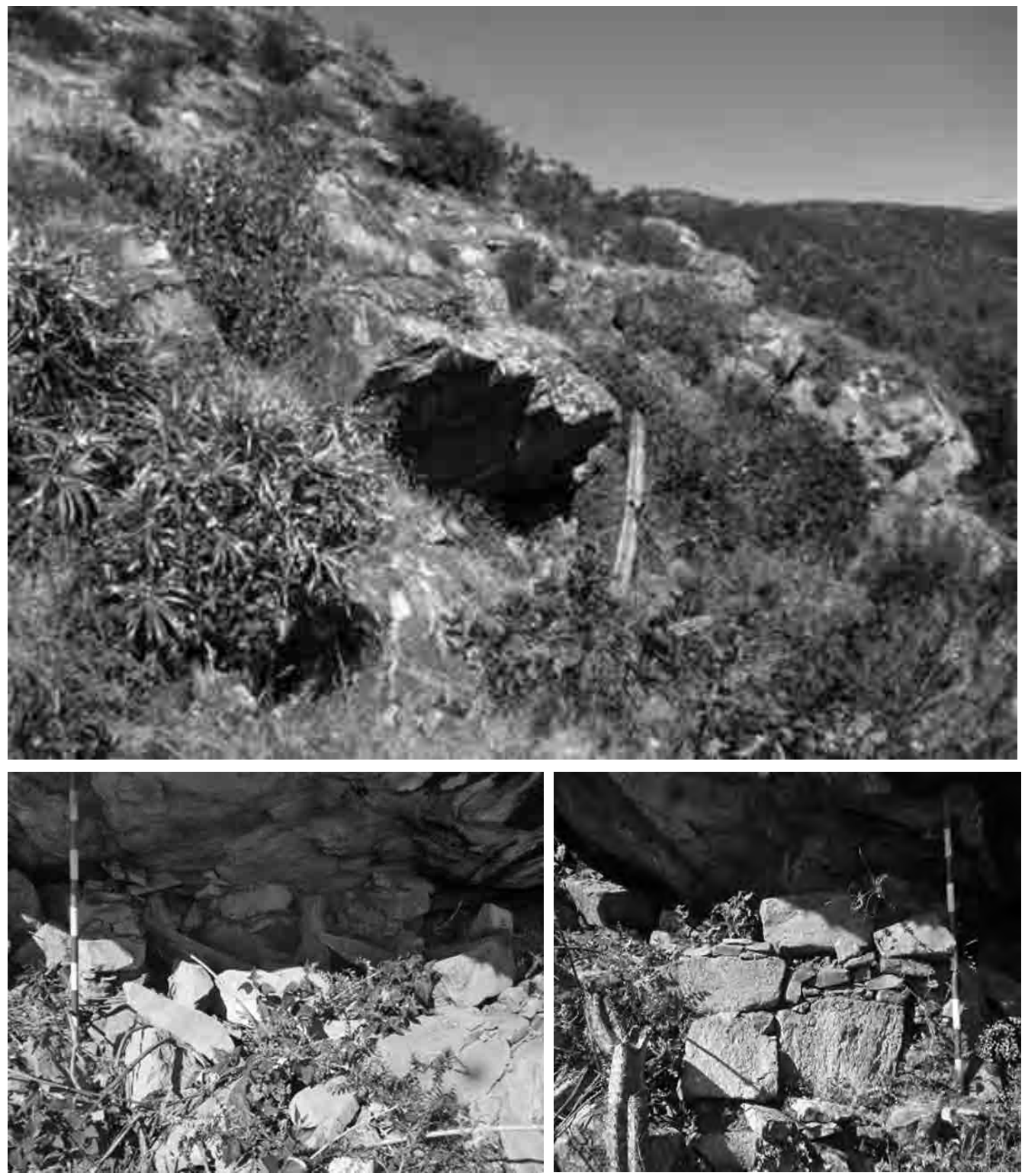

Figura 119 (izquierda): vista panorámica del abrigo rocoso del sector H. Figura 120 (centro): detalle de la estructura funeraria asociada. Figura 121 (derecha): vista panorámica del paramento norte de la estructura funeraria. Sitio Gallo Qaqa, sector $\mathrm{H}$. 
IX.- Sector I: Se encuentra ubicado a $50 \mathrm{~m}$ al sur del sector H; entre las coordenadas UTM: $8871696 \mathrm{~N}, 0225798 \mathrm{E}$ y a 2809 metros sobre el nivel del mar. Este sector corresponde a una cueva, en el interior de una gran roca del tipo andesita de unos $5 \mathrm{~m}$ de altura por $8 \mathrm{~m}$ de ancho, con la abertura del acceso orientado hacia el norte. La intrusión interna de la cueva ha sido acondicionada por medio de muros adosados a las paredes de la cueva, para construir una estructura funeraria de planta circular compuesta de dos cámaras, cuyas dimensiones son: la primera cámara tiene $2.04 \mathrm{~m}$ de ancho, $3.20 \mathrm{~m}$ de largo, y $1.50 \mathrm{~m}$ de altura. La segunda cámara es de planta en media luna, separado con un muro que va hasta la parte media de la cueva, tiene $2.25 \mathrm{~m}$ de ancho, $5 \mathrm{~m}$ de largo y $1.50 \mathrm{~m}$ de altura. Ambas cámaras en regular estado de conservación. Está edificado con muros simples adosados a la pared de la cueva, de piedras canteadas unidas con argamasa, de $0.40 \mathrm{~m}$ de grosor. En el interior se observa restos óseos (20 individuos aproximadamente), botánicos (soguillas, restos de maguey y madera), y fragmentos de textiles.
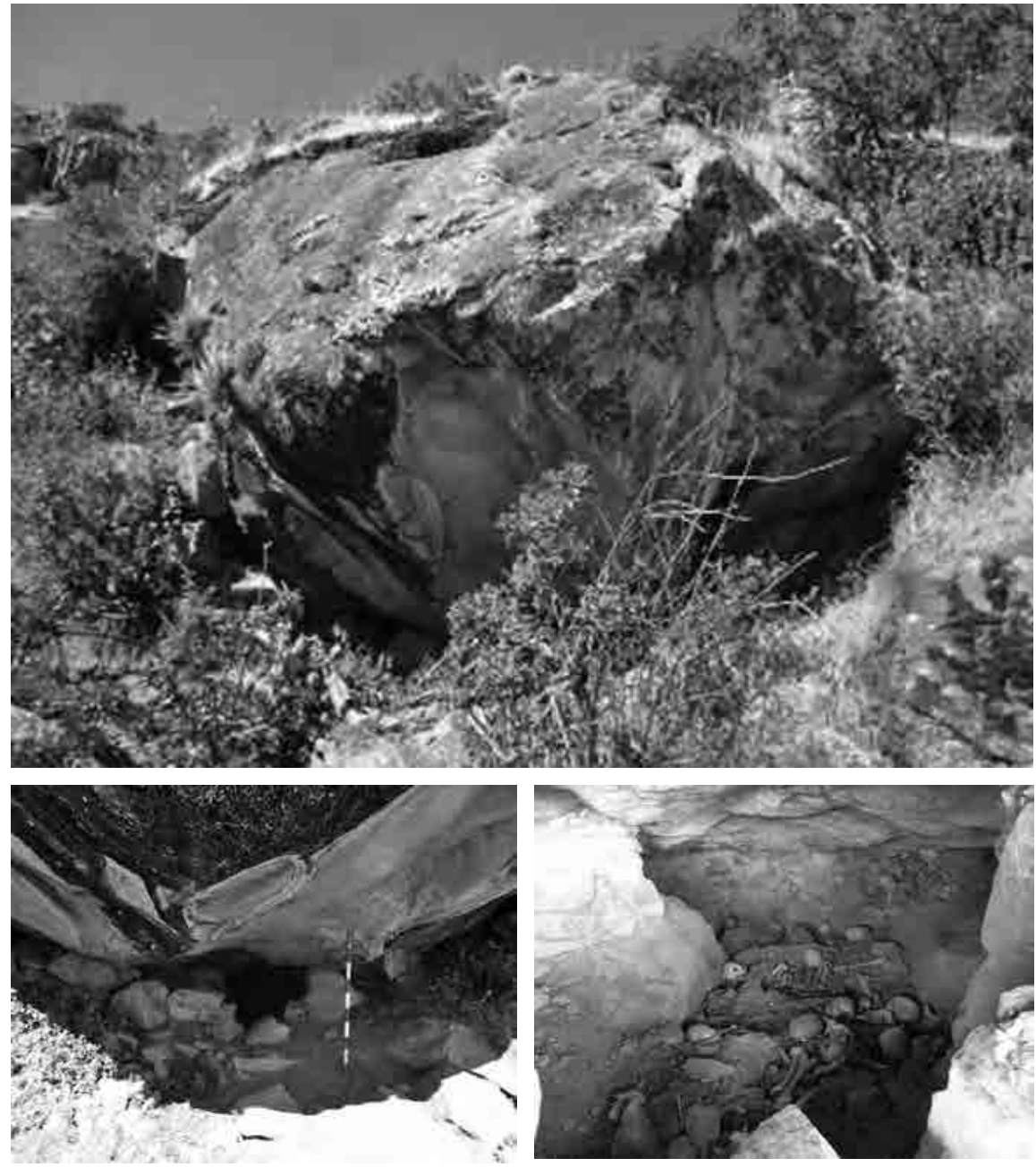

Figura 122 (izquierda): vista panorámica del abrigo rocoso del sector I. Figura 123 (centro): detalle del acceso de la estructura asociada. Figura 124 (derecha): vista en detalle de los restos óseos asociados en el interior de la estructura funeraria. Sitio Gallo Qaqa, sector I. 
X.- Sector J: Se encuentra ubicado a unos $30 \mathrm{~m}$ al sur del sector I; entre las coordenadas UTM: $8871668 \mathrm{~N}, 0225739 \mathrm{E}$ y a 2825 metros sobre el nivel del mar. Al igual que el sector I, corresponde a una cueva debajo de una roca del tipo andesita de color gris claro, de $6 \mathrm{~m}$ de altura por $9 \mathrm{~m}$ de ancho aproximadamente. En la parte baja de la roca fue acondicionada una estructura funeraria compuesta de 3 cámaras, divididas por medio de muros. La primera cámara de planta en media luna tiene $1.54 \mathrm{~m}$ de ancho, por $1.56 \mathrm{~m}$ de largo y $1.60 \mathrm{~m}$ de altura; la segunda cámara de planta en media luna, tiene $1.70 \mathrm{~m}$ de ancho por $1.80 \mathrm{~m}$ de largo y $0.50 \mathrm{~m}$ de altura; y por último, la tercera cámara de planta rectangular tiene $2.50 \mathrm{~m}$ de ancho, por $3.50 \mathrm{~m}$ de largo y $1.05 \mathrm{~m}$ de altura. Todos en regular estado de conservación. Están edificados con muros simples de piedras canteadas unidas con argamasa, con un grosor que varía de 0.25 a $0.30 \mathrm{~m}$. En el interior se observa restos óseos (13 individuos aproximadamente), asociados a materiales botánicos (soguillas, resto de maguey), entre otros.
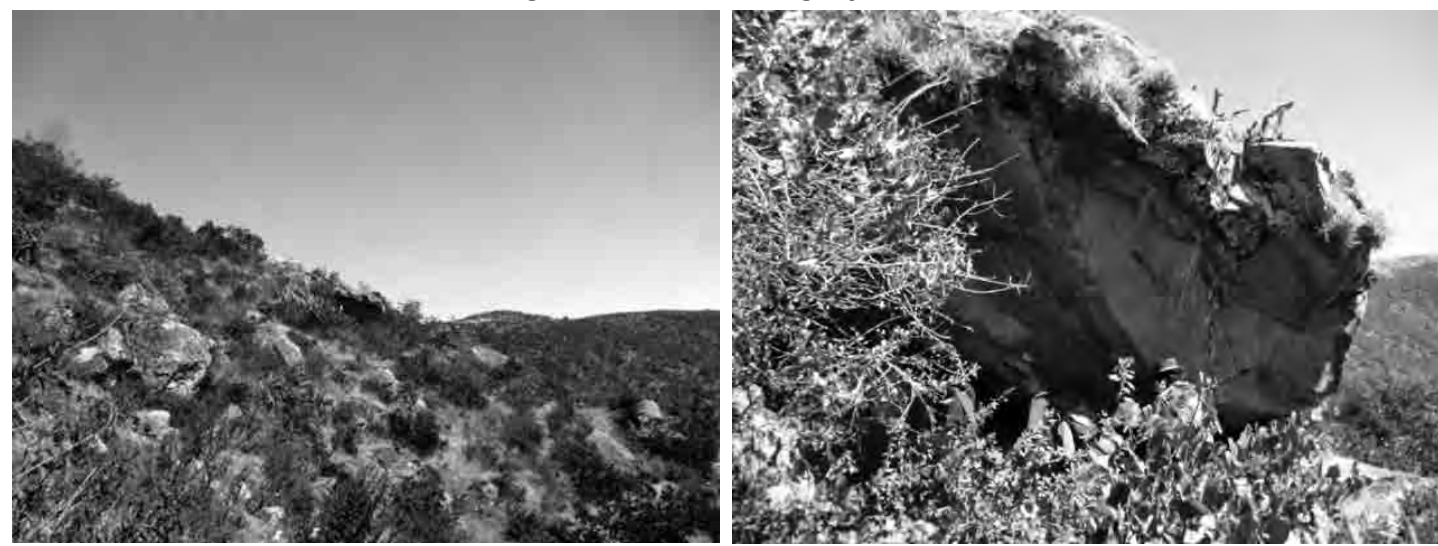

Figuras 125 y 126: vista panorámica y detalle respectivamente del abrigo rocoso del sector J. Sitio Gallo Qaqa.
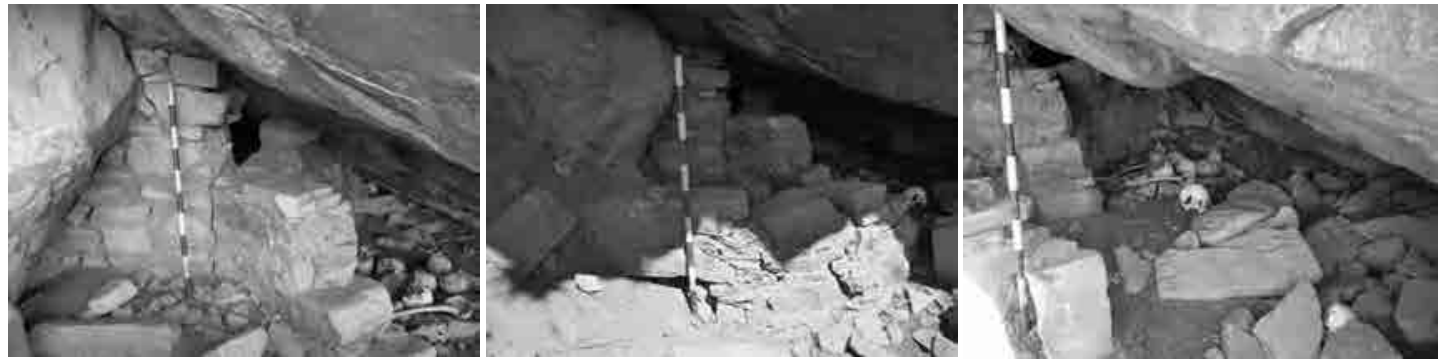

Figura 127 (izquierda): vista de la parte externa de la primera cámara. Figura 128 (centro): vista de la parte externa de la segunda camara. Figura 129 (derecha): detalle de los restos óseos asociados al interior de la tercera camara. Sitio Gallo Qaqa, sector J.
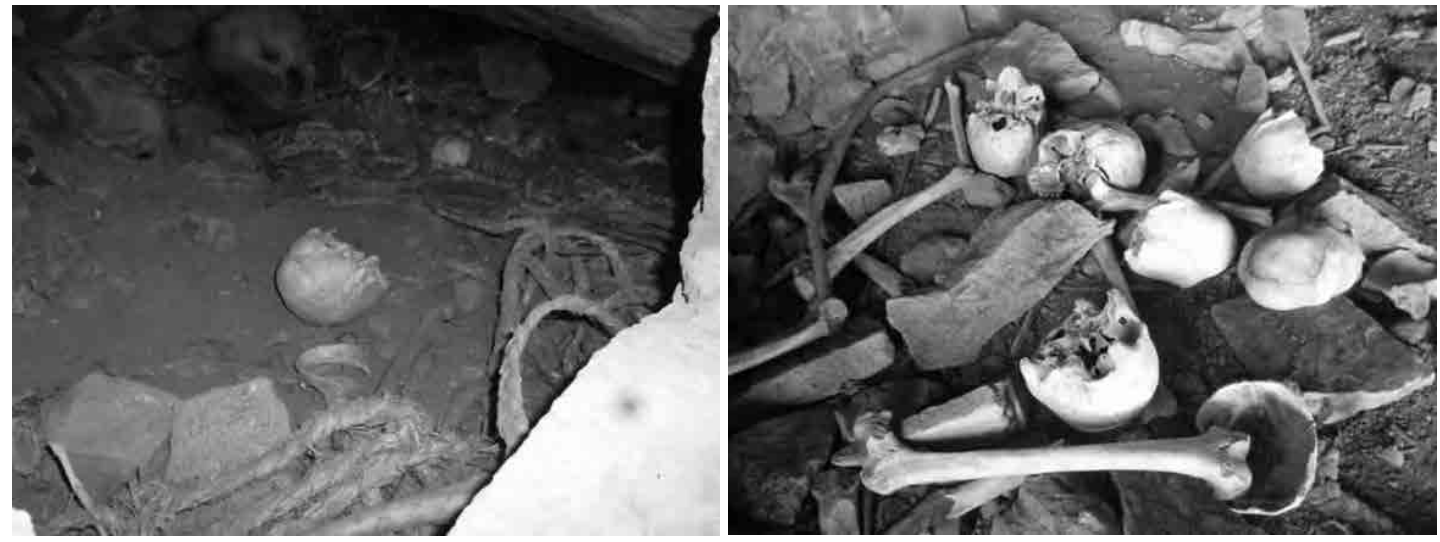

Figura 130 y 131: detalle de los restos óseos asociados en el interior de la primera y tercera camara respectivamente. Sitio Gallo Kaka, sector J. 


\section{C.- HUAUYA PUNTA}

Ubicación: Se encuentra ubicado hacia el oeste de la comunidad de Yamor, a unos 8 km aproximadamente, sobre una pequeña lomada del mismo nombre, que desciende del este en dirección noroeste, en la parte superior y margen izquierda de la quebrada Qashpawarar, al suroeste del sitio Gallo Qaqa. Políticamente está situado en la jurisdicción de la comunidad campesina de Yamor, distrito Antonio Raymondi, Provincia de Bolognesi, departamento de Ancash, entre las coordenadas UTM: $8871561 \mathrm{~N}, 0225471 \mathrm{E}$ y a 2884 metros sobre el nivel del mar.

Acceso: Desde la comunidad de Yamor, se toma un camino de herradura con dirección al sitio de Rurun Pukru, por un tramo de 1 hora, que conduce directamente al sitio.

Tipo de sitio: Paisaje Cultural Arqueológico (petroglifo).

Filiación cultural: posiblemente prehispánico tardío.

Estado de conservación: el sitio se encuentra en regular estado de conservación. Las afectaciones diagnosticadas son principalmente por factores climáticos (como calor, viento, lluvia y otros), que poco a poco está desgastando los motivos.

Descripción del sitio: este sitio está conformado por una roca de regular tamaño de unos $2.20 \mathrm{~m}$ de ancho por $2.30 \mathrm{~m}$ de largo y $1.60 \mathrm{~m}$ de altura, del tipo andesita y de color gris claro, el cual en la pared sureste (parte plana de la roca), fue tallado un petroglifo de forma geométrica: un motivo cuadrangular con líneas interiores, asociado a 3 motivos geométricos y circulares por debajo, que consiste en círculos unidos por uno de sus extremos. Las dimensiones son: el motivo cuadrangular tiene 0.34 $\mathrm{m}$ de altura por $0.17 \mathrm{~m}$ de ancho y $0.012 \mathrm{~cm}$ de grosor de las líneas del petroglifo. Los otros motivos conjuntamente miden $0.12 \mathrm{~m}$ de altura y $0.18 \mathrm{~m}$ de ancho. Estos últimos están unidos al primer motivo mediante una línea semicircular. Por delante (lado sureste) de la roca, se aprecia una intrusión en el terreno, donde según nuestros guías, un viajero extrajo un baúl de cuero repleto de oro.

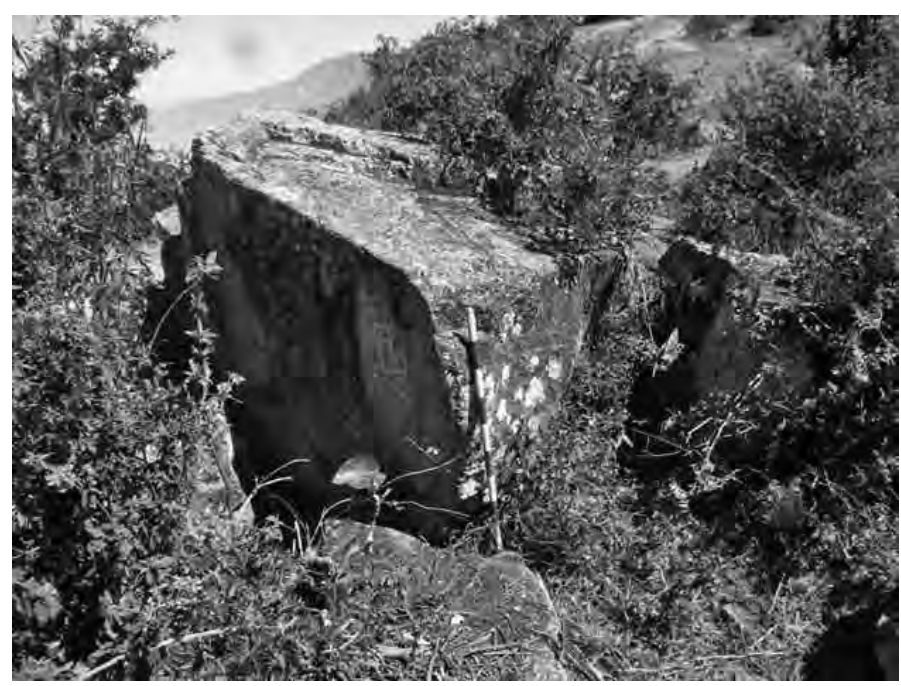

Figura 132: vista panorámica de la piedra asociada a petroglifos, Sitio Huauya Punta.

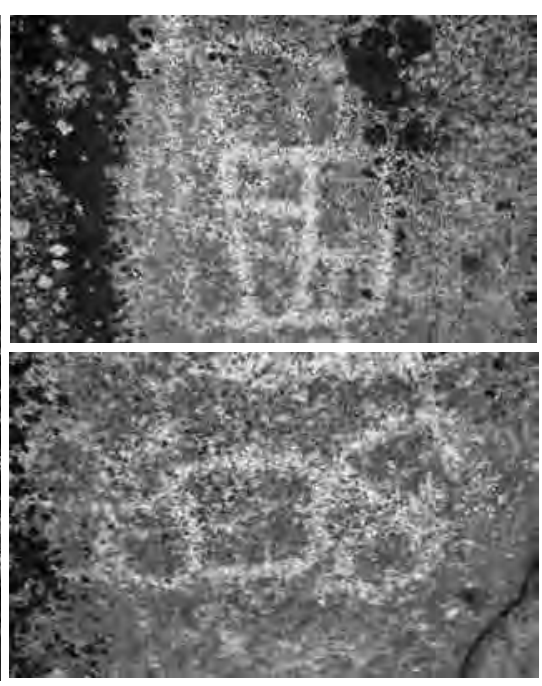

Figura 133 (arriba): detalle del motivo 1. Figura 134 (debajo): detalle del motivo 2. Sitio Huauya Punta. 


\section{D.- RURUN PUKRU}

Ubicación: Se encuentra ubicado hacia el oeste de la comunidad de Yamor, a unos $7 \mathrm{~km}$ aproximadamente, rodeado de un conjunto de despeñaderos y roquedales dispuestos sobre una pequeña hondonada que desciende de este a oeste; al este del sitio Huauya Punta y al sur del sitio Gallo Qaqa. Situado políticamente en la jurisdicción de la comunidad de Yamor, distrito de Antonio Raymondi, Provincia de Bolognesi, departamento de Ancash. El sitio se localiza entre las coordenadas UTM: $8871525 \mathrm{~N}, 0225713 \mathrm{E}$ y a 2910 metros sobre el nivel del mar. Presenta abundante vegetación arborea, arbustiva y cactácea. Corresponde a un conjunto de abrigos rocosos de tipo andesita.

Acceso: Desde la comunidad de Yamor, se toma un camino de herradura con dirección al oeste que conduce directamente al sitio.

Tipo de sitio: Paisaje Cultural Arqueológico (abrigos rocosos con pinturas rupestres y estructuras funerarias).

Filiación cultural: Intermedio Tardío.

Estado de conservación: El sitio se encuentra en regular estado de conservación. Las afectaciones diagnosticadas son principalmente por excesivo pastoreo de ganado ovino y caprino, y la abundante presencia de plantas herbáceas y arbustivas.

Descripción del sitio: El sitio ha sido dividido en 11 sectores, considerando para ello la ubicación y la configuración espacial de los mismos.

I.- Sector A: Se encuentra ubicado al lado oeste del sitio, al sureste del sitio Huauya Punta, entre las coordenadas UTM: $8871435 \mathrm{~N}, 0225629 \mathrm{E}$ y a 2923 metros sobre el nivel del mar. Corresponde a un abrigo rocoso de roca andesita, con la abertura del acceso orientado al noroeste, con las paredes completamente pintadas de color anaranjado. Está asociado a una estructura funeraria dispuesta sobre una plataforma, de $1.10 \mathrm{~m}$ de ancho, $2.20 \mathrm{~m}$ de largo, y $0.70 \mathrm{~m}$ de altura, en mal estado de conservación, con los muros desplomados. No está asociado a ningún material cultural.

II.- Sector B: Se encuentra ubicado a unos $120 \mathrm{~m}$ al noreste del sector A, entre las coordenadas UTM: $8871512 \mathrm{~N}, 0225666 \mathrm{E}$ y a 2920 metros sobre el nivel del mar. Corresponde a una cueva pequeña ubicada debajo de una roca del tipo andesita, de unos $6 \mathrm{~m}$ de altura por $10 \mathrm{~m}$ de ancho, con la abertura del acceso orientado al norte. Presenta las paredes de la cueva pintadas de color rojo óxido. En el inte-

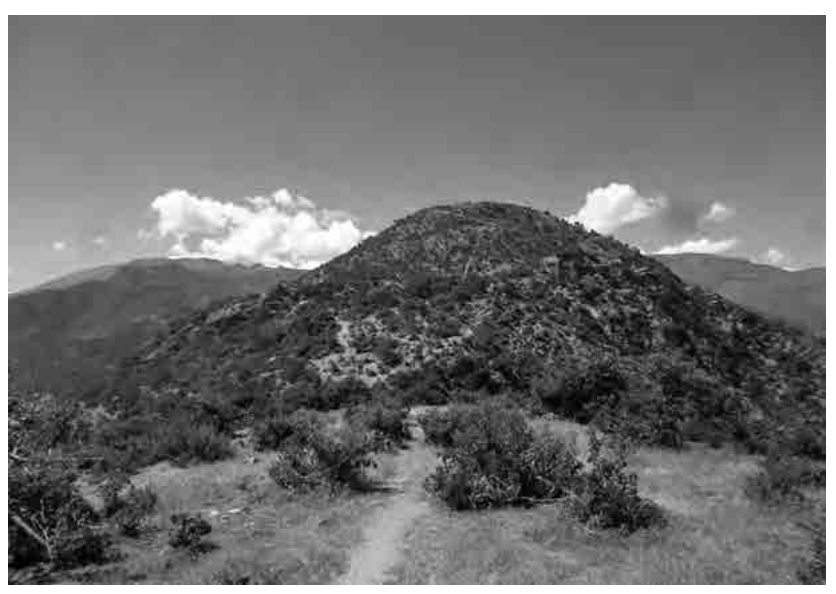

Figura 135: vista panorámica del sitio Rurun Pukru (desde el lado oeste). rior de la cueva presenta dos intrusiones que fueron acondicionados como estructuras funerarias. Se registró de 2 estructuras funerarias.

Estructura funeraria 1: está ubicado en el lado oeste de la cueva, en la primera intrusión de la misma. Tiene planta circular, de $3.25 \mathrm{~m}$ de diámetro por $3.30 \mathrm{~m}$ de profundidad, en regular estado de conservación. El acceso está edificado con muros de piedras canteadas unidas con argama$\mathrm{sa}$, de $0.40 \mathrm{~m}$ de ancho, orientado hacia el norte. En el interior se observa restos óseos (10 individuos aproximadamente), entre otros materiales. 

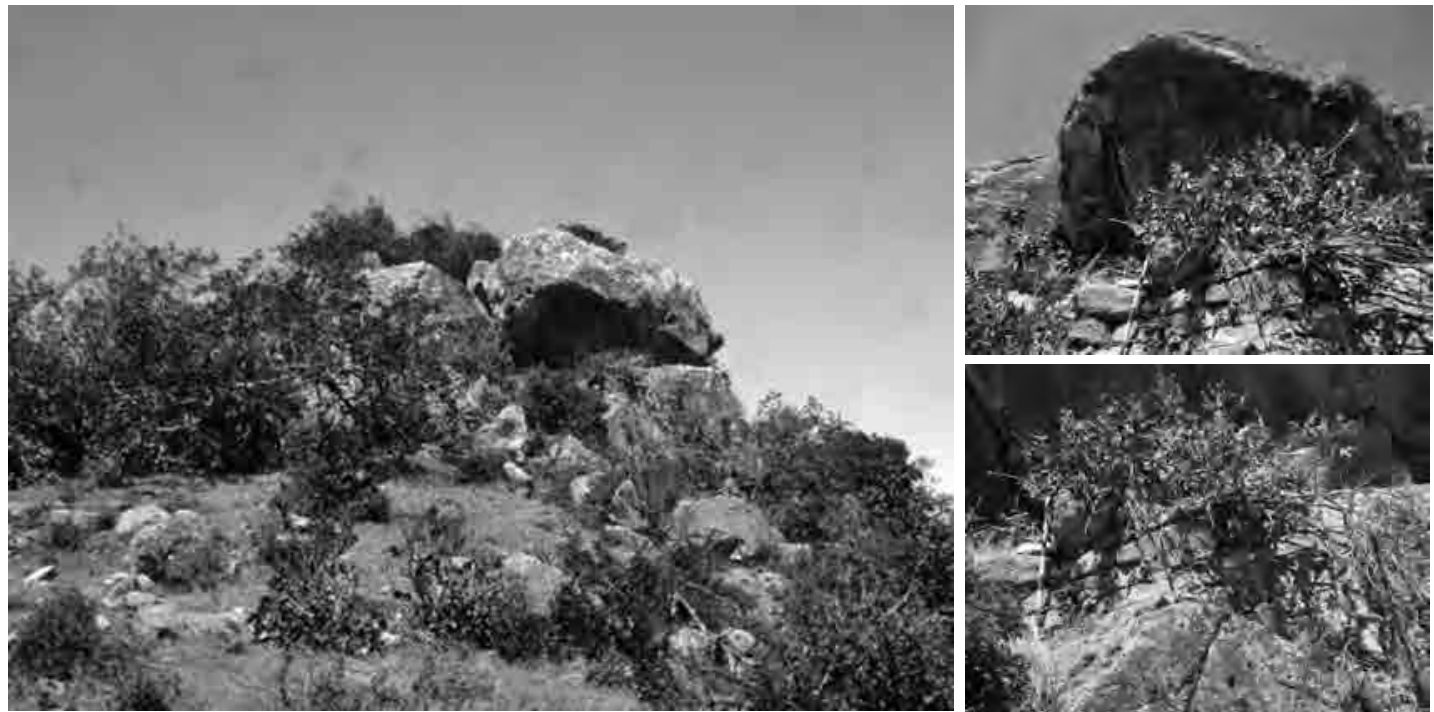

Figura 136 (izquierda): vista panorámica del abrigo rocoso del sector A. Figura 137 (superior derecha): detalle del sector A. Figura 138 (inferior derecha): detalle del paramento de la estructura funeraria asociada al abrigo rocoso. Sitio Rurun Pukru, sector A.
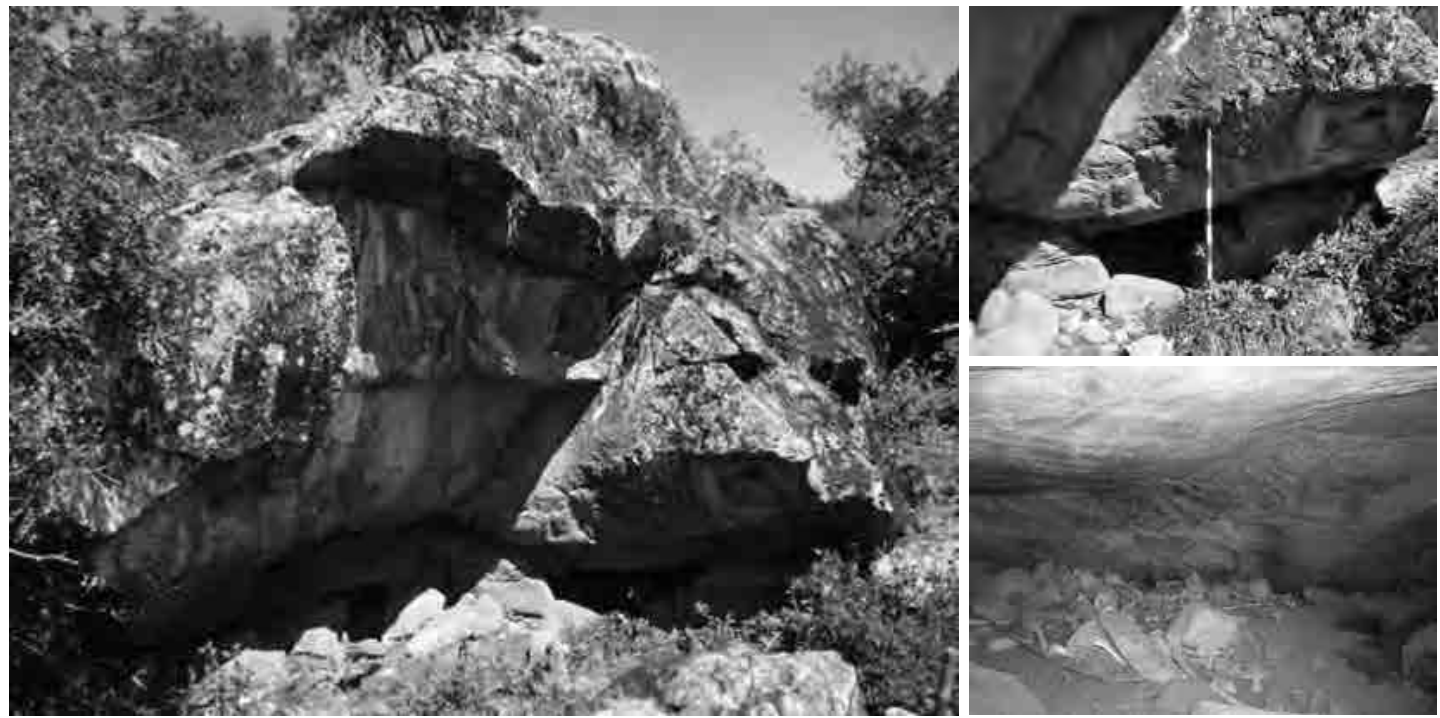

Figura 139 (izquierda): vista panorámica de la parte externa de la estructura funeraria 1. Figura 140 (centro): detalle del acceso de la estructura funeraria 1. Figura 141 (derecha): vista en detalle de los restos óseos asociados al interior de la estructura funeraria 1. Sitio Rurun Pukru, sector B. 
Estructura funeraria 2: está ubicado al noreste de la estructura funeraria 1, en la segunda intrusión de la cueva. Tiene planta circular, de $6 \mathrm{~m}$ de ancho, y $0.90 \mathrm{~m}$ de altura, en regular estado de conservación. Está edificado con muros de piedras canteadas unidas con argamasa, de $0.40 \mathrm{~m}$ de grosor. Presenta un acceso de forma cuadrangular de $0.50 \mathrm{~m}$ de ancho por $0.50 \mathrm{~m}$ de altura, orientado al norte. En el interior se observa restos óseos (21 individuos aproximadamente).
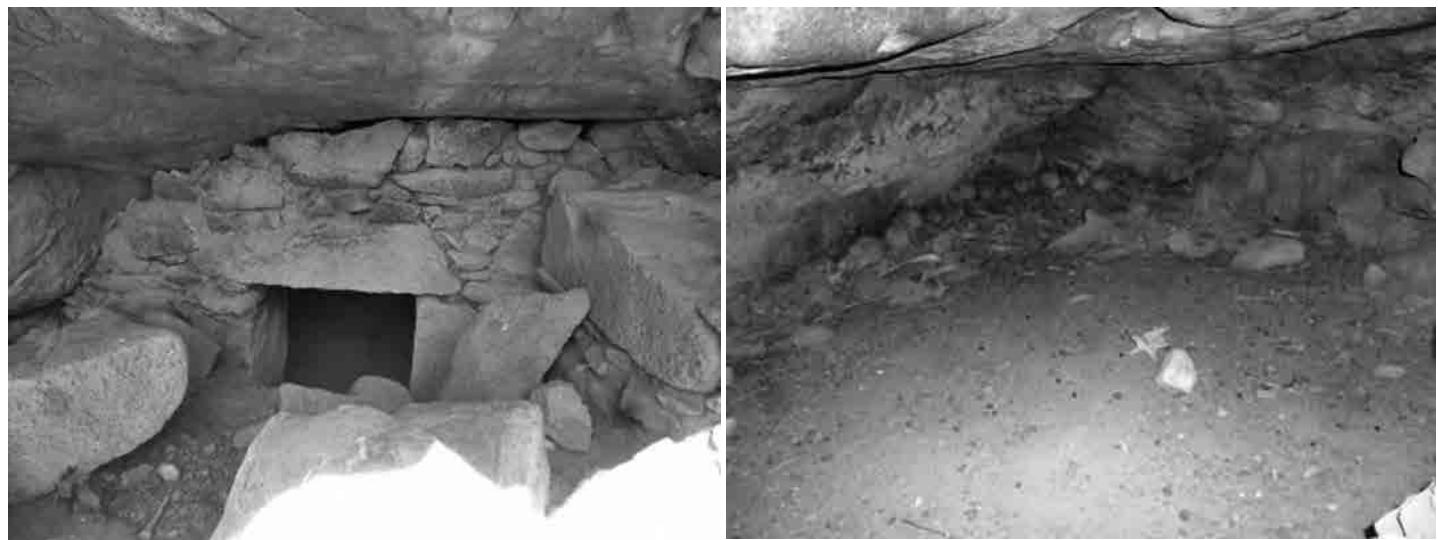

Figura 142: izquierda: detalle del acceso de la estrutura funeraria 2. Figura 143: derecha: vista en detalle de los restos óseos asociados en el interior de la estrutura funeraria 2. Sitio Rurun Pukru, sector B.

III.- Sector C: Se encuentra ubicado a unos $20 \mathrm{~m}$ al noreste del sector B, entre las coordenadas UTM: 8871550 N, 022702E y a 2920 metros sobre el nivel del mar. Forma parte de un conjunto de abrigos rocosos, debajo de una roca grande del tipo granito, de color gris claro con la abertura del acceso orientado al norte. En la parte baja están dos estructuras funerarias de planta cuadrangular tipo chullpa. Presenta las paredes de la cueva pintada de color rojo óxido.
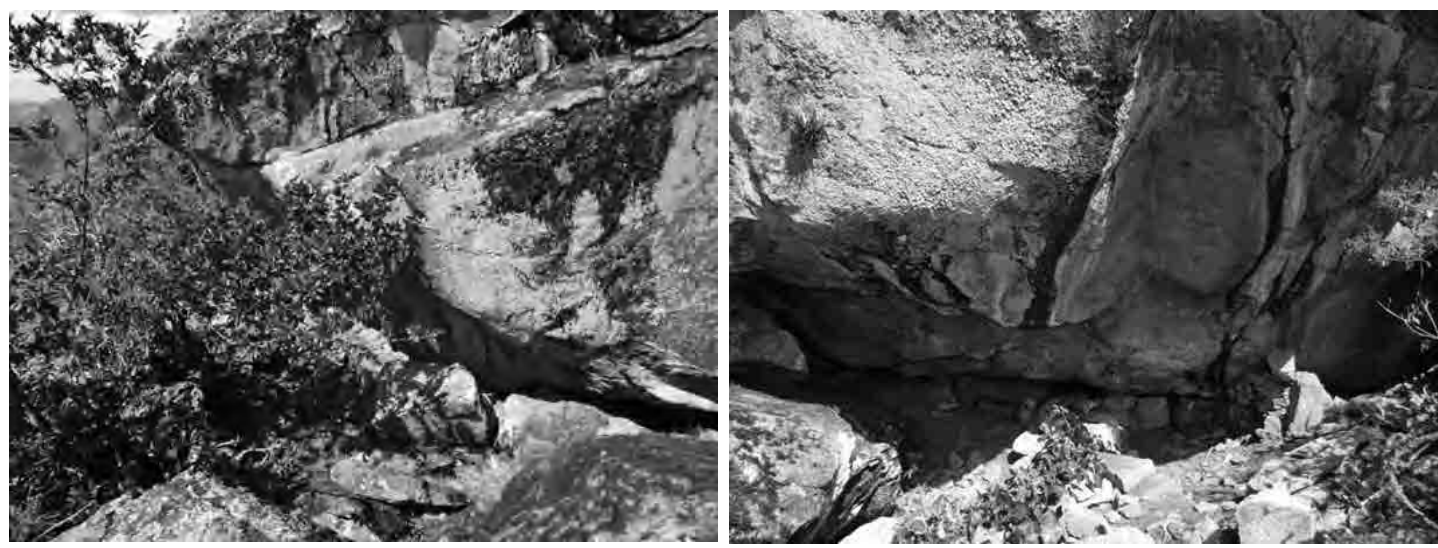

Figura 144 (izquierda): vista panorámica del abrigo rocoso del sector C. Figura 145 (derecha): vista en detalle de las estructuras funerarias asociadas. Sitio Rurun Pukru, sector C. 
Estructura funeraria 1: está ubicado en el lado oeste del abrigo rocoso. Tiene planta cuadrangular, de $1.50 \mathrm{~m}$ de ancho por $3.00 \mathrm{~m}$ de largo, y $0.60 \mathrm{~m}$ de altura, en mal estado de conservación, con muros derrumbados. Está edificado con muros de piedras canteadas unidas con argamasa, de 0.25 a $0.30 \mathrm{~m}$ de grosor. No se ha podido identificar el acceso. En el interior está asociado a restos óseos disturbados (3 individuos), así como también, en la parte externa en mayor cantidad (17 individuos).

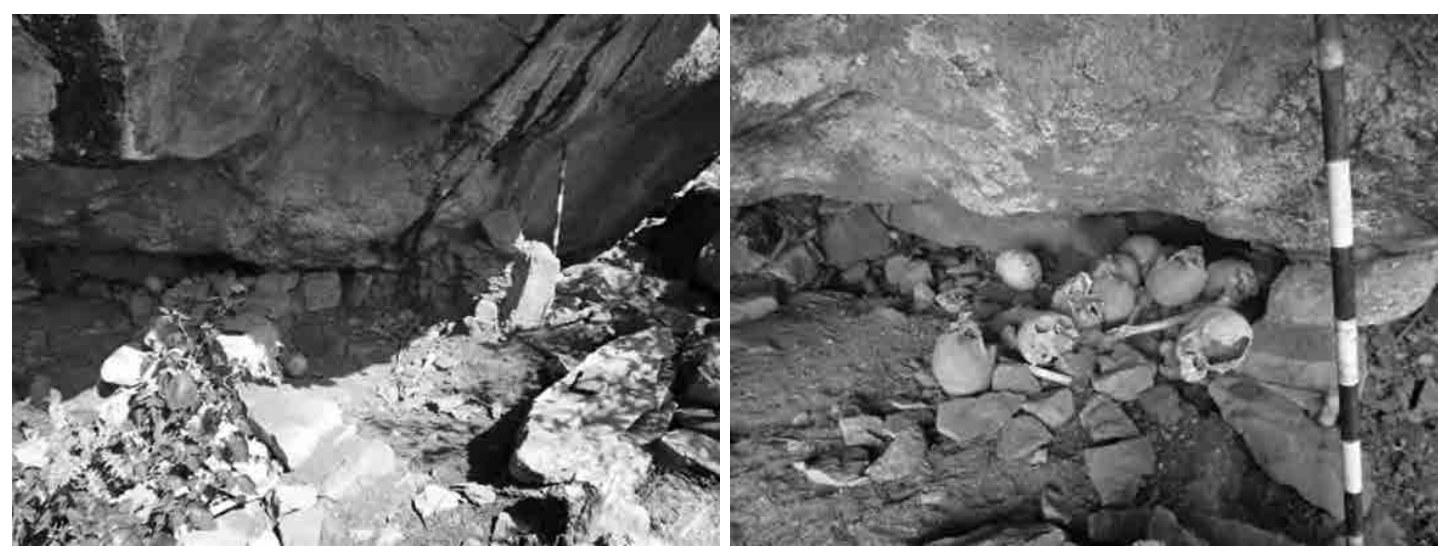

Figura 146 (izquierda): vista panorámica de la parte externa de la estructura funeraria 1. Figura 147 (derecha): vista en detalle de los restos óseos asociados en el exterior de la estructura funeraria. Sitio Rurun Pukru, sector C.

Estructura funeraria 2: está ubicado al este de la estructura funeraria 1, adosado a la pared del abrigo rocoso. Tiene planta cuadrangular, de $1.50 \mathrm{~m}$ de ancho por $1.50 \mathrm{~m}$ de largo, y $0.70 \mathrm{~m}$ de altura y $1.60 \mathrm{~m}$ de profundidad, en mal estado de conservación. Está edificado con muros de piedras canteadas unidos con argamasa, de $0.30 \mathrm{~m}$ de grosor. Presenta un acceso de forma cuadrangular de $0.40 \mathrm{~m}$ de ancho por $0.30 \mathrm{~m}$ de altura. Está asociado a restos óseos (2 individuos aproximadamente).
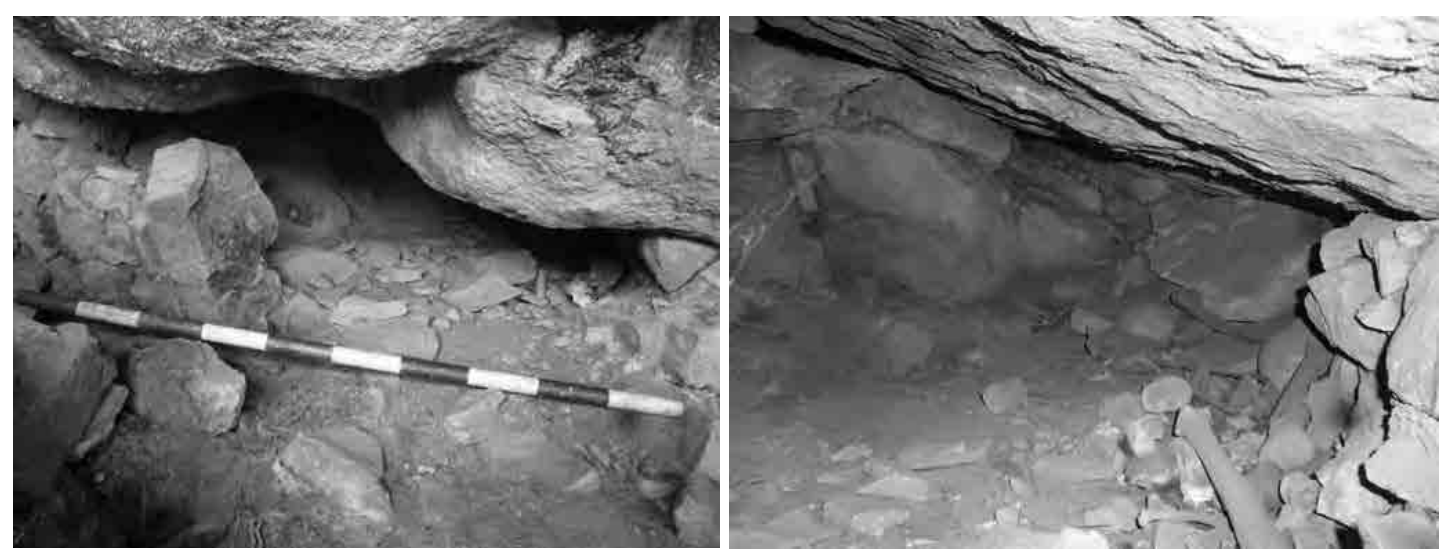

Figura 148 (izquierda): detalle del acceso de la estructura funeraria 2. Figura 149 (derecha): vista en detalle de los restos óseos asociados en el interior de la estructura funeraria 2. Sitio Rurun Pukru, sector C. 
IV.- Sector D: Se encuentra ubicado al norte del sector C y al noreste del sector B, entre las coordenadas UTM: 8871554N, 0225700E y a 2911 metros sobre el nivel del mar. Se ubica debajo de una roca grande del tipo granito de color gris claro, con la abertura del acceso orientado al norte, por debajo del sector C. En la parte baja hay una estructura funeraria tipo chullpa de planta en media luna, de $2.40 \mathrm{~m}$ de ancho por $2.90 \mathrm{~m}$ de largo, y $0.80 \mathrm{~m}$ de altura, en mal estado de conservación; edificado con muros dobles de piedras canteadas unidas con argamasa, de $0.30 \mathrm{~m}$ de grosor. En el interior se halló restos óseos (11 individuos) y cerámica.
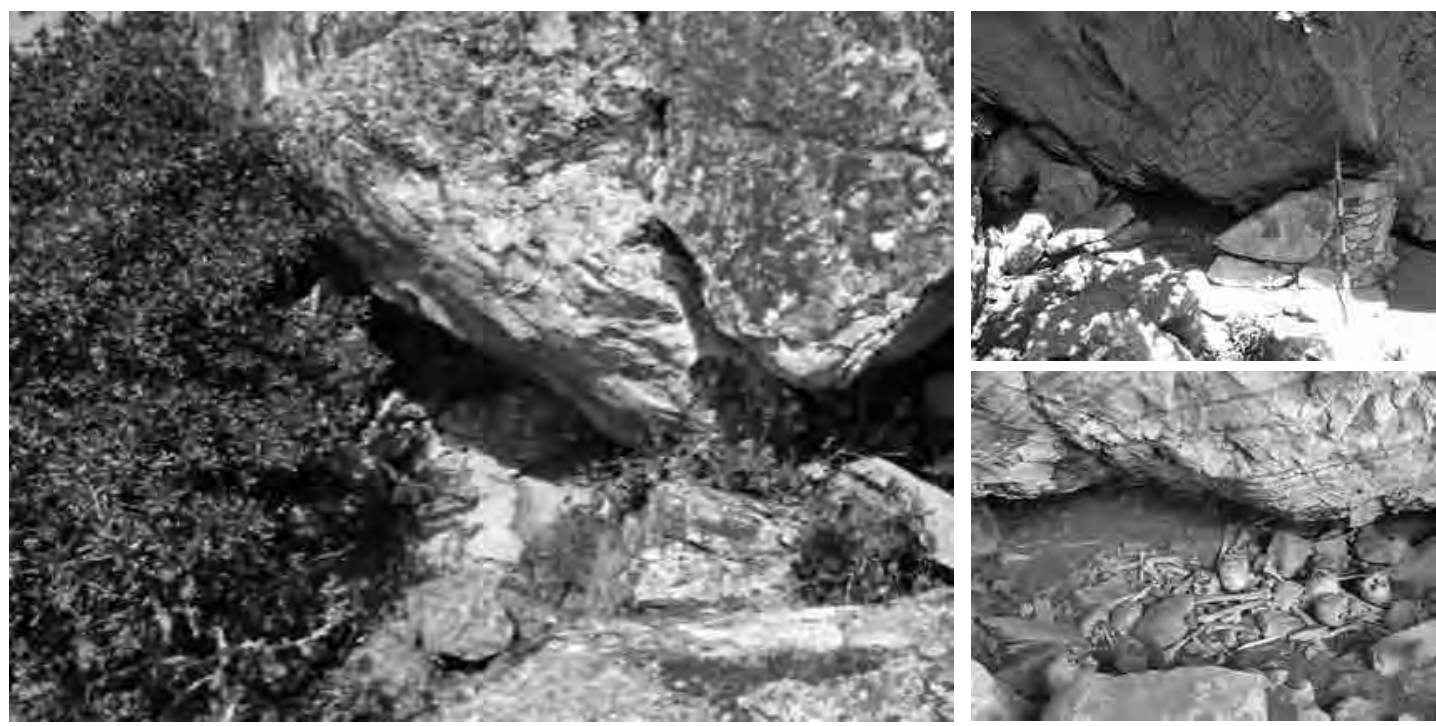

Figura 150 (izquierda): vista panorámica del abrigo rocoso del sector D. Figura 151 (centro): detalle de la estructura funeraria asociado al abrigo rocoso. Figura 152 (derecha): detalle de los restos óseos asociados en el interior de la estructura funeraria. Sitio Rurun Pukru, sector D.

V.- Sector E: Se encuentra ubicado al lado oriental del sitio, al sureste de los sectores C y D, a unos 20 m aproximadamente del último, entre las coordenadas UTM: 8871534N, 0225718E y a 2925 metros sobre el nivel del mar. Al igual que los otros sectores forma parte de un conjunto de abrigos rocosos, debajo de una roca grande de granito de color gris de forma triangular inclinado, con la abertura del acceso orientado hacia el sur, con las paredes pintadas de color anaranjado. Está apoyado sobre otro abrigo dispuesto oblicuamente debajo del anterior. Está asociado a una estructura funeraria de planta cuadrangular con todos los muros derrumbados. Tiene $1.70 \mathrm{~m}$ de largo por $1.60 \mathrm{~m}$ de ancho y $0.38 \mathrm{~m}$ de altura. Está edificado con muros de piedras canteadas unidas con argamasa de $0.30 \mathrm{~m}$ de ancho. No se observa ningún material cultural.
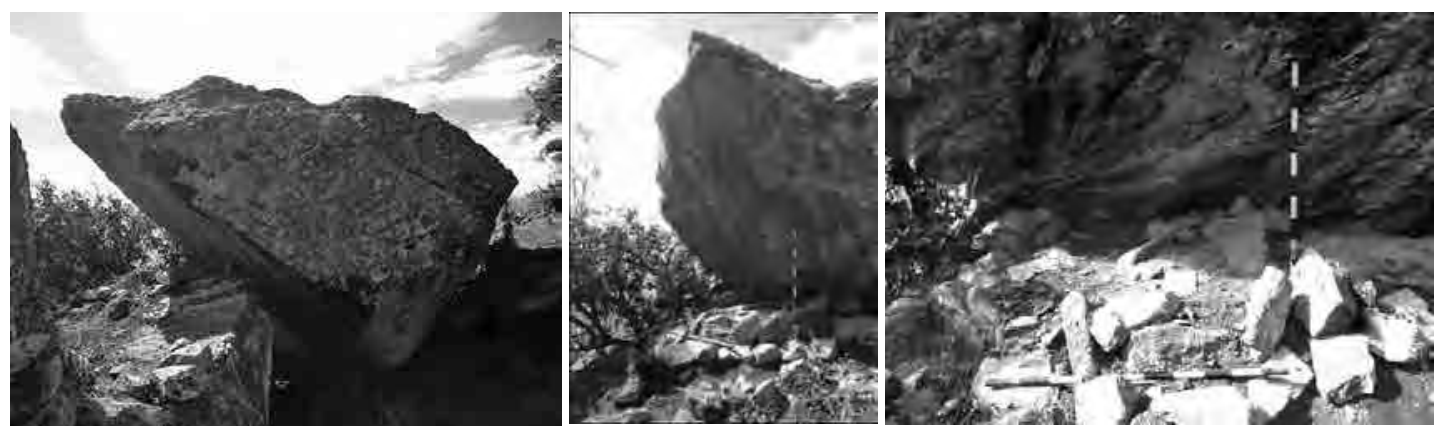

Figura 153 (izquierda): vista panorámica del abrigo rocoso del sector E. Figura 154 (central): vista panorámica de la estructura funeraria asociado al abrigo rocoso. Figura 155 (derecha): detalle de la estructura funeraria asociado. Sitio Rurun Pukru, sector E. 
VI.- Sector F: Se encuentra ubicado al lado este del sitio, a unos $8 \mathrm{~m}$ al sur del sector E y al sur del sector C y D, entre las coordenadas UTM: 8871527N, 0226723E y a 2922 metros sobre el nivel del mar. Corresponde a una estructura funeraria de planta en media luna, debajo de una roca de granito, en un abrigo rocoso de $1.60 \mathrm{~m}$ de ancho y $1.40 \mathrm{~m}$ de profundidad y $0.50 \mathrm{~m}$ de altura, con la abertura del acceso orientado al noroeste. En el interior está asociado a restos óseos (individuos). No presenta muros, solo corresponde a un acondicionamiento del espacio para depositar los cuerpos.

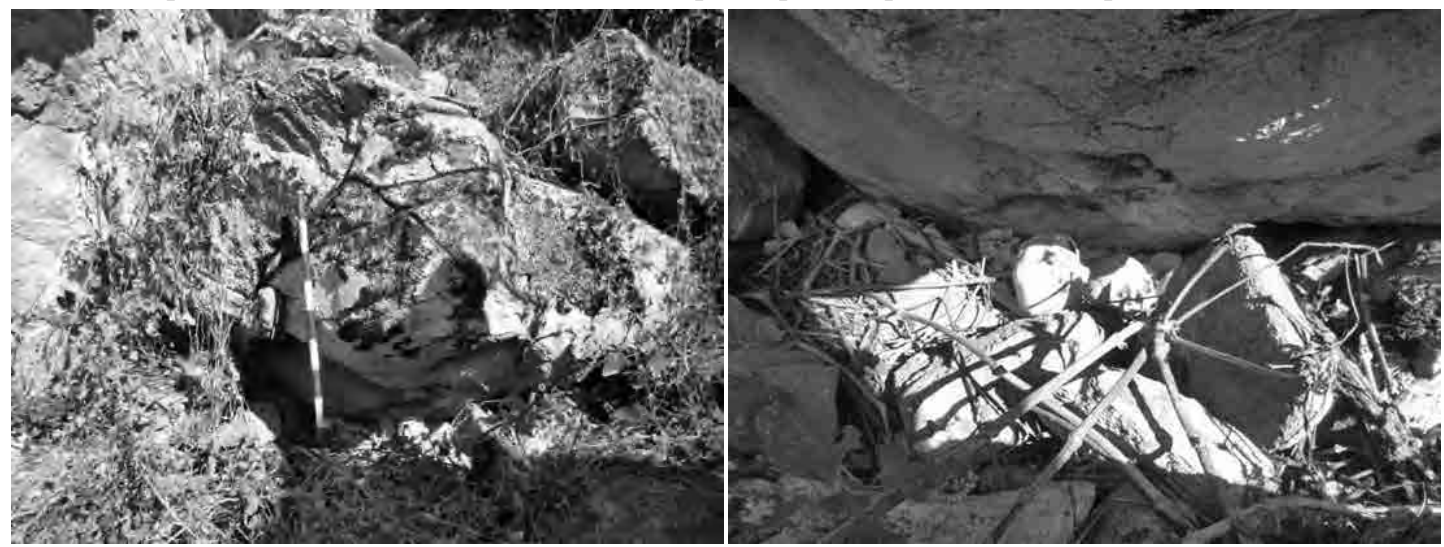

Figura 156 (izquierda): vista panorámica de la roca donde se ubica el sector F. Figura 157 (derecha): detalle de los restos óseos asociados en el interior de la roca. Sitio Rurun Pukru, sector F.

VII.- Sector G: Se encuentra ubicado hacia el este del sector E y F a unos $10 \mathrm{~m}$, al Sur del sector C, entre las coordenadas UTM: 8871529N, 0225731E y a 2927 metros sobre el nivel del mar. Está conformado por un abrigo rocoso ubicado debajo de una roca grande de granito de color gris claro, con la abertura del acceso orientado al noroeste. Presenta una estructura funeraria de planta semicircular tipo chullpa, de $2.40 \mathrm{~m}$ de largo, $2.30 \mathrm{~m}$ de ancho y $1.30 \mathrm{~m}$ de altura, en regular estado de conservación. Está edificado con muros simples de piedras canteadas unidas con argamasa, de $0.30 \mathrm{~m}$ de grosor. Presenta un acceso de forma cuadrangular de $0.46 \mathrm{~m}$ de ancho por $0.52 \mathrm{~m}$ de altura. Está asociado a restos óseos en el interior (8 individuos aproximadamente).
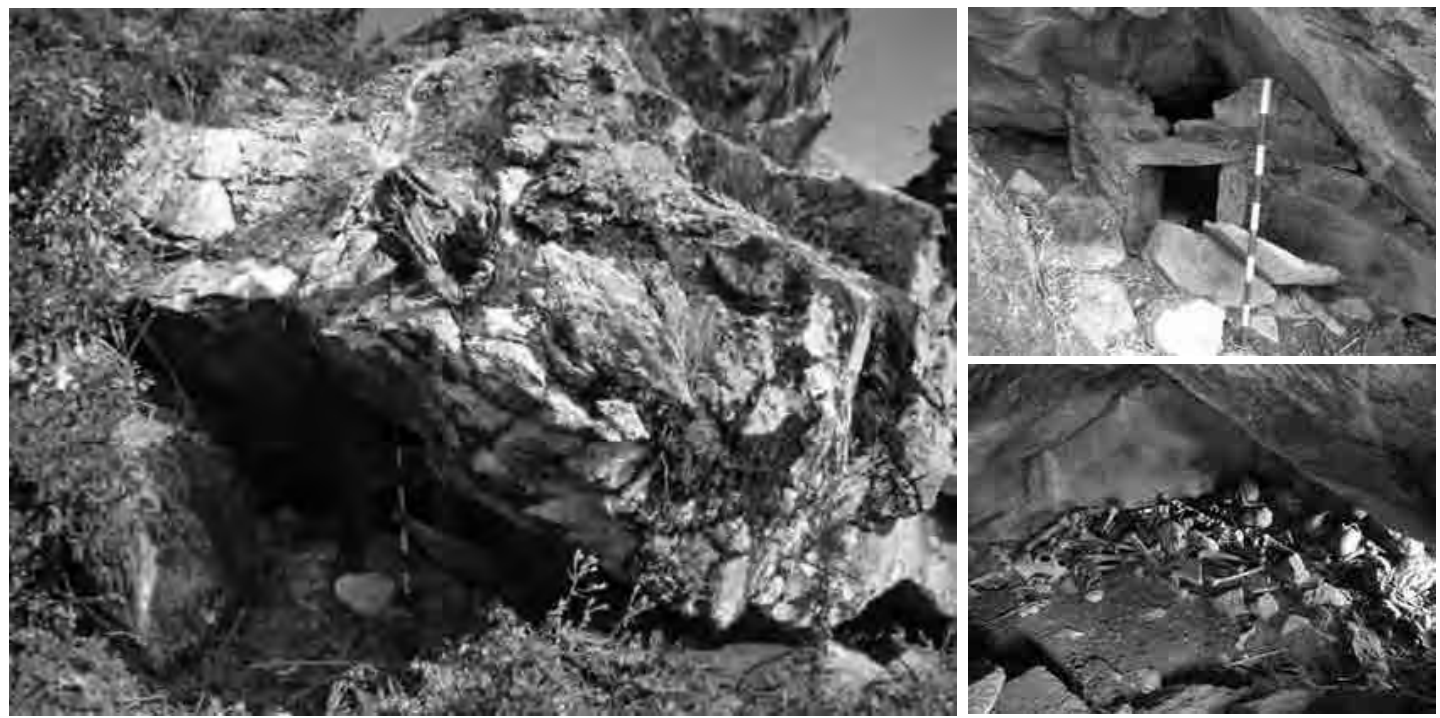

Figura 158 (izquierda): vista panorámica del abrigo rocoso del sector G. Figura 159 (centro): detalle del acceso de la estructura funeraria asociada. Figura 160 (derecha): detalle de los restos óseos asociados en el interior de la estructura funeraria. Sitio

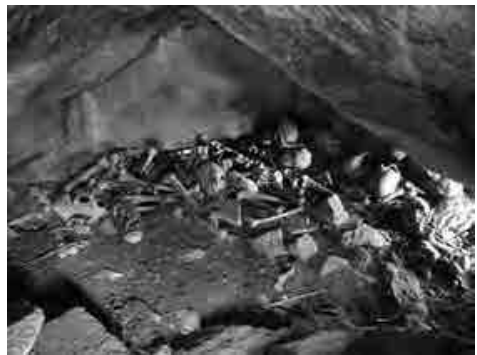
Rurun Pukru, sector G. 
VIII.- Sector H: Se encuentra ubicado al lado oriental del sitio, a unos $10 \mathrm{~m}$ al sur del sector $\mathrm{E}$ y $\mathrm{F}$, entre las coordenadas UTM: 8871525N, 0225713E y a 2910 metros sobre el nivel del mar. Corresponde a un abrigo de forma semitriangular de roca del tipo granito de color gris claro, de grandes dimensiones, con las paredes pintadas de color anaranjado. Posee dos intrusiones opuestas ubicados al este y al oeste, respectivamente. Las dimensiones son: la primera intrusión tiene la abertura del acceso de $5 \mathrm{~m}$ de ancho por $2.50 \mathrm{~m}$ de altura, mientras que la segunda intrusión tiene $1.90 \mathrm{~m}$ de ancho por 1.40 $\mathrm{m}$ de altura. Ambas intrusiones están asociadas a chullpas de planta circular adosadas a la pared del abrigo rocoso.
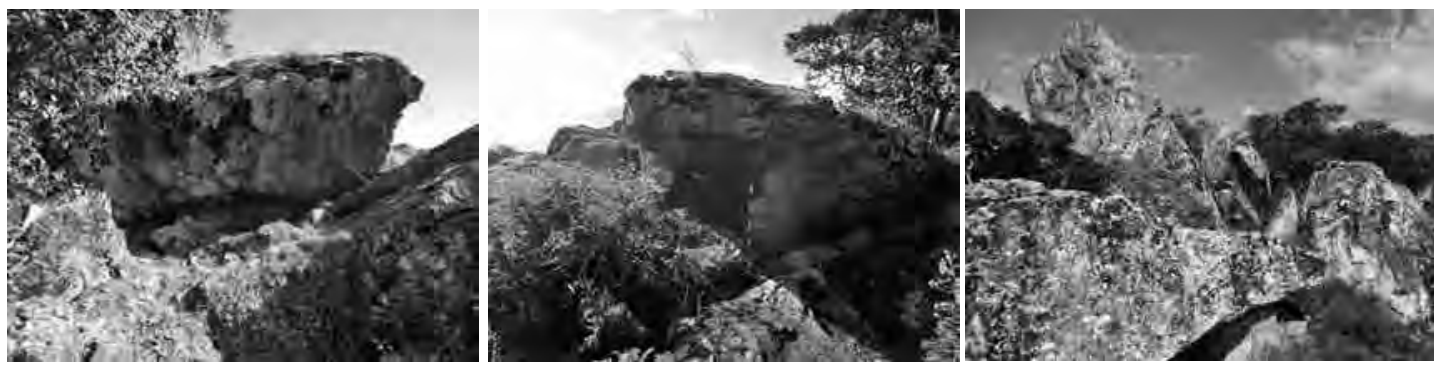

Figura 161 (izquierda): vista panorámica del abrigo rocoso del sector H (desde el este). Figura 162 (central): vista panorámica del abrigo rocoso del sector $\mathrm{H}$ (desde el oeste). Figura 163 (derecha): vista panorámica del abrigo rocoso del sector $\mathrm{H}$ visto desde el norte. Sitio Rurun Pukru, sector H.

Estructura funeraria 1: está ubicado al este y adosado a la estructura funeraria 2. Tiene planta circular de $2.70 \mathrm{~m}$ de diámetro en un eje, por $3.55 \mathrm{~m}$ de diámetro en otro eje, y $0.80 \mathrm{~m}$ de altura, en mal estado de conservación. Está edificado con muros de piedras canteadas unidas con argamasa, de 0.35 $m$ de grosor. No está asociado a ningún material cultural.

Estructura funeraria 2: está ubicado al oeste de la estructura funeraria 1, adosado a la pared del abrigo rocoso. Tiene planta casi ovalada de $1.90 \mathrm{~m}$ de ancho, $2.20 \mathrm{~m}$ de largo, y $1.00 \mathrm{~m}$ de altura, en regular estado de conservación. Está edificado con muros de piedras canteadas unidas con argamasa, de $0.30 \mathrm{~m}$ de grosor. El paramento externo se encuentra pintado de color rojo. No se pudo identificar el acceso. No está asociado a ningún material cultural en el interior.
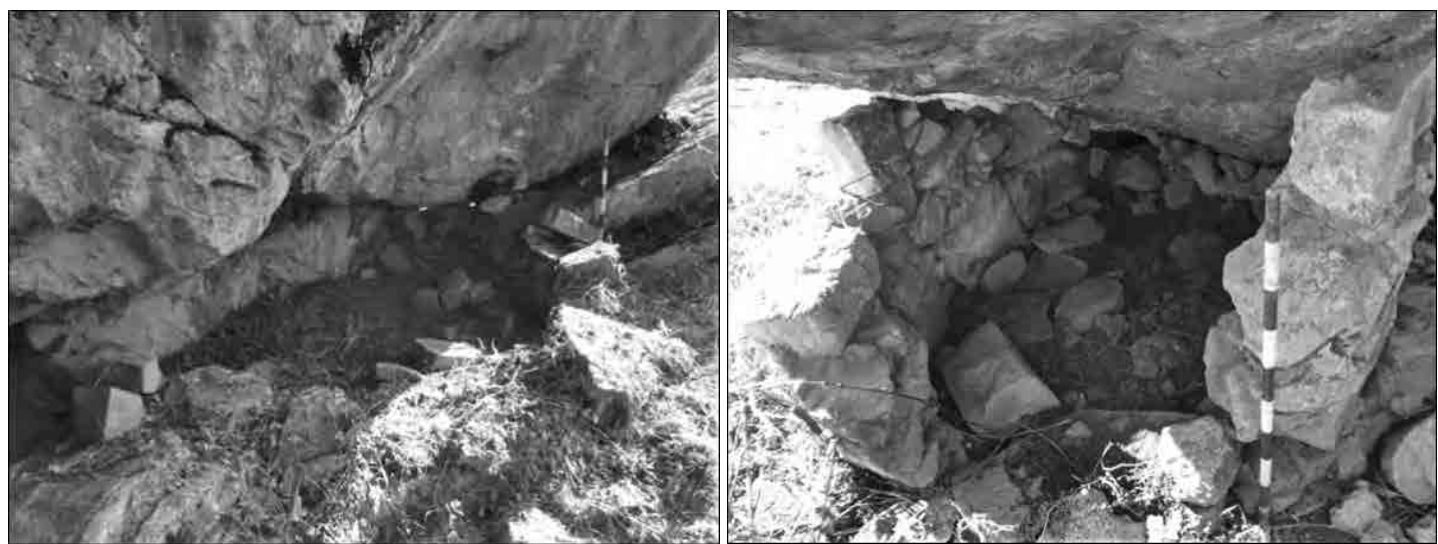

Figura 164 (izquierda): detalle de la estructura funeraria 1. Figura 165 (derecha): detalle de la estructura funeraria 2. Sitio Rurun Pukru, sector H. 
IX.- Sector I: Se encuentra ubicado en el centro del sitio, a unos $10 \mathrm{~m}$ al sur del sector $\mathrm{H}$, al este del sector A, entre las coordenadas UTM: 8871489N, 0225676E y a 2919 metros sobre el nivel del mar. Corresponde a un abrigo rocoso de grandes dimensiones de roca granito de color gris claro, debajo del cual está una intrusión (cueva al lado noroeste), con pintura rupestre en la pared oeste del abrigo y una arquitectura ceremonial de planta circular, adosado a la pared este y sobre el abrigo rocoso.
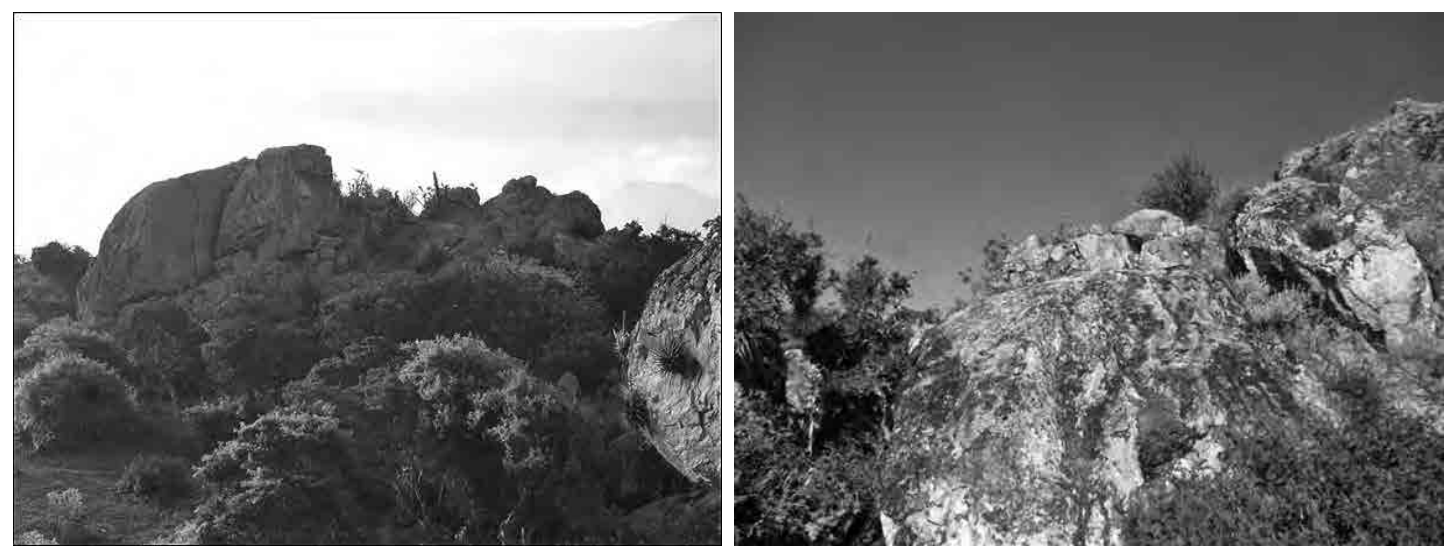

Figura 166 (izquierda): vista panorámica del sector I vista desde el lado norte. Figura 167 (derecha): vista panorámica del sector I vista desde el noroeste. Sitio Rurun Pukru.

La cueva, está ubicada debajo y al lado noroeste del sector, entre las coordenadas UTM: 8871489N, 0225676E y a 2919 metros sobre el nivel del mar. Corresponde a una intrusión amplia debajo del abrigo, de $2.60 \mathrm{~m}$ de ancho por $6.70 \mathrm{~m}$ de profundidad y $1.90 \mathrm{~m}$ de altura. Tiene todas las paredes internas pintadas de color rojo óxido. No está asociado a ningún material cultural.
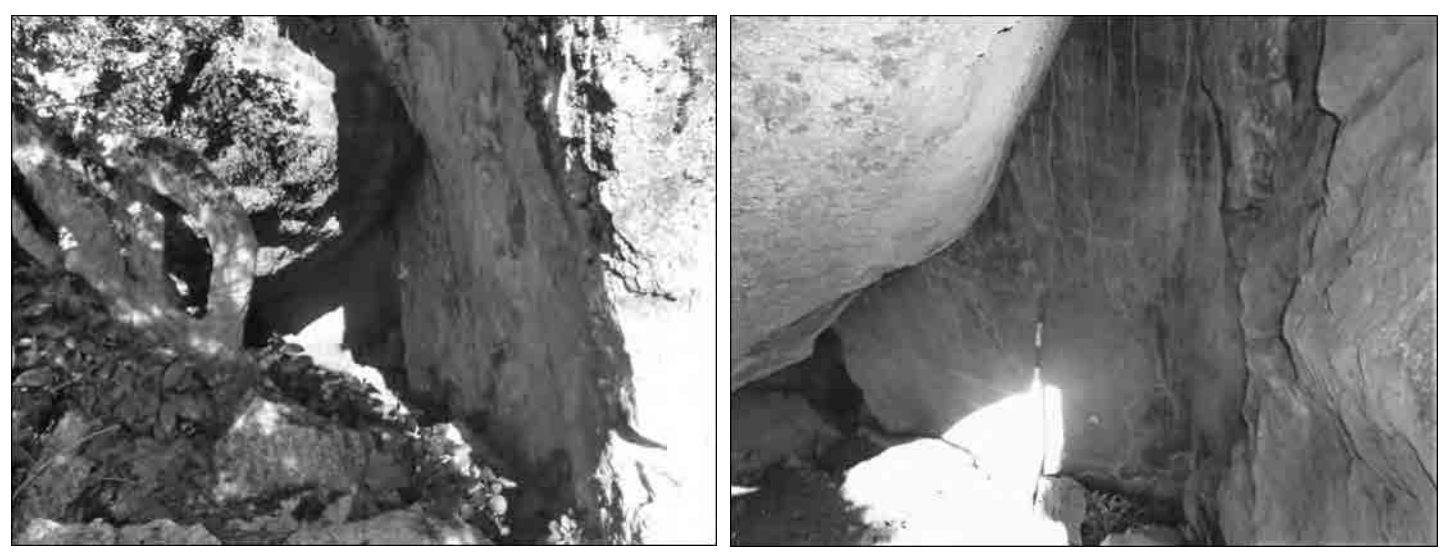

Figura 168 (izquierda): vista panorámica de la parte externa de la cueva. Figura 169 (derecha): detalle del interior de la cueva. Sitio Rurun Pukru, sector I. 
Las pinturas rupestres corresponde a diversos motivos geométricos de color rojo sobre fondo natural de la roca, ubicados en la pared noroeste del abrigo rocoso, entre las coordenadas UTM: $8871475 \mathrm{~N}, 0225674 \mathrm{E}$ y a 2909 metros sobre el nivel del mar. Además, existe un conjunto de motivos geométricos ubicados a unos $10 \mathrm{~m}$ de la primera, sobre la pared norte de una roca. El primer panel de la pintura rupestre de $1.72 \mathrm{~m}$ de ancho por $1.36 \mathrm{~m}$ de altura, corresponde a una serie de motivos geométricos ilegibles de color rojo sobre un fondo natural de la roca (gris claro). Se pudo identificar dos lineas entrecruzadas y una posible figura humana con los brazos extendidos.
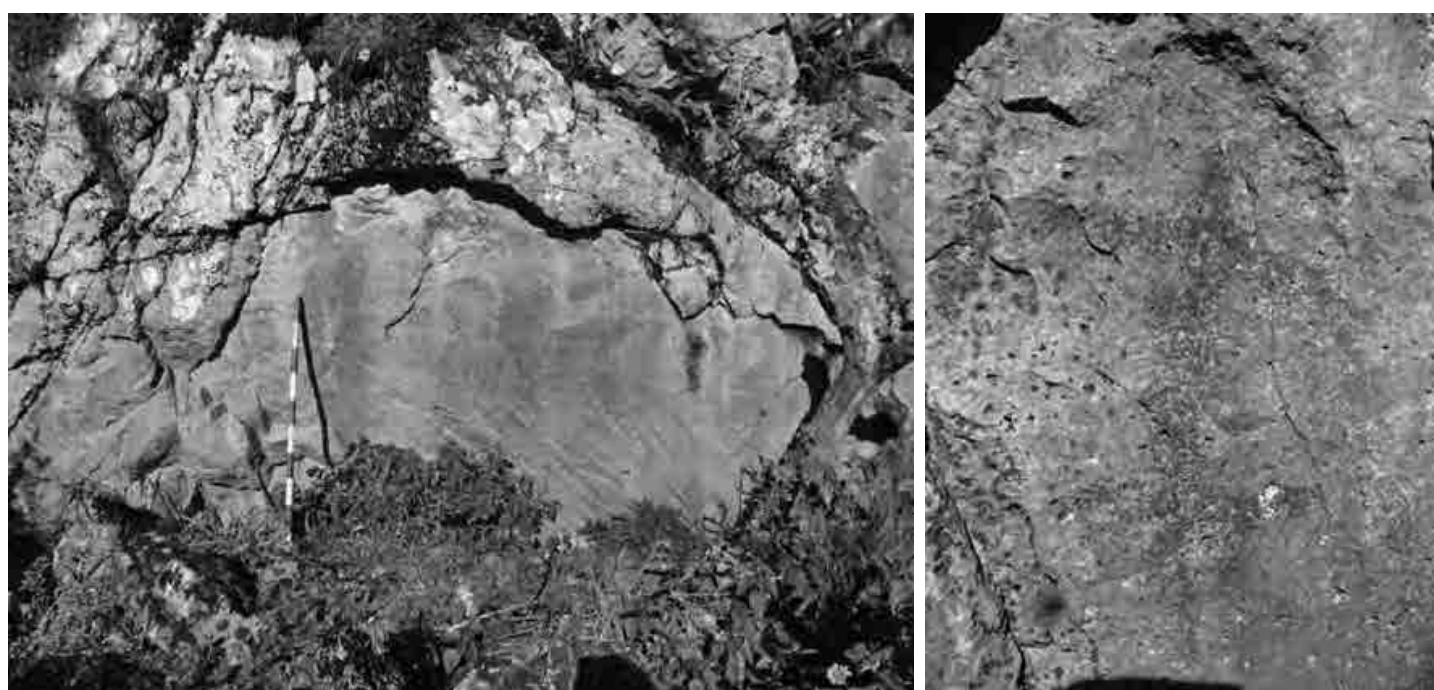

Figura 170 (izquierda): vista panorámica del panel 1 de la pintura rupestre. Figura 171 (derecha): detalle de la pintura rupestre. Sitio Rurun Pukru, sector I.

El segundo panel de pintura rupestre corresponde a un conjunto de figuras geométricas de color rojo de unos $0.21 \mathrm{~m}$ de altura por $0.22 \mathrm{~m}$ de ancho y $0.03 \mathrm{~m}$ de grosor, sobre un fondo natural de la roca. Está situado entre las coordenadas UTM: 8871480N, 0225669E y a 2917 metros sobre el nivel del mar.
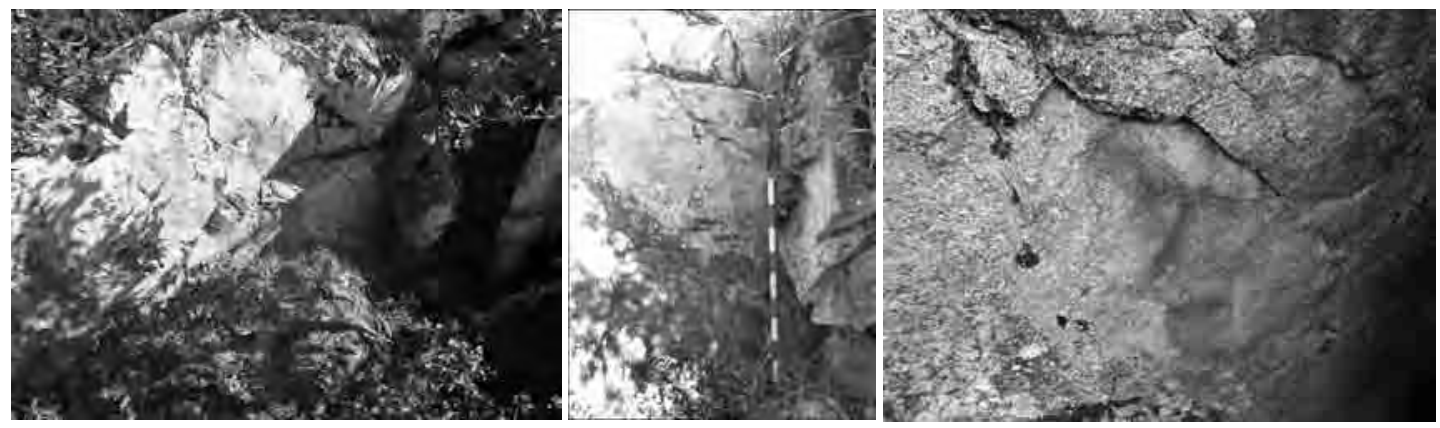

Figura 172 (izquierda): vista panorámica del panel 2 de la pintura rupestre. Figura 173 (centro): detalle del panel 2 de la pintura rupestre. Figura 174 (derecha): detalle de la pintura rupestre. Sitio Rurun Pukru, sector I. 
La Arquitectura ceremonial está situado en la parte oriental del sitio, opuesto a la cueva y a las pinturas rupestres, en la pared este y adosado al abrigo rocoso. Corresponde a una estructura arquitectónica ceremonial de planta semicircular superpuesta en dos plataformas de unos $4 \mathrm{~m}$ de altura por $5 \mathrm{~m}$ de diámetro (en la parte superior). La primera plataforma está adosada a la pared este del abrigo rocoso, y tiene $3.30 \mathrm{~m}$ altura. La segunda plataforma está sobre y adosado a la primera plataforma y a la parte superior del abrigo rocoso, y está asociado a 2 estructuras de planta circular situadas sobre un conjunto de banquetas. La primera estructura circular tiene un diámetro de $4 \mathrm{~m}(\mathrm{~N}-\mathrm{S})$ y 4.30 $\mathrm{m}$ (E-W), una altura del muro que varía de 0.80 a $1.00 \mathrm{~m}$ y de 0.40 a $0.50 \mathrm{~m}$ el ancho del muro. Mientras tanto la segunda estructura que está ubicada al oeste de la primera, tiene $3.10 \mathrm{~m}(\mathrm{~N}-\mathrm{S})$ por $3.25 \mathrm{~m}$ (EW), $0.50 \mathrm{~m}$ de altura y de 0.40 a $0.50 \mathrm{~m}$ de ancho del muro.
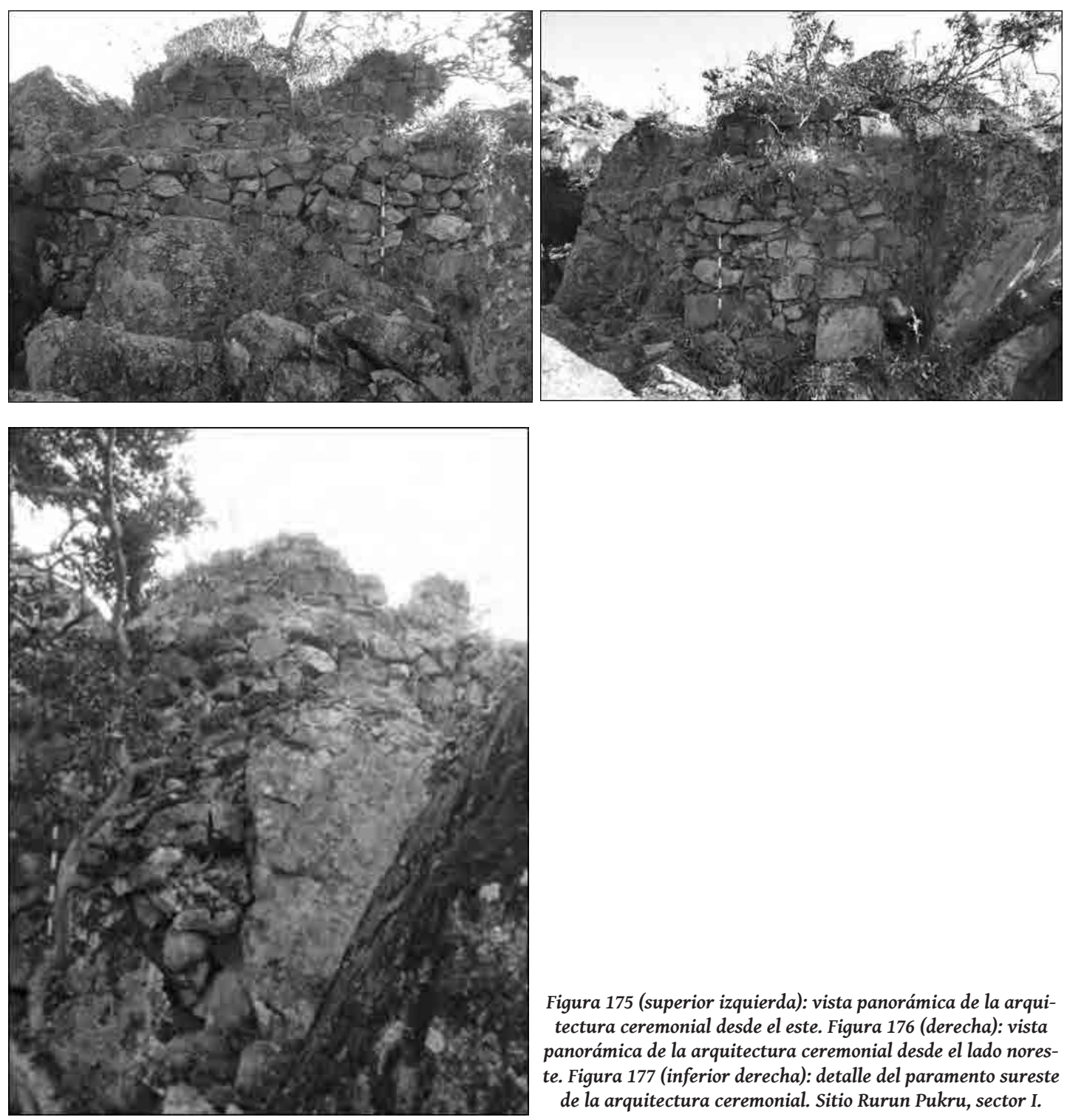

Figura 175 (superior izquierda): vista panorámica de la arquitectura ceremonial desde el este. Figura 176 (derecha): vista panorámica de la arquitectura ceremonial desde el lado noreste. Figura 177 (inferior derecha): detalle del paramento sureste de la arquitectura ceremonial. Sitio Rurun Pukru, sector I. 
Ambas estructuras están edificadas mediante muros de piedra canteada de forma cuadrangular, sin argamasa, con las caras planas orientadas hacia el exterior. Están en regular estado de conservación, con algunos muros derrumbados en la plataforma superior, por la densa vegetación que cubre este sector.
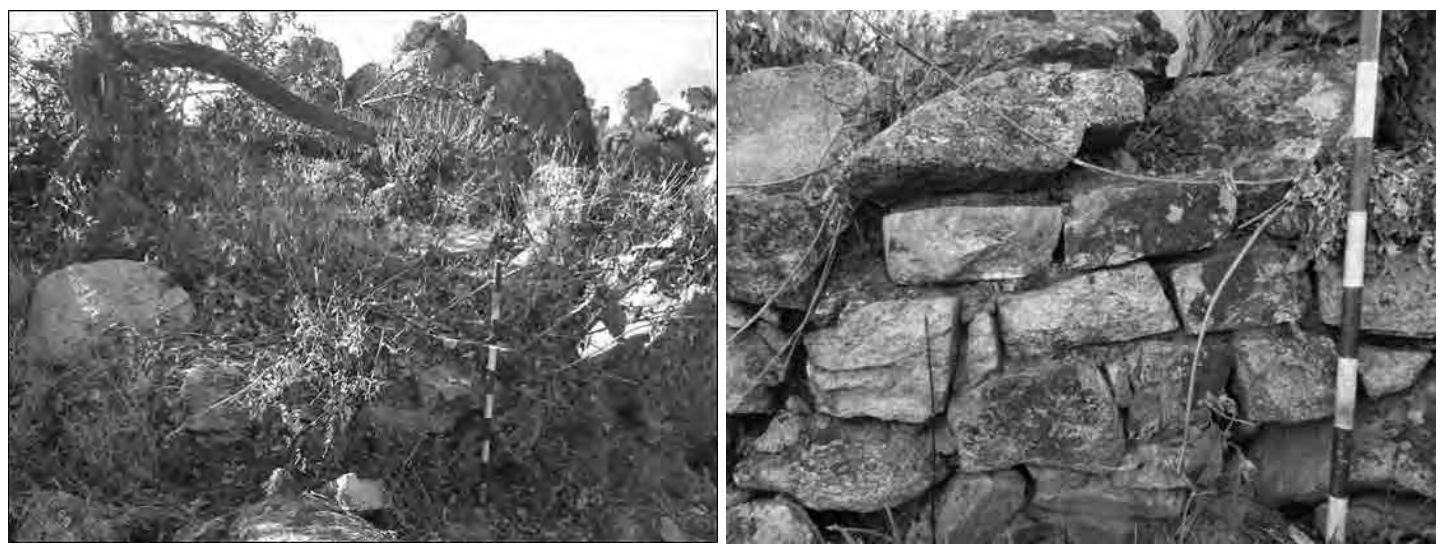

Figura 178 (izquierda): vista panorámica del recinto circular en la parte superior de la arquitectura ceremonial. Figura 179 (derecha): detalle del paramento del recinto circular. Sitio Rurun Pukru, sector I.

X.- Sector J: Se encuentra ubicado al lado sur del sitio y a unos $50 \mathrm{~m}$ al sur del sector I, al fondo de una pequeña planicie, entre las coordenadas UTM: 8871445N, 0225699E y a 2931 metros sobre el nivel del mar. Corresponde a un conjunto de abrigos rocosos de roca granito de color gris claro, con las paredes pintadas de color anaranjado, debajo de las cuales están dispuestas una serie de estructuras funerarias tipo chullpa. Está compuesto de dos abrigos rocosos asociados a 3 estructuras funerarias. El primer abrigo rocoso está asociado a 2 estructuras funerarias:
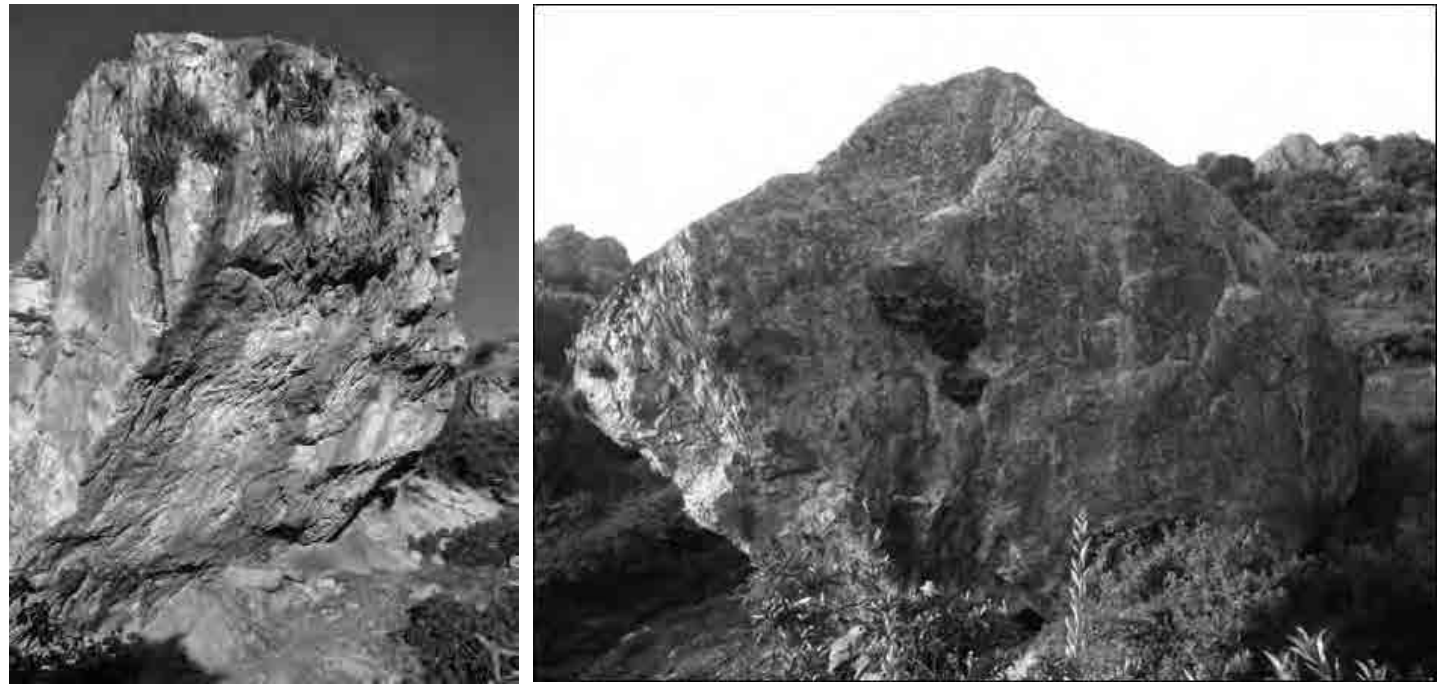

Figura 180 (izquierda): vista panorámica del abrigo rocoso (lado noroeste) del sector J. Figura 181 (derecha): vista panorámica del abrigo rocoso (lado sur) del sector J. Sitio Rurun Pukru. 
Estructura funeraria 1: está ubicado al noroeste y adosado a la pared del abrigo rocoso. Tiene planta ovalada, de $3.20 \mathrm{~m}(\mathrm{~N}-\mathrm{S})$ por $3.50 \mathrm{~m}$ (E-W) de diámetro, y $80 \mathrm{~cm}$ de altura del muro. Está edificado con muros de piedras canteadas unidas con argamasa, de $0.30 \mathrm{~m}$ de grosor, en mal estado de conservación. En la parte externa está asociado a una plataforma semicircular de una sola hilera unido con argamasa. No está asociado a ningún material cultural.

Estructura funeraria 2: está ubicado al suroeste de la estructura funeraria 1 y adosado a la pared del abrigo rocoso. Tiene planta cuadrangular, de $1.50 \mathrm{~m}$ de ancho, $1.20 \mathrm{~m}$ de largo y $1.00 \mathrm{~m}$ de altura, en mal estado de conservación. Está edificado con muros de piedras canteadas unidas con argamasa, de $0.26 \mathrm{~m}$ de grosor. No está asociado a ningún material cultural.
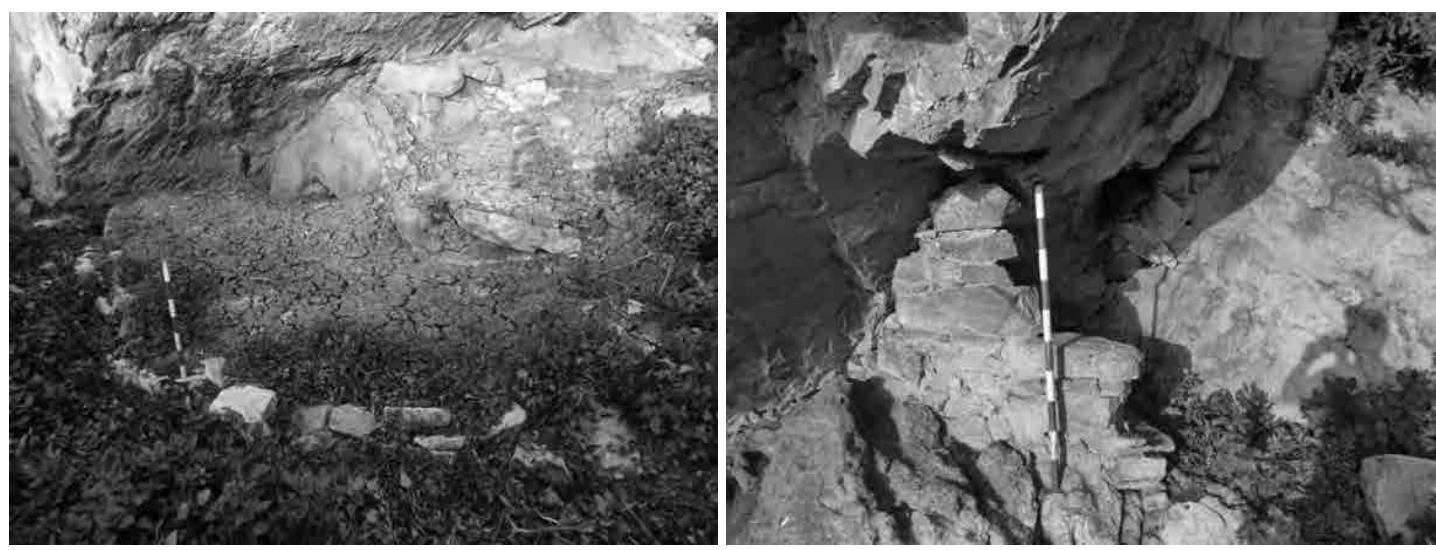

Figura 182 (izquierda): vista panorámica de la estructura funeraria 1. Figura 183 (derecha): detalle del paramento de la estructura funeraria 2. Sitio Rurun Pukru, sector J.

Estructura funeraria 3: está ubicado a unos $20 \mathrm{~m}$ al sur de las estructuras funerarias 1 y 2, y está adosado a la pared del segundo abrigo rocoso, entre las coordenadas UTM: 0871433N, 0225702 y a 2940 metros sobre el nivel del mar. Tiene forma cuadrangular, de $1.10 \mathrm{~m}$ de ancho, $1.20 \mathrm{~m}$ de largo, y $0.60 \mathrm{~m}$ de altura, en mal estado de conservación, con muros derrumbados casi por completo. Está edificado con muros de piedras canteadas unidas con argamasa, de $0.35 \mathrm{~cm}$ de grosor. No está asociado a ningún material cultural.
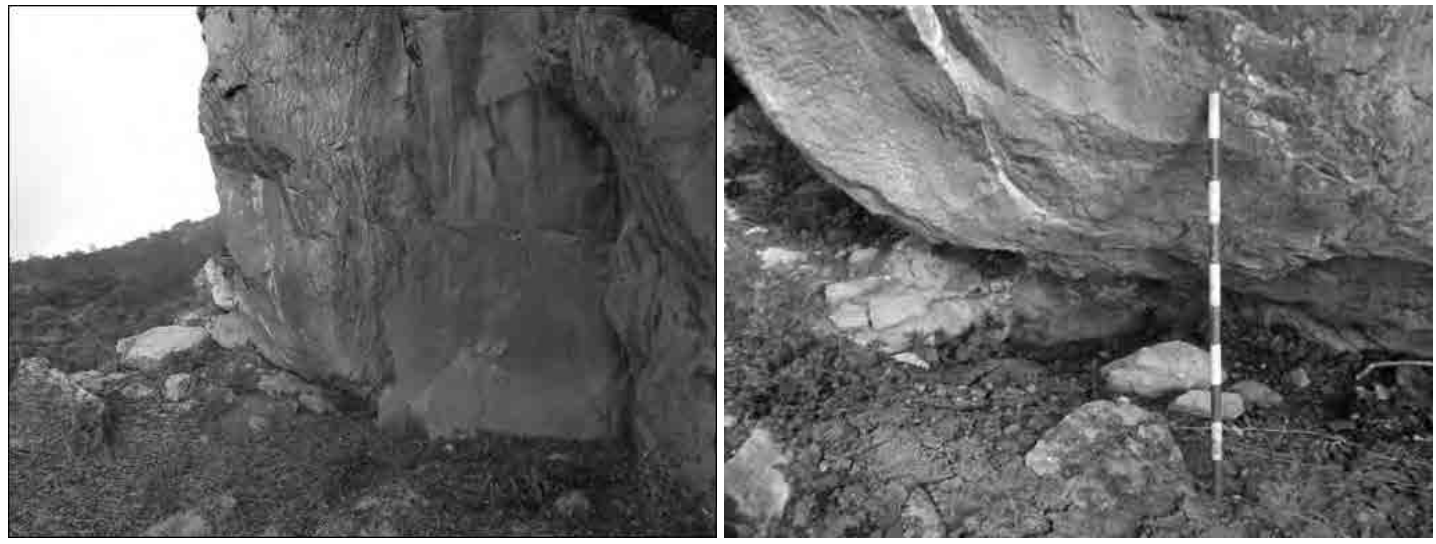

Figura 184 (izquierda): vista panorámica del segundo abrigo rocoso de sector J. Figura 185 (derecha): detalle de la estructura funeraria 3. Sitio Rurun Pukru, sector J. 
XI.- Sector K: llamado también como El Aukish. Se encuentra ubicado al lado sur del sitio, a unos $80 \mathrm{~m}$ al sur del sector J, sobre una pequeña planicie que desciende de este en dirección oeste, entre las coordenadas UTM: 8871392N, 0225719E y a 2953 metros sobre el nivel del mar. Corresponde a una huanca grande de roca granito de forma oblonda dispuesta verticalmente, de $5.20 \mathrm{~m}$ de circunferencia por $2.10 \mathrm{~m}$ de altura. Asociado a otras 12 huancas pequeñas dispuestas alrededor de la primera huanca. Para los pobladores de Yamor posee un gran significado, por ello ofrecen ofrendas de diversos contenidos como: coca, cigarros, varias bebidas en botellas y otros objetos, que son depositados al pie de la huanca.
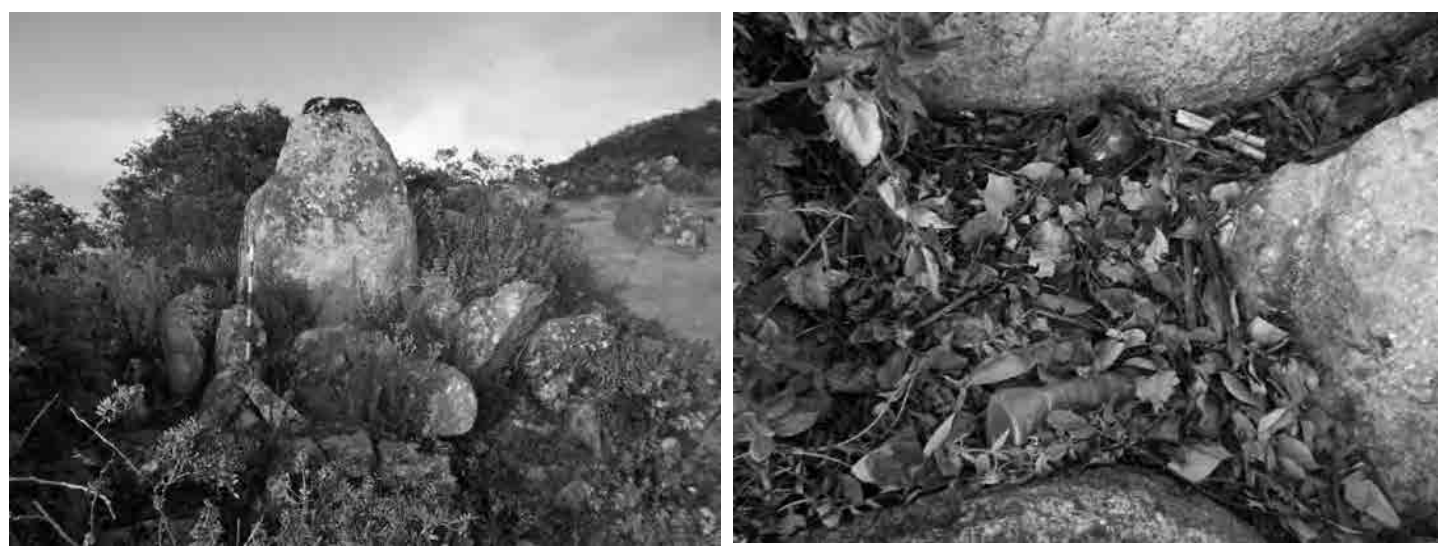

Figura 186 (izquierda): vista panorámica de la huanca del sector K. Figura 187 (derecha): detalle de diferentes tipos de objetos ofrecidos como ofrenda al "Aukish". Sitio Rurun Pukru, sector K.

\section{4.- InTerpretaciones Culturales}

Los sitios arqueológicos con pinturas rupestres identificados en el ámbito de la Comunidad Campesina de Yamor se caracterizan por estar asociados a áreas funerarias con chullpas. Estas chullpas datan del Horizonte Medio y periodos tardíos, correspondientes a la cultura Yamor, entidad sociopolítica local que se desarrolló en estos territorios (subcuencas de los ríos Yamor y Raquia) luego de la desintegración del estado Recuay, hacia mediados del Horizonte Medio. Gamboa (2009) señala que las chullpas de planta rectangular y cuadrangular aparecen como un componente fundamental de las prácticas funerarias Recuay hacia el Horizonte Medio, como estructura funeraria exenta, destinada a entierros múltiples y colectivos. Esta tradición constructiva funeraria de chullpas se va a mantener hasta la invasión hispana, relacionado con el culto a los ancestros, una práctica muy difundida en todos los Andes Centrales, lo cual fue registrado por los extirpadores de idolatrías del siglo XVI y XVII. Las chullpas identificadas en Yamor se caracterizan por presentar uno o más niveles constructivos, edificados debajo de farallones rocosos sobre plataformas naturales o al interior de abrigos rocosos y cuevas, aprovechando al máximo los espacios y oquedades naturales para la edificación de estructuras funerarias para el depósito colectivo de individuos. La mayoría de chullpas presentan los paramentos internos pintados de color rojo, del mismo color que las pinturas rupestres (lo que no necesariamente quiere decir que hayan sido hechos en el mismo periodo).

Sin embargo pareciera que las quillqas son más antiguas. Los farallones que se constituyen en el soporte natural de las quillqas son de gran altura y paredes casi verticales y lisas, sobre las cuales han sido dibujados diferentes motivos en color rojo, para lo cual se ha utilizado un material muy común en la zona: el óxido de hierro. Los motivos identificados son mayormente círculos simples o círculos 
con punto concéntrico, figuras estilizadas de serpientes o personajes antropomorfos así como motivos geométricos. Las pinturas se encuentran en regular estado de conservación.

La presencia de las chullpas evidencia que las zonas aledañas a las quillqas se configuraron como áreas de gran importancia religiosa y ceremonial, relacionado con el culto a las wacas y los wamanis. La importancia de estas zonas se mantuvo hasta periodos tardíos, incluso hasta la colonia. Justamente estos lugares con afloramientos rocosos fueron destruidos y registrados por los extirpadores de idolatrías:

"Arriba del pueblo de Yamor sacamos la huaca Libiac, que es del rayo, que era una piedra grande partida por medio con un rayo; tenia gran suma de sacrificios de carneros de la tierra y de otras cosas.

En la punta del cerro estaba la huaca Quenac, rodeada de muchas piedras; era de figura de un indio sin brazos ni pies; estaba soterrada a medio estado, acompanada de muchos sacrificios y una trompeta de cobre, con que se convocaban para sus fiestas." (Arriaga; 1968: Capítulo X)

\section{5.- Conclusiones}

Las conclusiones a las cuales se ha llegado en la presente investigación son:

a.- Las pinturas rupestres o quillqas de Yamor forman parte de una gran tradición cultural de quillqas que se desarrolló desde el Formativo en la cuenca alta del río Fortaleza.

b.- Se encuentran elaboradas en farallones rocosos, abrigos y cuevas, pintadas en color rojo.

c.- Entre los motivos decorativos figuran mayormente círculos simples y círculos con punto concéntrico, figuras estilizadas de serpientes o personajes antropomorfos, así como motivos geométricos.

d.- Debajo del soporte de las quillqas (farallón) se edificaron tardíamente estructuras funerarias tipo chullpas que datan del Horizonte Medio y periodos prehispánicos tardíos.

e.- El área contigua a las quillqas se configuró como un área ceremonial de gran importancia en la ideología andina local, relacionada con el culto a las wacas y los wamanis, importancia que se mantuvo hasta la época colonial.

\section{6.- RECONOCIMIENTOS Y AGRADECIMIENTOS}

Un especial reconocimiento al alcalde distrital de Antonio Raymondi: Vicente Jorge Nina Solano, quien con sus ganas e ímpetu hizo posible el desarrollo de la presente investigación. La nueva visita al distrito de Antonio Raymondi no hubiera sido posible sin la invitación del Dr. Filomeno Zubieta Núñez y la Asociación de Escritores y Poetas Ancashinos (AEPA). Es de reconocer el valioso apoyo brindado por el presidente de la Comunidad Campesina de Yamor, Don ; así como los guías de la Comunidad Campesina de Yamor que nos acompañaron en los recorridos de campo: Máximo Padilla León, Rufo Beltrán Bautista, Marcelino Bartolo Tadeo, Santos Gil León Salinas, Honorio Gavino Tadeo, Liceo Gavino Trinidad, Pedro Huertas Mauricio, Constantino Gamarra Francisco; así como a los pobladores que nos brindaron la alimentación: Fítero Riquenez Espinoza, Didi Beltrán Padilla y los esposos Vicente Gavino Salinas y Manuela Juan de Dios Beltrán. 


\section{BIBLIOGRAFÍA}

ARRIAGA, Joseph

1968 (1621) Extirpación de la idolatría en el Perú. Biblioteca de Autores Españoles, tomo 209

(Crónicas Peruanas de Interés Indígena). Ediciones Atlas. Madrid, pp. 191-277.

DUVIOLS, Pierre

1986 CULTURA ANDINA Y REPRESION. Procesos y visitas de idolatrías y hechicerías en Cajatambo, siglo XVII. Centro de Estudios Rurales Andinos Bartolomé de las Casas. Cusco, $570 \mathrm{pp}$.

GAMBOA VELASQUEZ, Jorge

2009 "Diversidad formal y cronológica de las prácticas funerarias Recuay". En: Kullpi. Investigaciones culturales en la provincia de Huaral y el Norte Chico. Año 4, No 4. Pieter van Dalen, editor. Huaral, pp. 217-294.

HORKHEIMER, Hans

1965 IDENTIFICACION Y BIBLIOGRAFIA DE IMPORTANTES SITIOS PREHISPANICOS DEL PERU. En: Arqueológicas № 8 M.N.A.A. Lima

HUERTAS VALLEJOS, Lorenzo

1981 La religión en una sociedad rural andina, Siglo XVII. Universidad Nacional San Cristóbal de Huamanga. Ayacucho, 158 pp.

MiLLA VILLENA, Carlos

1977-1978 “Metodología para un catastro”. En: Boletín del Seminario de Arqueología. Pontificie Universidad Católica del Perú. Instituto Riva Agüero. № 19-20. Lima, pp. 39-110.

ONERN

1972 Inventario, evaluación y uso racional de los recursos naturales de la Costa: Valle Fortaleza - Paramonga. Oficina Nacional de Evaluación de Recursos Naturales (ONERN) II Tomos. Lima.

PEREYRA PLASCENCIA, Hugo

1989 “Chiquián y la Región de Lampas entre los siglos XVI y XVII: una hipótesis sobre el origen de las campañas de extirpación de idolatrías en el Arzobispado” Boletín del Instituto Riva Agüero, PUCP, No 16. Lima, pp. 21 - 54.

ROBLES MENDOZA, Román

2000 La banda de músicos: las bellas artes musicales en el sur de Ancash. Instituto de Investigaciones Sociales, facultad de Ciencias Sociales, Universidad Nacional Mayor de San Marcos. Lima, pp.

2005 "Las iglesias andinas: huellas de la cristianización y religiosidad popular". En: Revista de Antropología. Cuarta época. Año III, № 3. Universidad Nacional Mayor de San Marcos. Lima, pp. $103-162$. 
2007 "El mensaje de los mitos: héroes fundadores y origen de los alimentos en la memoria de los pueblos andinos". En: Revista de Antropología. Cuarta época. Año V, № 5. Universidad Nacional Mayor de San Marcos. Lima, pp. 91 - 132.

2009 "Las comunidades campesinas en el proceso de desarrollo de los pueblos". En: Kullpi. Investigaciones culturales en la provincia de Huaral y el Norte Chico. Año 4, No 4. Pieter van Dalen, editor. Huaral, pp. 113 - 126.

RUIZ ESTRADA, Arturo

2003 “El poblamiento prehispánico de Cuspón” En: Cuspón. Comunidad e Identidad. Filomeno Zubieta, Editor. Ed. Imagen. Huacho, pp. 67-86.

2008 "Patrimonio arqueológico de Chiquián" En: Chiquián. Arqueología, Identidad y Turismo. Ed. Imagen. Huacho, pp. 9-50.

2009 “Capillapunta: un asentamiento prehispánico en Chiquián” Kullpi. Investigaciones culturales en la provincia de Huaral y el norte chico. $\mathrm{N}^{\circ} 4$. Lima, pp. 209-218.

SANCHEZ, Ana

1991 Amancebados, hechiceros y rebeldes (Chancay, siglo XVII). Centro de Estudios Rurales Andinos Bartolomé de las Casas. Cusco, 208 pp.

TABIO, Ernesto

1977 Prehistoria de la costa del Perú. Academia de Ciencias de Cuba. La Habana. 267 pp.

VAN DALEN LUNA, Pieter

2007 "Palpin: un asentamiento con arquitectura funeraria en el alto Fortaleza, Cajacay, Ancash" En: Tukuy Rikuq, N 4. Lima, pp. 51-57.

2013 "San Ignacio, un sitio arqueológico tardío en Yamor, distrito de Antonio Raymondi, provincia de Bolognesi, Ancash”. En: Tiempos. Revista de historia y cultura. № 8. Lima, pp. 107-122.

2014 "Introducción al estudio arqueológico de la provincia de Ocros, Ancash. Distritos de Ocros, Santiago de Chilcas y Acas". En: Investigaciones sociales. $\mathrm{N}^{\circ}$ 32. Instituto de Investigaciones Sociales, Facultad de Ciencias Sociales. Universidad Nacional Mayor de San Marcos. 2014. Lima, pp. 89-102.

VILLAR CORDOVA, Pedro

1982(1935) Arqueología del departamento de Lima. Ed. Atusparia, 2ํedic. Lima

ZUBIETA NUÑEZ, Filomeno

2003 Por la ruta del Huayhuash. Los recursos Turísticos de la provincia de Bolognesi. Huacho, $150 \mathrm{pp}$. 
